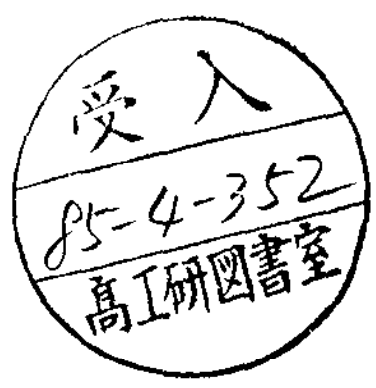

EUROPEAN ORGANIZATION FOR NUCLEAR RESEARCH

CERN-EP/85-34

March 18th, 1985

A Detailed Study of the Proton Structure Functions

in Deep Inelastic Muon-Proton Scattering

The European Muon Collaboration

CERN $^{1}$-DESY (Hamburg) ${ }^{2}-$ Freiburg $^{3}-\mathrm{Kiel}^{4}$-Lancaster ${ }^{5}-$ LAPP (Annecy) ${ }^{6}-$ Liverpoo $^{7}-$ Marseille ${ }^{8}-0 x$ ord $^{9}-$ Rutherford $^{10}-$ Sheffield $^{12}-$ Turin $^{12}$ and Wuppertal 13

J.J. Aubert ${ }^{8}$, G. Bassompierre ${ }^{6}$, K.H. Becks ${ }^{13}$, C. Best $^{108)}$, E. Böhrn 4 X. de Bouard ${ }^{6}$, F.W. Brasse, C. Brol16t), S. Brown ${ }^{7}$, J. Carriob), R.W. Clifft ${ }^{20}, J^{2}$. H. Cobb5c), G. Coignet ${ }^{6}$, F. Combley $^{11}$, G. D'Agostini ${ }^{8}$, W.D. Dau ${ }^{4}$, J.K. Davies9d), Y. Déclais ${ }^{9}$, R.W. Dobinson $\left.{ }^{2}\right)$, U. Dosse11ixf), J. Drees ${ }^{23}, A . W$. Edwardsi3a), M. Edwards20,

J. Favier ${ }^{6}$ M.I. Ferrero' 2, W. Flauger ${ }^{2}$, E. Gabathuler ${ }^{7}$, R. Gamet ${ }^{7}$, J. Gayler ${ }^{2}$,

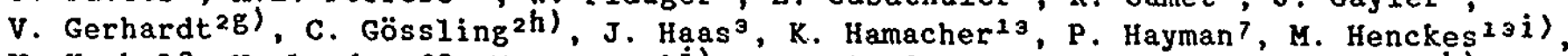

V. Korbel ${ }^{2}$ U. Landgraf ${ }^{3}$, M. Leenen ${ }^{2 j}$ ), M. Maire ${ }^{6}$, W. Mohr ${ }^{3}$, H.E. Montgomery ${ }^{2 k}$,

K. Moser ${ }^{3}$ ), R.P. Mount $\left.{ }^{9 m}\right)$, J. Nassalski ${ }^{2}$, P.R. Norton ${ }^{10}$, J. McNicholas ${ }^{9 n}$ ),

A.M. Osborne ${ }^{1}$, P. Payre ${ }^{8}$, C. Peroni ${ }^{12}$, H. Pessard ${ }^{6}$ U. Pietrzyk ${ }^{13}, K$. Rith ${ }^{3}$, M. Schneegans ${ }^{6}$, T. Sloan ${ }^{5}$, H.E. Stier ${ }^{3}$, W. Stockhausen ${ }^{23}$, J.M. Thénard ${ }^{6}$,

J.C. Thompson ${ }^{10}$, L. Urban ${ }^{60)}$, H. Wahlen ${ }^{13}$, M. Whalley ${ }^{11 p}$, W.S.C. Williams ${ }^{9}$, J. Williamson ${ }^{219}$ ), S.J. Wimpenny ${ }^{12 h}$ ).

\title{
Abstract
}

The $x$ and $Q^{2}$ dependences of the single photon exchange cross section $\frac{d^{2} \sigma}{d Q^{2} d x}$ and the proton structure functions $F_{2}\left(x, Q^{2}\right)$ and $R\left(x, Q^{2}\right)$ have been measured in deep inelastic muon proton scattering in the region $0.02<x<0.8$ and $3<Q^{2}<190 \mathrm{GeV}^{2}$. By comparing data at different incident muon energies $R$ was found to have little kinematic dependence and an average value of $-0.010 \pm 0.037$ (stat.) \pm 0.102 (syst.). The observed deviations from scaling gave the value of $\Lambda_{\mathrm{MS}}$, the QCD mass scale parameter, to be $10 S_{-45}^{+55}$ (stat.) +85 (syst.) Mev. The fraction of the momentum of the nucleon carried by gluons was found to be $\sim 56 \%$ at $Q^{2} \sim 22.5 \mathrm{GeV}^{2}$. It is shown that to obtain a description of the data for $F_{2}\left(x, Q^{2}\right)$ together with that measured in deep inelastic electron-proton scattering at lower $Q^{2}$ it is necessary to include additional higher twist contributions. The value of $\Lambda-$ remains unchanged with the inclusion of these contributions which were found to have an $x$-dependence of the form $\frac{x^{3}}{(1-x)}$.

(Submitted to Nuclear Physics B)

For footnotes see next page. 
(a) Now at JET, Joint Undertaking, Abingdon, England.

(b) Now at University of Colorado, Boulder, Colorado, U.S.A.

(c) Now at University of Oxford, England.

(d) Now at Plessey Defence System, Fareham, England.

(e) On leave of absence at University of Illinois, Urbana, Illinois, U.S.A.

(f) Now at INFN, Sez. Padova, Italy.

(B) Now at Beiersdorf AG, Hamburg, Germany.

(h) Now at CERN, Geneva, switzerland.

(i) Now at IBAT, Essen, Germany.

(j) Now at Physikalisches Institut der Universität Bonn, Bonn, Germany.

(k) Now at FNAL, Batavia, Illinois, U.S.A.

(1) Now at BWB Engineering GmbH, Lörrach, Germany.

(n) Now at California Institute of Technology, Pasadena, California, U.S.A.

(o) Now at Central Research Institute for Physics of the Hungarian Academy of Science, Budapest, Hungary.

(p) Now at Durham University, Durham, England.

(q) Now at RAL, Didcot, England.

$(+)$ Deceased. 


\section{Table of Contents}

$\underline{\text { Section }}$

Page

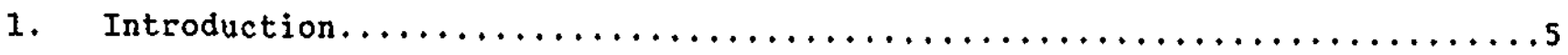

2. The Kinematics of Muon Scattering $\ldots \ldots \ldots \ldots \ldots \ldots \ldots \ldots \ldots \ldots \ldots$

3. The Apparatus

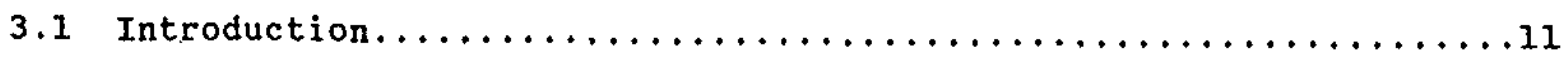

3.2 The Muon Beam Line and the Detector.......................

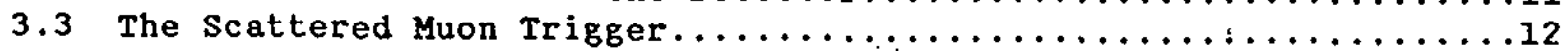

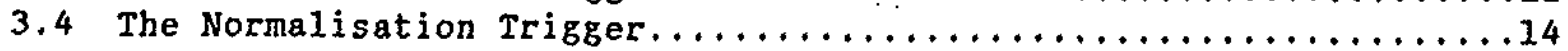

4. Data Analysis and the Extraction of $F_{2}$

4.1 Introduction. ..............................

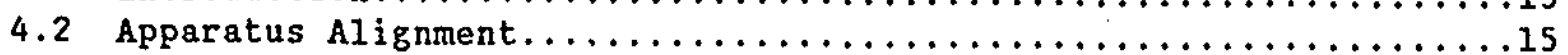

4.3 offline Event Reconstruction..........................

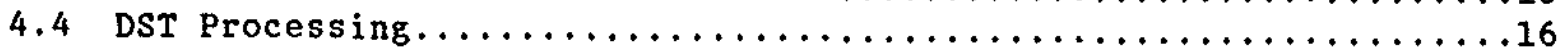

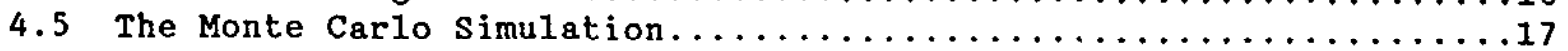

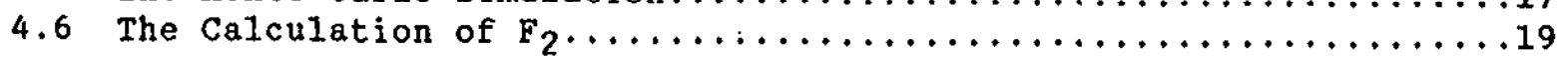

5. The Treatment of Systematic Errors

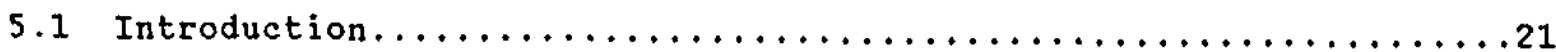

5.2 The Determination of the Incident and Scattered Muon Energies....21

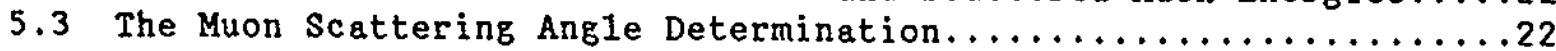

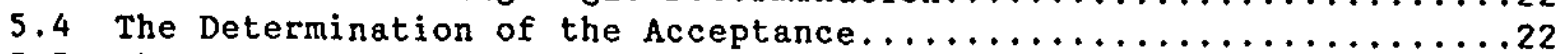

5.5 The Correction for Track Losses due to Chamber Inefficiencies....23

5.6 The Correction for Experimental Resolution..................23

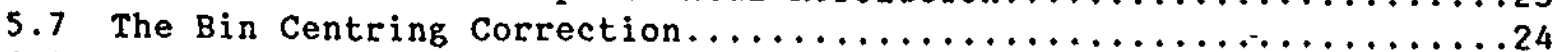

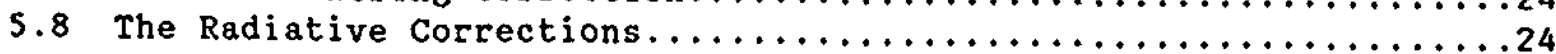

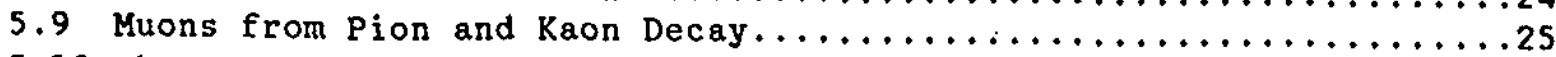

5.10 The Error on the Absolute Normalisation of $F_{2}\left(x, Q^{2}\right) \ldots \ldots \ldots \ldots \ldots 25$

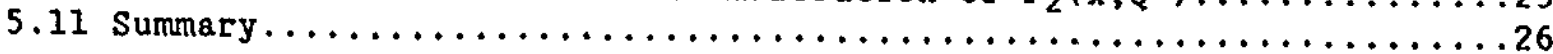

6. Results for the Structure Function $F_{2}\left(x, Q^{2}\right)$ and the Double Differential Cross-Section $\mathrm{d}^{2} \sigma / \mathrm{dQ}^{2} \mathrm{dx}$

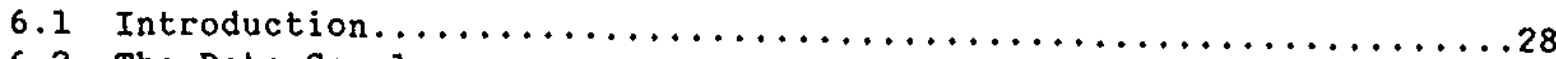

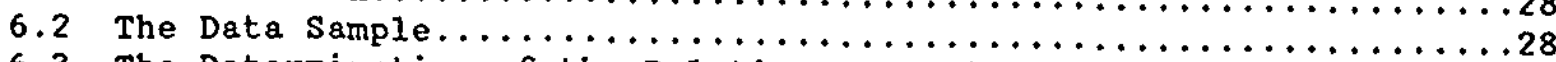

6.3 The Determination of the Relative Normalisation between

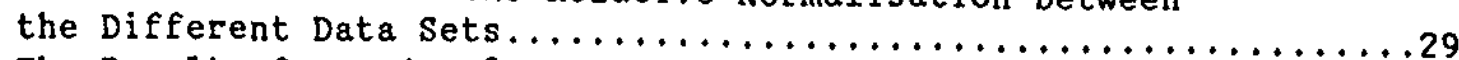

6.4 The Results for $F_{2}\left(x, Q^{2}\right)$ at $120,200,240$ and $280 \mathrm{GeV}$

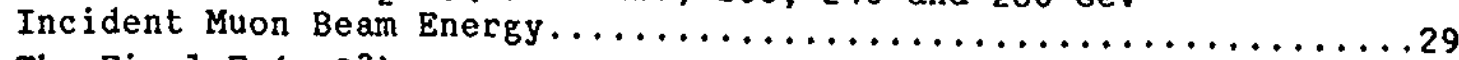

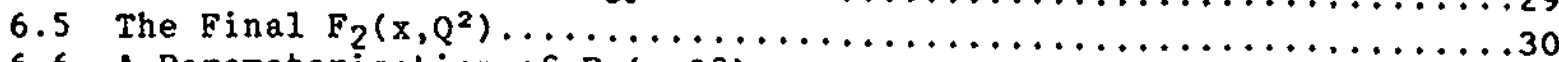

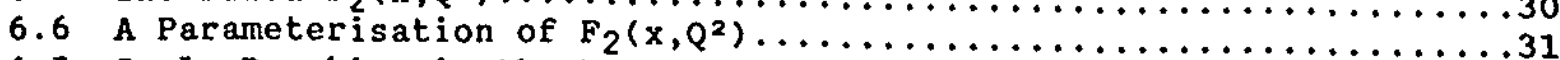

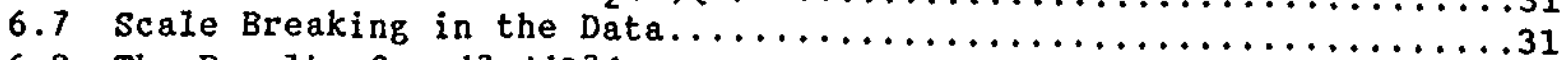

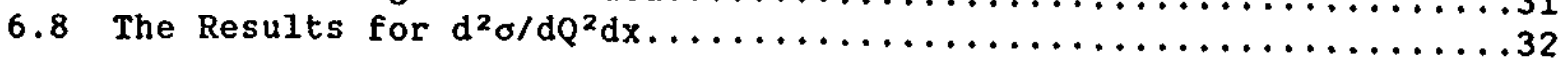


7. The Measurement of $R=\sigma_{L} / \sigma_{T}$

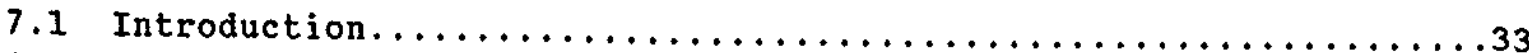

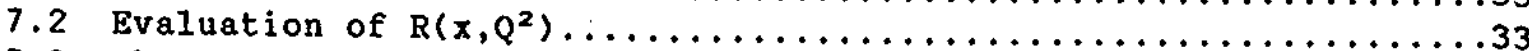

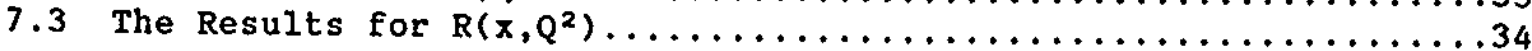

8. Comparison of the Results for $F_{2}\left(x, Q^{2}\right)$ and $R\left(x, Q^{2}\right)$ with the Predictions of QCD

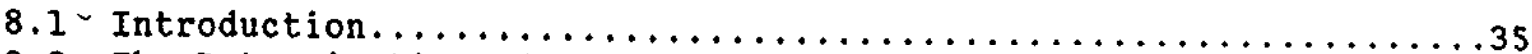

8.2 The Determination of the QCD Mass Scale Parameter $\Lambda \ldots \ldots \ldots \ldots \ldots . \ldots 5$

8.3 Estimation of the Gluon Distribution of the Proton $\ldots \ldots \ldots \ldots \ldots . \ldots 7$

8.4 Comparison of the Measurements of $R\left(x, Q^{2}\right)$ with $Q C D \ldots \ldots \ldots \ldots \ldots 38$

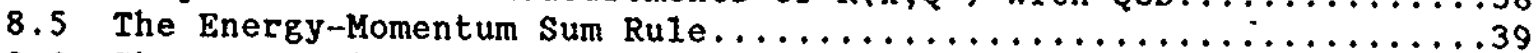

8.6 The Separation of Higher Twist Effects....................

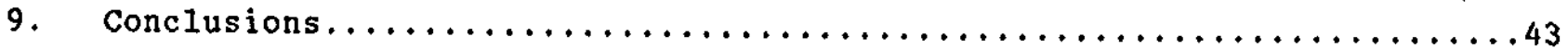

Appendix 1. Radiative Corrections........................45

Appendix 2. Combining the $F_{2}\left(x, Q^{2}\right)$ Results .................... 


\section{Introduction}

Over the past two decades the study of inelastic lepton-nucleon scattering has proved to be one of the most important methods of improving our understanding of the underlying nucleon sub-structure. Charged leptons, muons and electrons, may be considered as point-1ike Dirac particles [1]. The electromagnetic interaction of such particles can be explicitly calculated in quantum electrodynamics, QED [2]. As the electromagnetic coupling constant is sma11, the lowest order process is dominant in deep inelastic scattering i.e. the exchange of a single virtual photon (Fig. 1). This means that charged lepton scattering can be unambiguously interpreted in terms of the structure of the target nucleon.

In charged lepton scattering we measure both the incoming lepton of energy $\mathrm{E}$ and the outgoing lepton of energy $E^{\prime}$ after it has scattered through an angle $\theta$. Hence both the energy, $\nu=E-E^{\prime}$, and mass squared, $q^{2}=-Q^{2}$, of the exchanged virtual photon can be measured. ${ }^{*}$. Studies of deep inelastic scattering can therefore be made over a range of $Q^{2}$ and $v$. The kinematics of deep inelastic scattering are discussed in detail in the next section.

The differential cross section for deep inelastic lepton scattering from a nucleon target may be written as [3],

$$
\frac{d^{2} \sigma}{d \Omega d E^{\prime}}\left(E, E^{\prime}, \theta\right)=\sigma_{M}\left[W_{2}\left(\nu, Q^{2}\right)+2 W_{1}\left(\nu, Q^{2}\right) \tan ^{2} \theta / 2\right]
$$

where $\sigma_{M}=\frac{4 \alpha^{2} E^{2}}{Q^{2}} \cos ^{2} \theta / 2$ is the Mott cross section. The two structure functions $W_{1}$ and $w_{2}$ contain all the information about the structure of the nucleon obtainable from unpolarised lepton scattering. As opposed to real photons, the exchanged virtual photon can have a longitudinal as well as a transverse polarisation. The differential cross section is related to the total cross sections ( $\sigma_{L}$ and $\sigma_{T}$ ) for the absorption of transverse and longitudinally polarised virtual photons respectively by $[4]$

$$
\frac{d^{2} \sigma}{d \Omega d E^{\prime}}\left(E, E^{\prime}, \theta\right)=\Gamma\left[\sigma_{T}\left(\nu, Q^{2}\right)+\varepsilon \sigma_{L}\left(\nu, Q^{2}\right)\right]
$$

*) Throughout this paper we take $\hbar=c=1$ and the mass of the muon is neglected. 
where $\Gamma$ is the transverse virtual photon $f 1$ ux and $\varepsilon$ is the degree of transverse polarisation. The ratio $R=\sigma_{L} / \sigma_{T}$ is then related to the structure functions $w_{1}$ and $w_{2}$ by

$$
R\left(v, Q^{2}\right)=\frac{\sigma_{L}}{\sigma_{T}}=\frac{w_{2}\left(v, Q^{2}\right)}{w_{1}\left(v, Q^{2}\right)}\left(1+\frac{v^{2}}{Q^{2}}\right)-1
$$

The first studies of deep inelastic electron-proton scattering took place at the stanford Linear Accelerator Centre (SLAC) and DESY [5]. The measured cross sections showed a $1 / Q^{4}$ dependence [6], suggesting that the virtual photon was interacting with charged point-like objects in the nucleon. Furthermore, it was found that if the structure functions $w_{1}$ and $w_{2}$ were redefined as

$$
M W_{1}\left(v, Q^{2}\right)=F_{1}\left(v, Q^{2}\right) ; \quad v W_{2}\left(v, Q^{2}\right)=F_{2}\left(v, Q^{2}\right)
$$

then the structure functions $F_{1}$ and $F_{2}$ become functions of a single dimensionless variable $x=Q^{2} / 2 M v[6,7]$, where $M^{2}$ is the proton mass. This property, termed scaling, implies that the structure functions $F_{1}$ and $F_{2}$ are independent of any dimensional scale such as mass or length. Bjorken [8] had already predicted this property in the limit $Q^{2} \rightarrow \infty$ and $\nu \rightarrow \infty$ with $x$ remaining finite. It was surprising, however, to find such a behaviour for values of $Q^{2}$ as low as $2 \mathrm{Gev}^{2}$.

Feynman used the name partons for the point-like particles in the nucleon [9]. He showed in the simple parton model, that where $x$ was the fraction of the nucleon's momentum carried by the struck parton in the infinite momentum frame and the virtual photon was absorbed by point-like constituents in the nucleon, exact scaling resulted. Within this model the spin of these nucleon constituents is reflected in the magnitude of $R$. Neglecting the mass and transverse momentum of the partons, helicity conservation requires that $R=0$ for spin $1 / 2$ partons and that $R \rightarrow \infty$ for partons with spin 0 . This latter possibility was soon ruled out by experiments [5]. Subsequently these charged partons were identified with quarks leading to the Quark-Parton model (QPM) [10].

Measurements were made at $\operatorname{SLAC}[11,12]$ extending the range of $Q^{2}$ up to $30 \mathrm{GeV}^{2}$ and $v$ to $15 \mathrm{GeV}$. These allowed detailed studies of the behaviour of the structure functions from hydrogen and deuterium targets revealing, in some regions, that the scaling behaviour in $x$ appeared to be violated to about $20 \%$ confirming 
earlier results from FERMILAB [13]. R was found to be $0.16 \pm 0.12$ and to have little dependence on $x$ or $Q^{2}$. For spin $1 / 2$ partons with a transverse momentum $\mathrm{P}_{T}$, due to the Fermi motion of the partons inside the nucleon, the prediction for $R$ is modified to be $4\left\langle p_{T}^{2}\right\rangle / Q^{2}[9]$. The measurement of a small value of $R$ is consistent, therefore, with the assumption that the charged constituents of the nucleon have spin $1 / 2$.

Subsequent results from experiments at the Fermilab accelerator with high energy muon beams confirmed that scaling was violated. A Michigan-Cornell-La JollaPrinceton collaboration reported clear evidence for scale breaking in the region $1<Q^{2}<25 \mathrm{GeV}^{2}$ for muon scattering from an iron target [14]. These measurements were subsequently extended into the lower $x$ region by a Chicago-HarvardI1linois-Oxford collaboration using hydrogen and deuterium targets [15]. This group established that scaling was also violated for $x<0.1$ up to a level of about $30 \%$ and that at higher $x$, within the statistics, the data showed a similar pattern to that seen by the SLAC experiments.

Various theoretical attempts were made to explain the observed scale breaking of the structure function $F_{2}$. Extended quark-parton models [16], including target mass [17] and threshold effects, could account for small deviations from scaling, although they were unable to explain all of the observed violations. Conventional field theories [18] and asymptotically free gauge theories [19] also predict that the structure functions should not scale.

Quantum Chromodynamics (QCD) is one such theory in the latter class. Unlike the quark-parton model QCD has a rigorous theoretical basis [20], although it can be viewed as the QPM with the addition of gluon exchange and gluon radiation where the gluon is the mediator of the strong force. As QCD is an asymptotically free gauge theory, the effective coupling constant between quarks and gluons, $g_{\text {eff }}$, becomes smaller the larger the four momentum transfer of the virtual photon probe. The strong interaction coupling constant, $\alpha_{S}$, is defined in leading order perturbative $Q C D$ as

$$
a_{S}\left(Q^{2}\right)=\frac{g_{e f f}{ }^{2}}{4 \pi}=\frac{12 \pi}{(33-2 f) \text { In } Q^{2} / \Lambda^{2}}
$$


where $f$ is the number of quark flavours. The mass scale parameter $\Lambda$ is the only free parameter and has to be determined experimentally. As $\alpha_{s}$ vanishes when $Q^{2} \rightarrow \infty$, perturbation theory can be used to calculate the $Q^{2}$-development of the nucleon structure functions for $Q^{2} \gg \Lambda^{2}$.

From the definition of the coupling constant (eqn, 1.5), QCD predicts a logarithmic variation with $Q^{2}$ for the scaling violation of the structure functions. More rigourous checks on these predictions became possible with the new generation of muon experiments at CERN, capable of measuring to larger values of $Q^{2}$ and with high precision.

This paper reports on the experiment performed by the European Muon Collaboration (EMC) at CERN. The proton structure functions $F_{2}\left(x, Q^{2}\right)$ and $R\left(x, Q^{2}\right)$ have been measured using incident muon energies of $120,200,240$ and $280 \mathrm{GeV}$ over a $Q^{2}$ range from 3 to $190 \mathrm{GeV}^{2}$ and an $x$ range from 0.02 to 0.80 . The final results presented here both extend and supersede all of the previous data of references $[21-27\}$. 


\section{The Kinematics of Muon Scattering}

The various aspects of the apparatus and the definitions of all physical quantities are described with respect to the EMC co-ordinate system. This is a right-handed orthogonal co-ordinate system in which the $x$-axis is defined as the spectrometer axis along the beam direction and the azimuthal plane is defined by a horizontal $y$-axis and a vertical z-axis. In Fig. 1 the basic diagram for muon scattering in terms of single photon exchange is given. From this the kinematic. variables of deep inelastic muon scattering can be defined as shown in Table 1.

The differential cross section for inelastic muon-proton scattering, assuming one photon exchange and neglecting the muon mass is given by

$$
\begin{aligned}
\frac{d^{2} \sigma}{d Q^{2} d x} & =\frac{4 \pi \alpha^{2}}{Q^{4}}\left[\left(1-y-\frac{M x y}{2 E}\right) \frac{F_{2}\left(x, Q^{2}\right)}{x}+y^{2} F_{1}\left(x, Q^{2}\right)\right] \\
& =\frac{4 \pi \alpha^{2} F_{2}\left(x, Q^{2}\right)}{Q^{4} x}\left[1-y-\frac{M x y}{2 E}+\frac{y^{2}\left(1+\frac{4 M^{2} x^{2}}{Q^{2}}\right)}{2\left(I+R\left(x, Q^{2}\right)\right)}\right] .
\end{aligned}
$$

$R\left(x, Q^{2}\right)$ is the ratio of the absorption cross sections o and $\sigma_{T}$ for longitudinally and tranversely polarised virtual photons and can be written in terms of the proton structure functions $F_{1}$ and $F_{2}$ as

$$
R=\frac{\sigma_{L}}{\sigma_{T}}=\left[\left(1+\frac{4 M^{2} x^{2}}{Q^{2}}\right) F_{2}-2 x F_{1}\right] / 2 x F_{1}
$$

so that

$$
F_{1}=\frac{\left(2 M v-Q^{2}\right)}{8 \pi^{2} \alpha} \sigma_{T}
$$

and

$$
F_{2}=\frac{\left(2 M v-Q^{2}\right)}{8 \pi^{2} \alpha} \frac{Q^{2}}{\left(Q^{2}+v^{2}\right)} \frac{v}{M}\left(\sigma_{T}+\sigma_{L}\right) .
$$

An experimental knowledge of $R\left(x, Q^{2}\right)$ is necessary to determine the structure function $F_{2}\left(x, Q^{2}\right)$. In the approximation that $E \gg M$ and $Q^{2} \gg M^{2}$, equation 2.2 may be rewritten as 
$-10-$

$$
\frac{d^{2} \alpha}{d Q^{2} d x} \simeq \frac{4 \pi a^{2}}{Q^{4}} \frac{F_{2}}{x}\left[1-y+\frac{y^{2}}{2(1+R)}\right] .
$$

Hence the ratio of $F_{2}$ calculated with a given value of $R$ to that for $F_{2}$ with $R=0.0$ is

$$
\frac{F_{2}(R)}{F_{2}(R=0)}=\frac{1-y+y^{2} / 2}{1-y+y^{2} / 2(1+R)} .
$$

The resulting dependence of $F_{2}$ on $R$ for three finite values of $R$ is shown in Fig. 2 as a function of $y$.

The data may also be evaluated in bins of $Q^{2}$ and $v$. The measured cross section can be written as

$$
\begin{aligned}
\frac{d^{2} \sigma}{d Q^{2} d \nu} & =r\left[\sigma_{T}\left(Q^{2}, v\right)+\varepsilon \sigma_{L}\left(Q^{2}, v\right)\right] \\
& =r \sigma_{T}(1+\varepsilon R),
\end{aligned}
$$

where $r$ is the flux of transverse virtual photons and $\varepsilon$ the polarisation parameter, given respectively by

$$
r=\frac{\alpha}{4 \pi M} \frac{\left(2 M U-Q^{2}\right)}{Q^{2} E^{2}(1-\varepsilon)},
$$

and

$$
c=\frac{\left(1-y-Q^{2} / 4 E^{2}\right)}{\left(1-y+y^{2} / 2+Q^{2} / 4 E^{2}\right)} .
$$




\section{The Apparatus}

\subsection{Introduction}

The experiment was performed in the M2 muon beam 1 ine at the CERN SPS [28] using the EMC forward spectrometer [29]. The data were taken in twelve 10 day running periods of the SPS. The spectrometer, shown in Fig. 4, was designed to detect and analyse the scattered muon and produced hadrons over a wide range of angles and momenta. This is illustrated in Fig. 3 where a comparison is also made with previous charged lepton scattering experiments on hydrogen targets $[11,12,15]$. This section gives a brief outline of the general features of the apparatus.

\subsection{The Muon Beam Line and the Detector}

The muon beam, of momentum spread $\Delta \mathrm{p} / \mathrm{p} \sim 5 \%$, was produced from the decay in flight of charged pions and kaons resulting from the interactions of the $400 \mathrm{GeV}$ primary proton beam with a Beryllium target. The momentum of each incident muon was determined to an accuracy $\sim 0.2 \%$ by a spectrometer stage in the beam 1ine [30], the beam momentum station. An upper 1 imit for the residual pion contamination of the beam was measured to be $10^{-5}$, at $90 \%$ confidence level. Typical beam intensities ranged from $\sim 10^{7}$ muons/second at $280 \mathrm{GeV}$ to $\sim 4 \times 10^{7}$ muons/second at $120 \mathrm{GeV}$.

The beam was incident on a liquid hydrogen target of length $6 \mathrm{~m}$ and diameter $15 \mathrm{~cm}$. This contained parahydrogen at a pressure of 813 torr, temperature $20.5^{\circ} \mathrm{K}$ and density of $0.0699 \mathrm{~g} / \mathrm{cm}^{3}$. The density variation due to gas bubbles was estimated to be $8 \times 10^{-5} \mathrm{~g} / \mathrm{cm}^{3}$. Each beam track was measured to an accuracy of $\sim 0.15 \mathrm{mrad}$ in angle and $\sim 1 \mathrm{~mm}$ in position by the scintillator hodoscopes BHA and BHB [31], (Fig. 4).

Charged particles leaving the target were detected by the drift chambers W1-W7 and the multiwire proportional chambers PI-P3 (Fig, 4). These tracks were momentum analysed by measuring the deflections produced by the spectrometer magnet (FSM) in the drift chambers $W 1-W S$. The momentum resolution was $\Delta p / p \sim 10^{-4} p$ for 5 Tesla-metre bending power and the angular resolution was $\sim 0.15 \mathrm{mrad}$. The angular acceptance in the bending plane was $\pm 8^{\circ}$ for particles of momentum $>15 \mathrm{GeV}$ and $\pm 5^{\circ}$ in the non-bending plane. Particles which traversed the $2.5 \mathrm{~m}$ (15 interaction lengths) 
thick iron absorber were reconstructed in the drift chambers 667 and were designated as muons. The absorber was magnetised in the horizontal direction so as to induce a vertical deflection of the muon tracks. This allowed a momentum cut in the trigger to discriminate against low energy muons from $\pi$ or $K$ decays. Each of the drift chambers and the multiwire proportional chambers P1-P3 contained a dead region through which the beam passed. Particles which remained in the beam region were detected in the small proportional chambers $P O A$ and $P O B$.

A scintillator hodoscope, H5, located downstream of the apparatus was used to monitor the muon beam intensity. This consisted of two planes of scintillator, in coincidence, which were divided into small elements to reduce the counting rate per element to $<10^{7}$ per second.

\subsection{The Scattered Muon Trigger}

The scattered muon trigger was formed by selecting specific combinations of the elements of the trigger hodoscopes $\mathrm{Hl}, \mathrm{H} 3$ and $\mathrm{H} 4$ in anti-coincidence with the signals from the veto counters $V 1, V 2$ and $V 3$, such that the incident and scattered muons fulfilled the following requirements:

- target pointing in both the horizontal and vertical planes;

- momentum larger than a preselected value;

- scattering angle larger than a preselected value;

- no hit outside the beam hole in the veto system.'

The veto counters VI, V2 and V3 [32], detected halo muons. All three counters had a hole to allow the beam to pass with the hole in $V 2$ defining the accepted beam diameter of $6 \mathrm{~cm}$. The measured rate of halo muons traversing the apparatus was $\sim 7 \%$ of the beam rate at an incident muon energy of $280 \mathrm{GeV}$. A soft component of the halo increased the singles count rate in $\mathrm{V} 3$ to about $20 \%$ of the incident muon flux. This was considerably reduced by the iron wall placed just upstream of v3. Under these conditions the random vetoing at an incident rate of $3 \times 10^{7}$ muons/second was $\sim 8 \%$. 
The trigger hodoscopes $H 1$ and $H 3$ consisted of vertical (HIV, H3V) and horizontal (H1H, H3H) elements which defined the muon trajectory behind the FSM. The hodoscope $\mathrm{H} 4$ had only horizontal scintillator strips, allowing, together with $\mathrm{H} 3 \mathrm{H}$ the vertical angular component of the muon behind the absorber to be determined. A $40 \mathrm{~cm}$ thick iron wall was placed directly in front of $\mathrm{H} 4$ to absorb low energy electromagnetic showers.

The patterns of allowed hodoscope combinations to be satisfied by the scattered muon were determined by a Monte Carlo simulation. The two-dimensional correlations between the trigger hodoscopes were made using programmable fast coincidence matrices [33]. A common $O R$ of the allowed coincidences in each matrix was used to form the final muon trigger.

The basic muon trigger, $T$, shown in Fig. 5 was:

$I=\sqrt{\text { EEO }} \cdot \mathrm{VTP} \cdot \mathrm{HTP} \cdot \mathrm{MC} \cdot \mathrm{SCA} \cdot \mathrm{AC}$

where

$$
\begin{aligned}
& \text { Veto }=(\mathrm{V} 1 \text { or } \mathrm{V} 2 \text { or } \mathrm{V} 3) \\
& \text { HTP }=(\mathrm{H} I \mathrm{~V}, \mathrm{H} 3 \mathrm{~V})=\text { horizontal target pointing } \\
& \text { VTP }=(\mathrm{H} 1 \mathrm{H}, \mathrm{H} 3 \mathrm{H})=\text { vertica1 target pointing } \\
& \text { MC }=(\mathrm{H} 3 \mathrm{H}, \mathrm{H} 4 \mathrm{H})=\text { momentum cut } \\
& \mathrm{SCA}=(\mathrm{H} 3 \mathrm{~V} \cdot \mathrm{H} 3 \mathrm{H})=\text { high } \mathrm{v} \text { angle cut } \\
& \text { AC }=(\mathrm{H} 1 \mathrm{~V} \cdot \mathrm{H} 3 \mathrm{H})=\text { angle cut }
\end{aligned}
$$

The target pointing matrices $M O, M 1$ and $M S$ reduced the level of background triggers. Those channels of $\mathrm{HIV}$ and $\mathrm{H} 3 \mathrm{H}$ which satisfied these matrices were fed through to the matrix $M 2$ which imposed a minimum angle cut of $0.5^{\circ}$. The momentum cut matrix M3 selected scattered muons with momenta above $\sim 15 \mathrm{GeV}$. For low momentum or small scattering angles, where the muon passed through the beam hole, the trigger matrices could be confused by hadrons or electrons hitting H1. These false triggers were suppressed by the matrix M7 which used the signals from $\mathrm{H} 3 \mathrm{H}$ and $\mathrm{H} 3 \mathrm{~V}$. The resulting trigger rate was typically $\sim 3-5 \times 10^{-6}$ per incident muon. 
About 10\% of all triggers contained a scattered muon which alone fulfilled the trigger conditions. In another $20 \%$ of the events the trigger was satisfied by a combination of the muon and another particle. These were mainly muon-electron scatters, where the muon passed through the beam hole in $\mathrm{HI}$, into the live region of matrix M7 and the electron, or the electron initiated shower, struck the hodoscope $\mathrm{Hl}$. These and other false triggers were subsequently removed from the analysis by the requirement that the muon alone satisfied the trigger. Other sources of background triggers arose from halo muons which passed through the beam holes in the veto counters, hadron punch-through in the iron absorber and electro-magnetic showers.

\subsection{The Norma1i sation Trigger}

In order to measure the muon flux at intensities up to $10^{8}$ muons/ second a new technique was used [34]. A radioactive source was used to generate a random trigger with a rate of $5-10 \mathrm{~Hz}$ during the spill. By counting the number of beam tracks reconstructed within a known time window, the total reconstructable integrated beam flux was obtained from:

\section{Number of reconstructed tracks in the window}

Width of window $x$ random trigger rate

These tracks were reconstructed using the same programmes and cuts as those used for the physics triggers. The computed flux, therefore, corresponded to the reconstructable beam and was independent of the efficiency of the beam hodoscopes and the reconstruction method. In addition effects due to random vetoing and dead time were automatically taken into account. 


\section{Data Analysis and the Extraction of $\mathrm{F}_{2}$}

\subsection{Introduction}

In this section the complete data analysis leading to the extraction of the nucleon structure function $F_{2}$ will be described. Further details concerning the analysis techniques are given in references [24, 26 and 27].

\subsection{Apparatus A1ignment}

During each running period data were taken with the forward spectrometer magnetic field turned off in order to calibrate and spatially align each of the wire chambers and scintillation hodoscopes. This procedure resulted in a positional accuracy of $\sim 0.1 \mathrm{~mm}$ in $y$ and $z$. In $x$, the positions were determined by surveying to a precision of $\sim 1.5 \mathrm{~mm}$.

\subsection{Off-1ine Event Reconstruction}

The off-line event reconstruction proceeded in two stages. In the first stage, the pattern recognition programme, the hits recorded in the wire chambers were associated into tracks. In the second stage, the geometry programme, the best fit track and vertex parameters were obtained.

The philosophy of the pattern recognition was to find tracks starting in the most downstream chambers where the inter-track separation was greatest and from there to progress upstream. The search then proceeded in stages; the track segments in W67 were found and used to point into a small spatial region in w45 and thence upstream to the target. Track projections were found initially in the non-bending plane followed by the bending plane and then correlated by hits in the inclined wire planes.

The search for beam tracks proceeded in the same way for both the physics and normalisation triggers. In both the beam momentum station and the beam hodoscopes track segments were found using a combined space and time analysis of the hits in the respective scintillation hodoscopes. The same time analysis also provided a means of correlating tracks seen in the two detectors. 
Track fits were performed in the geometry programme. Fits were also made to determine the interaction vertex between the incident and scattered muons and the kinematics of the events. These were performed in two orthogonal projections, $x y$ and $x z$, using the Quintic spline method [35] and the effects of multiple scattering were included for tracks of momentum less than $100 \mathrm{GeV}$. Like sign muon vertices were fitted using the single track parameters. The method of Lagrange's undetermined multipliers [36] was used to find the common vertex which minimised the $x^{2}$, simultaneously improving the track parameters in the constraint fit. The muon vertex for each event was found independently of any hadron track in the event, so as to avoid any bias, for example, from the effects of secondary hadron interactions.

The output of the geometry programme was an intermediate Data Summary Tape, the MAXI DST, which contained fitted track and vertex parameters, the Iine vectors from the reconstruction programe and the raw event data.

\subsection{DST Processing}

The final event processing was performed using the MAXI DST. The scattered muon was first checked against the trigger requirements to select those events where it alone had satisfied the hardware trigger. In addition the scattered muon and beam particle were demanded to form an interaction vertex. A condensed record for each event was then written to a MINI DST. This contained the kinematic parameters for the event and sufficient extra information to allow studies of detector performances.

The MINI DST was processed to provide the necessary output files for the analysis. These files were:

\section{a) The NANO DST}

This contained the final data for each event compacted into a format similar to that from the Monte Carlo and hence ready for the calculation of $F_{2}$. Information from the normalisation trigger was also passed to the NANO DST to allow calculation of the incident muon flux. For both the physics and normalisation triggers the beam track was accepted if it had correlated beam momentum station and beam hodoscope timing information and a measured beam momentum. 


\section{b) The Chamber Efficiency Maps}

Efficiency maps were determined for each of the 99 wire chamber planes. The efficiency of each plane was deduced from a comparison of the reconstructed hits on each muon track and the reconstruction requirements of the pattern recognition programme. These were then averaged over $a 11$ of the muon tracks to produce detailed efficiency maps which allowed any variation in efficiency over the planes to be seen. Account was taken of insensitive regions in the chambers due to dead wires, beam killers, chamber edge effects and support wires. The final efficiency maps were written out to a file for later use in the apparatus simulation in the Monte Carlo programe. By using the track data in this way allowance was made both for hardware inefficiencies and software failures to find a hit on a track.

\subsection{The Monte Carlo Simulation}

A simulation of the apparatus was made for each running period by a Monte Carlo programme using the following input information.

a) The Alignment File: The information in this file specified the positions of each chamber and hodoscope plane, their dead regions, beam holes and calibration constants. The same file was used in the Monte Carlo programme as in the reconstruction and geometry programmes.

b) The Beam Phase Space file: This file consisted of all the beam tracks reconstructed from the normalisation trigger. The unbiased random nature of this trigger ensured that the beam phase space used by the Monte Carlo was an accurate representation of the beam for each period.

c) Hodoscope Efficiencies: Each hodoscope efficiency was found by reconstructing halo muon tracks in data taken with triggers which excluded that hodoscope. The efficiency for each element was determined from the fraction of reconstructed tracks which registered a hit in that element. These were entered into the Monte Car10, typical values being greater than $99 \%$. 
d) Wire Chamber Efficiency Parameterisations: From the map obtained for each detector plane (section 4.4 b) fits were made using simple functional forms to describe the spatial variation of the efficiency. The results of the fits were fed into the Monte Car10, along with a list of dead wires and the positions of the chamber support wires. A typical example of the radial dependence of the efficiency and the resulting parameterisation is shown in Fig. 6. The parameterisations were sufficient to describe these variations to a precision of $\sim 1-2 \%$ at any given point.

e) Experimental Resolution: The experimental resolutions for track momenta, angles and vertex position were parameterised using geometrical fits to the data for each beam energy (see Table 2). These were included in the Monte Car1o to smear the generated kinematic quantities for each event.

f) The Absorber Magnetic Field: This was determined from the data for each running period and used to simulate the deflection of muons which passed through the absorber.

The Monte Carlo simulation proceeded for each event as follows. A beam muon was first selected from the beam phase space file and the coordinates of the interaction vertex in the target generated randomly. Values of $Q^{2}$ and $v$ were chosen randomly following a $1 / Q^{2}$ distribution and a flat distribution in $v$. The scattered muon was tracked through the spectrometer taking account of multiple scattering and energy losses. The generated variables were smeared within the experimental resolutions to allow the measured kinematics of the event to be determined. The hodoscope and wire chamber hit patterns for the scattered muon were then determined from the calculated track positions, including the effects of chamber inefficiencies. The results for each event were written to a Micro DST. To reduce the statistical error on the Monte Carlo corrections approximately five times as many accepted events were generated as those present in the data. 


\subsection{The Calculation of $\mathrm{F}_{2}$}

The structure function $F_{2}\left(x, Q^{2}\right)$ was determined by comparing data and Monte Carlo events on a grid of $\left(x, Q^{2}\right)$ bins. Identical cuts were applied both to the data and smeared kinematic parameters of the Monte Carlo events. Each Monte Carlo event was weighted by the deep inelastic cross-section at the generated value of $x$ and $Q^{2}$ for that event using a functional form for $F_{2}\left(x, Q^{2}\right)$ and assuming $R\left(x, Q^{2}\right)=0$. The procedure was iterated several times to obtain a better functional form at each iteration, as described below.

In order to extract the deep inelastic cross-section corrections for radiative effects were made using the functon $\eta\left(x, Q^{2}\right)$, where

$$
n\left(x, Q^{2}\right)=\frac{d^{2} \sigma^{D I}\left(x, Q^{2}\right)}{d Q^{2} d x} / \frac{d^{2} \sigma^{O B S}\left(x, Q^{2}\right)}{d Q^{2} d x} .
$$

The deep inelastic cross-section, $\mathrm{d}^{2} \sigma^{\mathrm{DI}} / \mathrm{dQ}^{2} \mathrm{dx}$, corresponds to that for single photon exchange and the observed cross-section, $\mathrm{d}^{2} \sigma^{O B S} / \mathrm{dQ}^{2} \mathrm{dx}$, contains the extra contributions from radiative effects (Figs. 7 and 8 ) as described in Appendix 1. The event weight in the Monte Carlo was corrected by dividing by $n\left(x, Q^{2}\right)$ so that it corresponded to the weight for the observed cross-section at that $x$ and $Q^{2}$.

The normalised yield of Monte Carlo events in each bin, $\mathrm{N}_{\Delta x \Delta Q^{2}}^{\text {, was calculated }}$ using the incident muon flux determined from the normalisation trigger (section 3.4 ). By comparing this yield with the observed number of events in the bin, $N^{\text {DATA }}$, the
\[ \times \Delta Q^{2} \] structure function $\mathrm{F}_{2}\left(x, Q^{2}\right)$ was obtained using the relationship

$$
\mathrm{F}_{2}\left(\mathrm{NEW}, \mathrm{Q}^{2}\right)=\frac{\mathrm{N}_{\Delta \mathrm{x} \Delta Q^{2}}^{\mathrm{DATA}}}{\mathrm{N}_{\Delta \mathrm{X} \Delta \mathrm{Q}^{2}}^{\mathrm{MC}}} \quad \mathrm{F}_{2}\left(\mathrm{OLD}, \mathrm{Q}^{2}\right)
$$

where both $F_{2}^{O L D}$ and $F_{2}^{N E W}$ are at the $x$ and $Q^{2}$ of the bin centre. $F_{2}^{O L D}\left(x, Q^{2}\right)$ was calculated using the same function for $F_{2}\left(x, Q^{2}\right)$ as used in the radiative correction calculations. This was re-fitted to $\mathrm{F}_{2}^{\mathrm{NEW}}\left(\mathrm{x}, Q^{2}\right)$, the radiative corrections recalculated and the process repeated. At most three such iterations were required for convergence. The parameterisation of $F_{2}\left(x, Q^{2}\right)$ is described in section 6.6 . 
Investigations using different functional forms showed that the same results were obtained in each case, demonstrating that they are independent of the initial choice of this function.

The magnitude of the radiative correction function $n$ is shown in Fig. 9 for an incident muon energy of $280 \mathrm{GeV}$ as a function of $\mathrm{y}$ at several different values of $x$. This shows that the corrections are in general small $(\leq 10 \%)$ except at small $x$ and slowly varying except in the region of $y>0.8$. Here the events from the elastic radiative tail dominate and give rise to a rapidly changing contribution with $y$ which can reach values in excess of $30 \%$. For comparison, the corresponding electron scattering radiative corrections are typically a factor of three times - larger than those for muon scattering. 


\section{The Treatment of Systernatic Errors}

\subsection{Introduction}

As the principal aim of this experiment was to determine the structure functions $F_{2}\left(x, Q^{2}\right)$ and $R\left(x, Q^{2}\right)$ with high precision, it was necessary to consider the sources of systematic error which are, in general, the dominant uncertainties. A discussion of the individual systematic errors and the cuts used to minimise their effects is given in this section.

\subsection{The Determination of the Incident and Scattered Muon Energies}

A small systematic error in the measurement of either the incident or scattered muon energies ( $E, E^{\prime}$ ) will produce distortions in the measured structure functions $F_{2}\left(x, Q^{2}\right)$ due to the observed $\sim(1-x)^{3}$ dependence of $F_{2}$ for $x \gtrsim 0.2$. The effect of a $0.4 \%$ calibration error in $\mathrm{E}$ is shown in Fig. 10. Calibrations of the energy scales of the incident and scattered muon were made as follows

a) Firstly the measurement of the scattered muon energy was verified using the observed position of the $J / \psi$ mass peak obtained from the dimuon mass spectrum [29]. The centre of the peak was determined to be $(3094.8 \pm 2.1) \mathrm{MeV}$ with a width of $(34.3 \pm 1.8) \mathrm{MeV}$. This is in good agreement with the known $J / \psi$ mass of (3096.9 \pm 0.1$) \mathrm{MeV}$ and the forward spectrometer resolution in this region. From this the absolute calibration for $E^{\prime}$ was deduced to be $1.000 \pm 0.002$.

b) The incident beam energy was calibrated by comparing the beam energy measured in the beam momentum station (section 3.2), with that measured by the forward spectrometer. The calibration was performed for each of the four beam energies, measurements being made with both polarities of the forward spectrometer magnet. This removed, by cancellation, uncertainties due to local chamber misalignments. From the comparison of the measured energies the absolute calibration for $E$ was determined to be $1.000 \pm 0.004$. 
c) In comparing muon track momenta measured in the beam momentum station with those measured in the forward spectrometer with opposite magnet polarities, it was observed that momenta measured in a local region of the spectrometer could be wrongly determined by up to $\sim 1 \%$. This was in contrast to the maximum error of $0.2 \%$ estimated for the scattered muon energy from the $J / \Psi$ mass determination where the events illuminated the whole detector.

In summary a systematic error of $0.4 \%$ was assigned to the measurement of the incoming bean energy. The systematic error for the scattered muon energy was taken to be $0.2 \%$ for those bins with full azimuthal illumination, rising to a value of $1 \%$ where less than a quarter of the azimuthal range was populated. The error on $F_{2}$ due to these errors was then computed for each quantity separately by evaluating the change in $F_{2}$ resulting from a shift in the mean values of $E$ or $E^{\prime}$ for a given bin. A cut at low $v$ (Table 3 ) was made to eliminate the regions most sensitive to these uncertainties. The resulting errors are given in Tables 4 and 5 in which columns 6 and 7 correspond to the errors in $E$ and $E^{\prime}$ respectively. Typically these are $\lesssim 1 \%$ but for some bins, especially at large $x$ and small $Q^{2}$, they reach values as large as $15 \%$.

\subsection{The Muon Scattering Angle Determination}

The assessment of the accuracy of the alignment procedure for the early running periods showed that systematic shifts of up to $\sim 0.3 \mathrm{mrad}$ in the muon scattering angle were possible. Subsequent refinement of the procedure reduced this to a negligible error for the data of the later periods. The effect of this error on $F_{2}$ is given in column 8 of Tables 4 and 5 . This was minimised by the use of a $10 \mathrm{mrad}$ angle cut for the 240 and $280 \mathrm{GeV}$ data which were affected most.

\subsection{The Determination of the Acceptance}

The systematic error on $F_{2}$ arising from the Monte Carlo acceptance calculations was empirically determined to be

$$
\frac{1}{\text { Acceptance }\left(x, Q^{2}\right)} \%
$$


by comparing corrected data for a given $x, Q^{2}$ and beam energy from different running conditions. This acceptance represents the geometrical acceptance reduced by the cuts applied to the data. Data points were excluded for which this is $<15 \%$. The resulting errors are typically $\sim 1.5 \%$ and are given in column 1 of Tables 4 and 5 .

\subsection{The Correction for Track Losses Due to Chamber Inefficiencies}

In any $\left(x, Q^{2}\right)$ bin only a certain fraction of the tracks, $\varepsilon\left(x, Q^{2}\right)$, were reconstructed due to chamber inefficiencies. These losses can be determined to an accuracy $\sim 20 \%$ and gave systematic errors on $\mathrm{F}_{2}$ of:

$$
20\left[1-\varepsilon\left(x, Q^{2}\right)\right] \% \text {. }
$$

The resulting errors are given in column 4 of Tables 4 and 5 and are typically $\lesssim 1 \%$. Data points were excluded for which the inefficiency correction was $>20 \%$.

\subsection{The Correction for Experimental Resolution}

The correction factor $S\left(x, Q^{2}\right)$ for $F_{2}$ due to the smearing of the kinematic variables is defined to be

$$
S\left(x, Q^{2}\right)=\frac{\text { number events in }\left(x, Q^{2}\right) \text { bin after smearing }}{\text { number events generated in }\left(x, Q^{2}\right) \text { bin }}
$$

The determination of the experimental resolutions is described in section $4.5(e)$. It was estimated that the uncertaity in the correction was $\lesssim 20 \%$ resulting in a systematic error on $F_{2}\left(x, Q^{2}\right)$ of:

$$
20\left|1-s\left(x, Q^{2}\right)\right| \%
$$

This error is in general small $(\sim 0.2 \%)$ and is given in column 3 of Tables 4 and 5. A cut at low $v$ (see Table 3 ) was made to exclude the regions where the correction is large and data points were excluded if it is $>15 \%$. 


\subsection{The Bin Centring Correction}

The values of $F_{2}\left(x, Q^{2}\right)$ quoted are at the bin centre, and not at the mean $x$ and $Q^{2}$ of the bin. The bin centring correction is defined as

$$
\frac{\left[F_{2}\left(\bar{x}, \bar{Q}^{2}\right)-F_{2}\left(x_{c}, Q_{c}^{2}\right)\right]}{F_{2}\left(\bar{x}, \bar{Q}^{2}\right)}
$$

where $\bar{x}, \bar{Q}^{2}$ and $x_{c}, Q_{c}^{2}$ are the bin averaged and bin centred values of $x$ and $Q^{2}$, respectively. This correction is small for all bins except for the $Q^{2}$ bins at the edges of phase space where $\bar{x}$ and $\bar{Q}^{2}$ differ significantly from the central values. The systematic error on $F_{2}$ coming from this source was estimated to be

$20 \mid$ Bin Centring Correction $\left(x, Q^{2}\right) \mid \%$

This error is normally small $(\leq 0.4 \%)$ and is listed in column 5 of Tables 4 and 5. Data points were excluded if the bin centring correction is $>15 \%$.

\subsection{The Radiative Corrections}

As described in section 4.6 and Appendix 1 the data were corrected for radiative effects using the formulae of Tsai [37]. The dominant contribution to these, that of internal bremsstrahlung (Figs. $7(a)$ and (b)), was measured in separate studies [44] and found to be in good agreement with these calculations.

To allow for any remaining theoretical uncertainties, the systematic error on $F_{2}$ was taken to be:

$$
15\left|1-n\left(x, Q^{2}\right)\right| \%
$$

This is typically $<1 \%$ but $r$ ises to $3 \%$ in the region of low $x$ and large $y$ (see column 2 of Tables 4 and 5). A cut in $y$ of 0.85 was imposed on the data to remove the kinematic regions where the radiative corrections became large and data points were excluded if $\left|1-\eta\left(x, Q^{2}\right)\right|>25 \%$. 


\subsection{Muons from Pion and Kaon Decays}

Background events can occur from low $Q^{2}$ scattering in which a $\pi^{+}$or $\mathrm{K}^{+}$ decays to a muon which satisfies the trigger, leaving the true scattered muon undetected in the bean region. The spectrum of these muons is sharply peaked towards low momentum. The cut of $y<0.85$, imposed to remove those regions where the radiative corrections were large, strongly inhibits these events. Additional cuts on the scattered muon momentum (Table 3) further reduce the effect such that the residual contamination becomes negligible in all bins. Thus the systematic error on $F_{2}$ from this source is also negligible.

\subsection{The Error on the Absolute Normalisation of $F_{2}\left(x, Q^{2}\right)$}

The factors affecting the absolute normalisation for $F_{2}$ are discussed in this section together with their associated errors.

a) The Luminosity: The method of determining the integrated muon flux is described in section 3.4 . The statistical error on this determination was $\sim 1 \%$ for each period of data and the corresponding systematic error was $\sim 2 \%$. The latter arose from uncertainties in the calibration of the time window, within which the beam tracks were counted, and non uniformities in the spill structure. As a cross-check the flux was determined by using the hodoscope $H 5$ and in each case the values obtained were found to be in good agreement within these errors. Further uncertainties arose from the knowledge of the purity and temperature stability of the target. Combining all of these leads to a final uncertainty in the integrated luminosity for each period $\sim 2.5 \%$.

b) Software Losses: The losses in the reconstruction software were estimated to be $4 \pm 4 \%$. These were determined by feeding events into the reconstruction programme from the Monte Carlo simulation with the inclusion of observed background hits. The correction was independent of $Q^{2}, v$ or $x$.

c) Readout Truncations: The data acquisition computer (DAC) had a finite event buffer size of 4000 16-bit words. Larger events were truncated and could not be 
reconstructed offline. Studies of those events with a word length $>2000$ words showed that the reconstruction efficiency and kinematic dependence upon $Q^{2}$ and $v$ is the same as those events with a word length of $\leq 2000$. Further, the reconstruction efficiency was found to be independent of event length. From this it was concluded that truncated events could be treated by a normalisation correction. The size of this correction was typically between $0.1 \%$ and $0.3 \%$.

d) Empty Target Data: In order to estimate the fraction of events which did not come from muon-proton interactions, data were taken with the target emptied of liquid hydrogen. By comparing the target full to target empty data as a function of the interaction vertex position (Fig. 11), vertex cuts were derived which eliminated nearly all events not coming from the liquid hydrogen. From Fig. 11 the ratio of empty to full target events within the target volume was deduced to be $(0.15 \pm 0.03) \%$. The calculated ratio, from the residual hydrogen gas in the empty target at atmospheric temperature and pressure, was $0.13 \%$. These results are compatible within errors and it was assumed that after making the cuts on the interaction vertex position all events originated from muon-proton interactions within the liquid hydrogen volume itself. The systematic error on $\mathrm{F}_{2}$ coming from this source was taken to be $\sim 0.1 \%$.

Combining all these uncertainties gives an overall normalisation uncertainty of $5 \%$. Neglecting the software correction which was common to all periods gives a relative normalisation uncertainty between data sets of $\sim 3 \%$.

\subsection{Summary}

The above errors are summarised in Tables 4 and 5 . Columns 1 to 8 correspond to the errors arising from:

1. - the final acceptance after a.1 cuts,

2. - the radiative corrections,

3. - the correction for the smearing of events from one bin to another,

4. - the correction for the loss of events due to detector inefficiencies,

5. - the correction introduced to determine $F_{2}$ at the bin centre,

6. - the measurement of the incoming beam energy,

7. - the measurement of the outgoing scattered muon energy,

8. - the measurement of the muon scattering angle. 
These represent the point-to-point systematic uncertainties on $F_{2}\left(x, Q^{2}\right)$ several of which are strongly correlated. The cuts applied to minimise these are summarised in Table 6 .

The overall normalisation uncertainty from the individual contributions described in section 5.10 is $\sim 5 \%$ for each data set and the relative normalisation uncertainty between the different data sets is $3 \%$.

The procedure used to determine the systematic error on a quantity $g$, which is derived from $F_{2}\left(x, Q^{2}\right)$ is sumarised as follows. Having first calculated the actual value of $g$, the first of the quoted individual systematic errors on $F_{2}$ was taken, i.e. that for the final acceptance. The value of $F_{2}$ for every bin was then shifted by the full value of the error for that bin and a fit to these adjusted values of $F_{2}$ performed to obtain a new value of $\mathrm{g}$. This procedure was repeated in turn for each of the other seven systematic errors. The final systematic error on $g$ was then calculated according to

$$
\left(\Delta g^{5 y s}\right)^{2}=\sum_{i=1}^{8}\left(g-g_{i}\right)^{2}
$$

where $\Delta g^{\text {sys }}$ is the total systematic error, $g$ is the actual fitted value and $\mathbf{g}_{\mathbf{i}}$ is the fitted value determined after varying $F_{2}$ by the systematic error labelled $i$. This procedure takes into account that the systematic errors are in general not randomly distributed, but depend on the kinematic variables and are therefore strongly correlated from point to point. 


\section{The Results for the Structure Function $F_{2}\left(x, Q^{2}\right)$ \\ and the Double Differential Cross Section $\mathrm{d}^{2} \sigma / \mathrm{dQ}^{2} \mathrm{dx}$}

\subsection{Introduction}

The results of the measurement of the proton structure function, $F_{2}\left(x, Q^{2}\right)$, are presented in this section. A value for $R\left(x, Q^{2}\right)=0.0$, consistent with that measured (see section 7 ), was used to extract these results. The measured values of $F_{2}\left(x, Q^{2}\right)$ at the four incident muon energies, $120,200,240$ and $280 \mathrm{GeV}$ for which data was taken are first presented separately. These are then combined to produce our best estimate of the values of $E_{2}\left(x, Q^{2}\right)$. Results for the radiatively corrected cross-section $\mathrm{d}^{2} \sigma / \mathrm{dQ}^{2} \mathrm{dx}$ at each incident muon energy are also presented.

\subsection{The Data Sample}

In order to accumulate sufficient statistics in regions where the crosssection is small (i.e. large $Q^{2}$, large $x$ ) the data were taken over several SPS running periods at each of the four nominal beam energies. Each of these was analysed independently following the procedure described in section 4 to produce results for $F_{2}\left(x, Q^{2}\right)$. The combined data then cover the kinematic region of $0.02 \leq x \leq 0.80$ and $3 \leq Q^{2} \leq 190 \mathrm{GeV}$.

Kinematic cuts were applied to the data so as to remove regions of poor resolution and rapidly varying acceptance. These are summarised in Table 3 and result in the event samples listed in Table 7. This also gives the corresponding muon flux for each period and the total number of evenis at each energy. Additional cuts as discussed in the previous section (see Table 6) were used to minimise the effect of systematic errors. 


\subsection{The Determination of the Relative Normalisation between the Different Data Sets}

Given the normalisation uncertainty on each data set of $\sim 5 \%$ (section 5.11) it is necessary to determine the relative normalisation factor for each one before combining them. This divides into two parts: that of combining periods taken at the same energy and that of combining the results at different energies. The former is insensitive to the value of $R\left(x, Q^{2}\right)$ but the second is not.

The relative nomalisations at each energy were determined as follows. Initially the measured $F_{2}$ values for each period at the same incident energy were combined by using the procedure given in Appendix 2 and the total $x^{2}$ at that energy evaluated. In order to minimise the influence of systematic error only those points which satisfied the cuts given in Table 6 and in addition had a final acceptance $>30 \%$ and a total systematic error $<5 \%$ were used. Then, keeping the average normalisation factor at 1.0 for that energy, the relative normalisations of each data set was adjusted so as to minimise the total $x^{2}$. A few points which gave an abnormally large contribution to the $x^{2}$ were removed.

To determine the relative normalisation factor between each energy, the above procedure was applied to the combined data with the additional requirement that the bins had an average $y<0.5$. For this the data were binned in $Q^{2}$ and $v$. It can be seen from Fig. 2 that $F_{2}$ determined at such small values of $y$ is insensitive to the value of $R$, if $R$ is small. The results are sumarised in Table 8 from which it $c$ an be seen that there is good agreement between the different energies within the quoted relative normalisation uncertainty of $3 \%$.

\subsection{The Results for $\mathrm{F}_{2}\left(\mathrm{x}, \mathrm{Q}^{2}\right)$ at $120,200,240$ and $280 \mathrm{GeV}$ Incident Muon Beam Energy}

At each muon beam energy the results from the different periods were combined using the relative normalisation factors discussed above. In doing so it was assumed that all the error on $F_{2}$ at a particular $x$ and $Q^{2}$ was statistical. The values of $F_{2}\left(x, Q^{2}\right)$ obtained for each energy are presented in Tables $9 a-d$ and are given at 
the centre of each bin. Both the statistical and the total systematic errors are given, the latter being estimated by adding the individual systematic errors in quadrature. In Fig. 12 a.11 four energies are shown together for comparison. The error is that obtained from adding in quadrature the statistical and systematic errors given in Table 9*. It can be seen that the agreement between the data at the different energies is good.

\subsection{The Final $\mathrm{F}_{2}\left(\mathrm{x}, \mathrm{Q}^{2}\right)$}

The results from the four different energies were combined to obtain the final values of $F_{2}\left(x, Q^{2}\right)$ using the following procedure. For most of the data the systematic errors are dominant, the statistical errors being small. Consequently it would be incorrect to obtain the best estimate of $F_{2}\left(x, Q^{2}\right)$ by taking a simple weighted average in each $\left(x, Q^{2}\right)$ bin. Instead, the procedure adopted averages the data assuming that it is distributed according to the student's $t$ distribution [45]. Here the fluctuations in the data were used to determine the statistical error. If only one data point was available in any given $\left(x, Q^{2}\right)$ bin its Poisson statistical error was increased by the average increase for the data sample as a whole. To produce these results individual measurements were excluded if the acceptance was less than $30 \%$ or the systematic error greater than $6 \%$ in order to avoid combining data with large variations in the systematic error. The final results are presented in Table 10 and Fig. 13. The systematic errors were obtained from the quadratic sum of the individual systematic errors (Table 5). The latter were obtained from a weighted average of the individual systematic errors at each of the four energies (Table 4).

The data from Fig. 13 and Table 10 are shown in Fig. 14 together with those from the SLAC-MIT electron proton scattering experiment [12] for $Q^{2}>2 \mathrm{GeV}^{2}$. Small shifts in $x$ have been made to the SLAC-MII data by interpolation in order to compare with the data presented here. They have also been renormalised by a factor of 0.925 . The latter shift which results from comparing individual $x$ bins of both data sets is well within the normalisation uncertainty of the two experiments. The two data samples show a smooth variation of $F_{2}$ as a function of $x$ and $Q^{2}$ and indicate agreement between the two experiments within the quoted normalisation uncertainties.

*These and all of the other data contained in this paper are available on the Durham-Rutherford Laboratory data base. 


\subsection{A Parameterisation of $\mathrm{F}_{2}\left(\mathrm{x}, \mathrm{Q}^{2}\right)$}

A convenient parameterisation of $F_{2}\left(x, Q^{2}\right)$ is:

$$
\mathrm{F}_{2}\left(\mathrm{X}, \mathrm{Q}^{2}\right)=\mathrm{F}_{2}^{\mathrm{SC}}\left(1+\mathrm{F}_{2}^{\mathrm{SCB}}\right)
$$

where

$$
F_{2}^{S C}=C_{1} x^{C_{2}}(1-x)^{C_{3}}+C_{4}(1-x)^{C_{5}}
$$

and

$$
F_{2}^{\mathrm{SCB}}=\left[\mathrm{C}_{6}(1-\mathrm{x})^{\mathrm{C}_{7}}+\mathrm{C}_{8}\right] \log \left(\frac{Q^{2}}{3}\right)
$$

This function was chosen to have two parts, the first being a function of $x$ only, i.e. a pure scaling function $\left(\mathrm{F}_{2} \mathrm{SC}\right.$ ) and the second allowing some $Q^{2}$ dependence of $\mathrm{F}_{2}$ at fixed $\mathrm{x}$, i.e. a scale breaking function $\left(\mathrm{F}_{2}^{\mathrm{SCB}}\right.$ ). This form was used as the iterative function in the extraction of $F_{2}$ as described in section 4.6 .

By fitting to the values of $F_{2}$ given in Table 10 the following values of the constants $C_{1}-C_{8}$ were obtained

$$
\begin{aligned}
& c_{1}=3.373, c_{2}=0.985, c_{3}=3.688, c_{4}=0.276, \\
& C_{5}=10.629, C_{6}=0.282, C_{7}=8.995, C_{8}=-0.078 .
\end{aligned}
$$

The total $x^{2}$ for this fit was 119 for 84 degrees of freedom (dof) giving a $x^{2} /$ dof of 1.42. The main contribution to the $x^{2}$ came from the low $x$ points and was largely due to to those data points to which only one energy contributed. For these points only the global increase of the error was made (section 6.5) as no contribution from additional fluctuations could be estimated.

\subsection{Scale Breaking in the Data}

The degree of scale breaking present in the data can be seen from a fit of of the form

$$
F_{2}\left(x, Q^{2}\right)=\frac{d F_{2}\left(x, Q^{2}\right)}{d\left(\ln Q^{2}\right)} \ln Q^{2}+C
$$


to each $x$ bin. Certain theories of deep inelastic scattering provide a basis for adopting this type of fit [46]. The values of the slope parameter, $b(x)=$ $\mathrm{dF}_{2}\left(x, Q^{2}\right) / \mathrm{d}$ In $Q^{2}$ as a function of $x$ are shown in Fig. 15(a). A clear pattern of scale breaking is seen with the slopes changing from positive at small $x$ to negative at large $x$ with approximate scaling in the region $0.1<x<0.2$. The errors shown are statistical (inner error bars) and total (outer error bars) where the total errors were determined by suming the statistical and systematic errors in quadrature.

\subsection{The Results for $d^{2} \sigma / d Q^{2} d x$}

Tables 1la-d give the values of the single photon exchange double differential cross-section $\mathrm{d}^{2} \sigma / \mathrm{dQ}^{2} \mathrm{dx}$ at each of the four beam energies. The results are quoted at the mean $x$ and $Q^{2}$ of each bin and for the mean beam energy of the events contributing to that bin.

In order to determine these, $F_{2}$ was recalculated for the mean $x, Q^{2}$ of each bin using the data of Table 10 and the function used in the final $F_{2}$ iteration. The differential cross-section was then determined using eqn. 2.2 assuming a value of $R\left(x, Q^{2}\right)=0$. 


\section{The Measurement of $R=\sigma_{L}{ }^{\prime \sigma} T$}

\subsection{Introduction}

The measurements of the proton structure function $R\left(x, Q^{2}\right)$ are presented in this section. The values were derived by comparing the measured cross-sections at the four incident muon energies.

\subsection{The Evaluation of $R\left(x, Q^{2}\right)$}

To determine $R$ from the experimental data the measured cross section was evaluated in bins of $Q^{2}$ and $v$ at each of the four beam energies. The values of $R$ were determined from linear fits to $1 / \Gamma\left(d^{2} \sigma / d Q^{2} d v\right)$, measured at a fixed $Q^{2}$ and $v$, as a function of $\varepsilon$ (see eqns. 2.8 to 2.11). Fig. 17 shows examples of such fits to the data for $v=90 \mathrm{GeV}$ and $Q^{2}=11.5,15.0$ and $27.0 \mathrm{GeV}$. The relative normalisation factors were applied to the data sets at the different beam energies as outlined in section 6.3 .

The region in $Q^{2}$ and $v$ over which $R$ has been measured in this experiment is shown in Fig. 16 together with the beam energies used at each point. A minimum of three energies were required at every point although for $v<100 \mathrm{GeV}$ it was possible to use all four energies at most points. To avoid large systematic effects, the measurement of $R$ was restricted to a kinematic region where the total systematic error on each point was < $5 \%$, excluding the uncertainty on the normalisation. In addition the final acceptance for each point after all cuts was required to be $>30 \%$ and, at least one of the energies in each $\left(Q^{2}, v\right)$ bin to have $y>0.5$, to select those bins sensitive to the value of $R$. 


\subsection{The Results for $R\left(x, Q^{2}\right)$}

The measured values of $R$ are given in Table 12. The total error was calculated by adding the statistical and total systematic error in quadrature. The systematic error was determined according to the procedure outlined in section 5.11, including the relative normalisation uncertainty of $3 \%$ in the calculation.

The data show little dependence of $R$ on $Q^{2}, v$ or $x$. To further investigate the variation as a function of $Q^{2}, v$ and $x, R$ has been re-evaluated integrating over each of the other variables. The results as a function of $Q^{2}, v$ and $x$ are given in Table 13 and are shown in Fig. 18. The smooth curves are the predictions of the QCD calculation described in section 8.4 .

Within the kinematic domain of this experiment there is no significant dependence of $R$ on $Q^{2}, v$ or $x$. The value of $R$ determined globally over the whole kinematic region was

$$
R=-0.010 \pm 0.037 \text { (stat) } \pm 0.102 \text { (syst) }
$$

This is consistent with the assumption, $R\left(x, Q^{2}\right)=0.0$, used to extract the values of $F_{2}\left(x, Q^{2}\right)$. 


\section{Comparison of $F_{2}\left(x, Q^{2}\right)$ and $R\left(x, Q^{2}\right)$ with the Predictions of $Q C D$}

\subsection{Introduction}

Considerable theoretical literature exists concerning the interpretation of deep inelastic lepton-proton scattering data [47). Since the early papers on this subject, comparing the measured scale breaking of $F_{2}\left(x, Q^{2}\right)$ with the predictions of QCD, considerable uncertainties regarding the treatment of the data have arisen. This is partly due to imprecise knowledge of the gluon distribution $G\left(x, Q^{2}\right)$ and the sea quark distribution in a free nucleon; and partly because of theoretical difficulties in calculating the exact scale breaking contribution to $F_{2}\left(x, Q^{2}\right)$ coming from the leading twist operator. QCD predicts a logarithmic variation of $F_{2}$ with $Q^{2}$ at a fixed $x$, as compared to that arising from higher twist terms which imply a $\left(1 / Q^{2}\right)^{n}$ dependence. In this section fits to the data are used to determine the QCD mass scale parameter and the higher twist contributions. The gluon distribution is estimated from combined singlet and non-singlet QCD fits and the total fraction of the momentum of the proton carried by the quarks is also estimated. More detailed discussions of the theoretical interpretations of these data can be found in $[24,25,26]$.

\subsection{The Determination of the QCD Mass Scale Parameter, $\Lambda$}

The theoretical uncertainties in the determination of $\Lambda$ are minimised by messuring the $Q^{2}$ evolution of a non-singlet structure function as this does not require knowledge of the gluon distribution. To perform such a fit to the proton structure function $F_{2}\left(x, Q^{2}\right)$, the analysis has to be limited to a kinematic domain in which $\mathrm{F}_{2}\left(x, Q^{2}\right)$ approximates well to a non-singlet structure function, $i . e$. one where only valence quarks contribute. Such an analysis for these data was performed for the region $0.35 \leq x \leq 0.75$. The advantages in using this region may be summarised as follows:

a) Measurements of the antiquark distribution $\vec{q}\left(x, Q^{2}\right)$ in neutrino scattering [48] show that for $x \geq 0.35, \bar{q}\left(x, Q^{2}\right)$ is close to zero. Related determinations of the gluon distribution $G\left(x, Q^{2}\right)$ indicate that this quantity is also sma11 in this region $[49]$. 
b) It has been shown [50] that for $x \rightarrow 1$, soft gluon emission can considerably change the $Q^{2}$ evolution of a structure function. Fron a phenomenological point of view the leading order calculation plus additional soft gluon effects is different from a complete second order calculation only for $x \geq 0.8$. This indicates that a large part of the soft gluon emission is absorbed in the second order correction, at least for the region $x \leq 0.8$. A recent analysis of the EMC data [51] also concluded that within the $x$ range chosen here, soft gluon effects beyond the second order are of minor importance. Thus their inclusion in a full next-to-leading order analysis has little effect on the value of $\Lambda \overline{M S}[52]$.

c) Scaling violations also arise from other sources, for example threshold effects, such as the production of particles containing heavy quarks. However at large $x$, the $Q^{2}$ region considered here lies well above the charm threshold and hence such threshold effects can be neglected. In addition charm production at large $x$ is small [53].

d) In section 8.5 an analysis of the data is presented in which both leading and 'higher twist' terms are considered. The latter are suppressed by additional powers of $Q^{2}$ of the form $\left(1 / Q^{2}\right)^{n}$, and should be unimportant for the values of $Q^{2}$ in this experiment.

In summary, the $x-Q^{2}$ domain selected for this analysis is well suited to a reliable determination of the mass scale parameter $\Lambda$, as $F_{2}\left(x, Q^{2}\right)$ within this kinematic region can be treated as a pure non-singlet structure function.

The analysis was based on fitting the $Q^{2}$ evolution of $E_{2}$ to the AltarelliParisi equations [54]. As the data were well above the charm threshold 4 flavours were used in the expressions for $\alpha_{s}\left(Q^{2}\right)$ and the QCD splitting functions. The fits were performed using the programme MINUIT [55], taking into account only the statistical errors. The quoted systematic error on $\Lambda$ corresponds to the sum in quadrature of the changes in $\log \Lambda$ caused by each systematic error given in Table 5 .

The method of Abbott et a1., [56] was used to solve the Altare11i-Parisi equations in next-to-leading order for a non-singlet structure function. $F_{2}$ was parameterised at $Q_{0}^{2}=5 \mathrm{GeV}^{2}$ as

$$
F_{2}\left(x, Q_{0}^{2}\right)=A x^{\alpha}(1-x)^{\beta}(1-\gamma x)
$$


and a simultaneous fit to $A, \alpha, \beta, Y$ and $\Lambda$ made to the data.

Results are given in Table 14 for fits both with and without the inclusion of conventional target mass corrections and also for a leading order non-singlet fit. The values of $\Lambda$ were not sensitive to the particular parameterisation of $F_{2}$ or to the choice of $Q_{0}^{2}$. Different techniques were used to verify the numerical correctness of the calculations [21]. The value of $\Lambda$ as determined by the next-toleading order non-singlet $f$ it is

$$
\Lambda_{\mathrm{MS}}=105_{-45}^{+55} \text { (stat) }{ }_{-45}^{+85} \text { (syst) } \mathrm{MeV} \text {. }
$$

This corresponds to a value of $\alpha_{s}$, the strong coupling constant, of

$$
\alpha_{s}=0.16 \pm 0.02 \text { (stat.) } \underset{-0.02}{+0.03} \text { (syst.) }
$$

at an average $Q^{2} \sim 22.5 \mathrm{GeV}^{2}$. The $\mathrm{fit}$ is shown superimposed on the data in Fig. 19.

\subsection{Estimation of the Gluon Distribution of the Proton}

After fitting the high $x$ data to determine $\Lambda$, the data for the whole $x$ range were used to obtain an estimate of the shape of the gluon distribution. As both $\Lambda$ and the gluon distribution are strongly correlated they cannot be determined independent1y.

The fit was made in a similar manner to that described in section 8.2 , solving the Altarelli-Parisi evolution equations in leading order. The gluon distribution of the nucleon was taken to have the functional form

$$
x G\left(x, Q_{0}^{2}\right)=D(1-x)^{n}
$$

$F_{2}\left(x, Q^{2}\right)$ can be expressed in terms of singlet and non-singlet parts via [47]:

$$
F_{2}\left(x, Q^{2}\right)=\frac{5}{18} F_{2}^{S}\left(x, Q^{2}\right)+\frac{1}{6} F_{2}^{N S}\left(x, Q^{2}\right) . \quad 8.3 .2
$$

The singlet term can be parameterised in the form

$$
F_{2}^{S}\left(x, Q_{0}^{2}\right)=A x^{\alpha}(1-x)^{\beta}+B(1-x)^{\gamma} \text {. }
$$


and the non-singlet term in the form given in eqn. 8.2.1. The non-singlet parameters were taken from an independent non-singlet fit to the difference between the proton and neutron structure functions taken from reference [57]. A fit to the data was performed to determine the singlet $F_{2}$ and gluon distribution parameters, taking $\Lambda_{L O}$ to have the value determined in the previous section. The points which were most sensitive to the complications associated with the charm threshold at sma11 $x$ [21] were not included in the fit. Only the lowest $Q^{2}$ points for $x \leq 0.05$ were used to constrain the low $x$ behaviour of $x G(x)$ and $F_{2}^{S}(x)$ and to allow the imposition of the momentum sum rule. For $R\left(x, Q^{2}\right)$ the leading order $Q C D$ prediction was used [58] $i . e$. one which is non-zero at small $x$ and small $Q^{2}$.

The results are given in Table 15 for $\Lambda_{L O}=90 \mathrm{MeV}$ and for the maximum and minimum values allowed by the errors in the fit to the high $x$ data (Table 14). The best fit to the gluon distribution (eqn. 8.3.1) gave $n=6.7 \pm 1.5$ (stat.) \pm 1.7 (syst.) with $D=3.8$ from the energy-momentum sum rule, at $Q_{0}^{2}=5 \mathrm{Gev}^{2}$. The power $n$ was found not to change significantly if $\Lambda_{\text {LO }}$ was varied between the above limits. The fit was also insensitive to the addition of multiplicative terms of the form $(1+C x)$ as suggested by the parameterisation of reference [49]. The rather large values of $x^{2}$ are due to dominance of systematic errors at small $x$ as discussed earlier. The solid curve in Fig. 15(b) is the QCD prediction for the slopes $b(x)$ using the parameters taken from this fit. Here the data slopes were evaluated from the values of $F_{2}\left(x, Q^{2}\right)$ obtained using $R=R_{Q C D}$ rather "than $R=0.0$ which was used in Fig. $15(a)$. The comparison of Figs. $15(a)$ and (b) shows that such a change in $R$ results in an increase of up to $\sim 8 \%$ in the scale breaking in the region of $x \leq 0.1$. The agreement between the solid curve in Fig. 15 (b) and the data demonstrates that the data can be well described by a leading order QCD $Q^{2}$ evolution over the full $\times$ range of the measurements.

\subsection{Comparison of the Measurements of $R\left(x, Q^{2}\right)$ with $Q C D$}

$R\left(x, Q^{2}\right)$ can be calculated using leading order $Q C D[58,59]$ once the values of $\Lambda$ and the gluon distribution are known. The values calculated in this way are shown as the smooth curves in Fig. 18 taking $\Lambda_{\text {LO }}$ to be $90 \mathrm{MeV}$ and the gluon distribution to be that derived above. The calculations were rather insensitive to the assumptions about the shape of the latter within the region in which we have measured $R$. They suggest a weak kinematical dependence but are, nevertheless, compatible with the data. 


\subsection{The Energy-Momentum Sum Rule}

The integral of $F_{2}$ over the $x$ range from 0 to $1, I\left(Q^{2}\right)$ can be expressed in terms of the incoherent sum of the squared charge weighted distribution functions of the quarks inside the nucleon. Thus $I\left(Q^{2}\right)$ is related to the fraction of the momentum of the proton carried by its constituent quarks, i.e.

$$
I\left(Q^{2}\right)=\int_{0}^{2} F_{2}\left(x, Q^{2}\right) \mathrm{dx}=\int_{0}^{1} \sum_{i} e_{i}^{2} x g_{i}\left(x, Q^{2}\right) d x
$$

where $e_{i}$ is the charge of the $i^{\text {th }}$ quark and $q_{i}\left(x, Q^{2}\right)$ is its density distribution function inside the proton.

In the past the study of the $Q^{2}$-dependence of this integral has proved to be difficult due to the limited $x$-range covered by the data at any given value of $Q^{2}$. However by combining the EMC and SLAC-MIT data it is possible to evaluate $I\left(Q^{2}\right)$ over the $Q^{2}$ region $3 \leqq Q^{2} \leqq 100 \mathrm{GeV}^{2}$ with only small systematic uncertainties. The results are shown in Fig. 20 expressed in terms of both Cornwa1l-Norton [60] and Nachtmann [17] moment integrals. The errors shown are statistical only and the systematic uncertainty is approximately $6 \%$ and $Q^{2}$ independent.

The integrals were evaluated by numerical integration over the $x$ range of the data at each $Q^{2}$ with the use of functions to extrapolate into the unmeasured regions $x \rightarrow 0$ and $x \rightarrow 1$. For all of the points shown the measured fraction of the integral is $>50 \%$ and it is typically $\gtrsim 75 \%$. The functions used were determined from fits to the EMC and SLAC-MIT data using extended versions of eqn. 6.6.1. The systematic uncertainty coming from this source was evaluated by using a variety of functional forms and allowing the fit parameters in each to vary within their errors. For the measured region the systematic errors were taken from the integrals directly. The additional contribution to each integral coming from the elastic peak was also included by integrating over a modified dipole fit to the existing data on $G_{E}\left(Q^{2}\right)$ and $G_{M}\left(Q^{2}\right)$ [43]. The systematic uncertainty from this source was evaluated as in the case of the extrapolation functions.

In both cases the integrals show a slow decrease with increasing $Q^{2}$, as predicted by QCD [20], corresponding to a gradual decrease in the fraction of the nucleon's momentum carried by the constituent quarks. The curves in Fig. 20 were derived by fitting the leading order singlet and non-singlet QCD moment evolution 
equations of reference [20] to the data. $\Lambda_{\text {LO }}$ was fixed at $90 \mathrm{MeV}$ in accordance with the result obtained in section 8.2. The Cornwal1-Norton integrals do not take account of the $Q^{2}$-dependence coming from finite target mass effects and so they diverge from the Nachtmann values for $Q^{2} \leq 20 \mathrm{GeV}^{2}$. For these integrals the fit was made using only the higher $Q^{2}$ points and is shown as the dashed curve when extrapolated to lower values of $Q^{2}$. The agreement with the data is good especially for the case of the Nachtmann moments.

In the naive quark-parton model for the proton, $I=1 / 3$ and is independent of $Q^{2}$. In $Q C D$, in the large $Q^{2}$ limit, it is given by

$$
\sum_{Q^{2} \rightarrow \infty}=\sum_{i} \frac{e_{i}^{2}}{(3 f+2 g)}
$$

where the sum runs over $f$ flavours and 3 colours and $g=8$ is the number of gauge gluons [61]. Thus for 4 flavours this gives a limit of 0.119 . The data for both sets of integrals 1 ie between this QCD limit and the naive parton model value. Taking an average value of $\sim 0.145$ from the Nachtmann integrals discussed above, implies that $\sim 44 \%$ of the energy-momentum of the proton is carried by its charged constituents leaving a residual gluon momentum fraction $\sim 56 \%$ at a mean $Q^{2} \sim 22.5 \mathrm{GeV}^{2}$.

\subsection{The Separation of Higher Twist Effects}

There is now general agreement within the theoretical literature [62] concerning the contribution of 'higher twist', that the structure function $F_{2}\left(x, Q^{2}\right)$ can be written as

$$
F_{2}\left(x, Q^{2}\right)=F^{(2)}\left(x, 1 n \frac{Q^{2}}{\Lambda^{2}}\right)+F^{(4)}\left(x, 1 n^{Q^{2}}\right) \frac{1}{\Lambda^{2}} Q^{2}+F^{(6)}\left(x, \ln \frac{Q^{2}}{\Lambda^{2}}\right) \frac{1}{Q^{4}}+\cdots \quad 8.6 .1
$$

where the $Q^{2}$ dependence of the different terms $F^{(2)}, F^{(4)}, F^{(6)}$, is governed by different evolution equations. To disentangle the logarithmic and power law contributions to the observed scaling violations coming from the leading twist term $F^{(2)}$ and the higher twist terms $F^{(4)}, F^{(6)}$, precise experimental data over a large range of $Q^{2}$ are reguired. Furthermore, despite the statistical 
power of the available data, theoretical guidance on the forms of the different non-perturbative higher twist terms is required in order to determine their relative contributions to $F_{2}\left(x, Q^{2}\right)$.

To extend the $Q^{2}$ range, SLAC-MIT electron-proton scattering data [12] were used together with the results for $F_{2}$ given in Table 10 . These data were shifted to the same $x$ bins as the EMC data, the $Q^{2}$ binning remaining unchanged.

To determine the magnitude of twist 4 contributions, $F_{2}\left(x, Q^{2}\right)$ can be written as

or

$$
F_{2}\left(x, Q^{2}\right)=F_{2}^{L T}\left(x, Q^{2}\right)\left(1+\frac{H_{4}(x)}{Q^{2}}\right)
$$

$$
F_{2}\left(x, Q^{2}\right)=F_{2}^{L T}\left(x, Q^{2}\right)+\frac{H_{4}^{\prime}(x)}{Q^{2}} .
$$

$F_{2}^{L T}\left(x, Q^{2}\right)$, as parameterised in eqn. 8.2.1, is considered to be a non-singlet structure function whose evolution is calculable by perturbative QCD. A $f$ it was made in which the values of $\mathrm{H}_{4}(x)$ (or $\mathrm{H}_{4}^{\prime}(x)$ ) in each $x$ bin were free parameters. There are thus 12 free parameters to be fitted: the six values of $\mathrm{H}_{4}(x)$ or $\mathrm{H}_{4}^{\prime}(x)$ for the $x$ bins from $0.35 \leq x \leq 0.80$, the four parameters describing $F_{2}^{L T}\left(x, Q^{2}\right)$ at $Q_{0}^{2}$ (eqn. 8.2.1), $\Lambda$ and the relative normalisation between the two data sets. $\Lambda$ was left free to take account of possible correlations between the values of $\Lambda$ and $\mathrm{H}_{4}(x)$ or $\mathrm{H}_{4}^{\prime}(x)$. On1y data for $Q^{2}>2 \mathrm{GeV}^{2}$ were used.

The results of the fits for the determination of the values of $\mathrm{H}_{4}(x), \mathrm{H}_{4}^{\prime}(x)$ and $\overline{\mathrm{MS}}$ are given in Table 16, where the quoted errors are statistical only. Results are given both with and without the inclusion of target mass corrections in $E_{2}^{L T}$. Although these corrections can be regarded as a component of the higher twist terms, it has been argued [63] that they should be included into the leading twist analysis in order to determine the 'genuine' higher twist contributions. The relative normalisation determined from the fit results in the SLAC-MIT data being multiplied by a factor of 0.925 consistent with that found in section 6.5 . The values of $\Lambda_{\text {MS }}$ are similar to those determined in section 8.2 using the EMC data alone. The results for $H_{4}(x)$ and $H_{4}^{\prime}(x)$ are shown in Fig. 21. Qualitatively $H_{4}(x)$ is found to be approximately zero for $x \leq 0.4$ and rises sharply for $x>0.5$. $H_{4}^{\prime}(x)$ shows a similar behaviour for $x \leq 0.65$ at which it reaches a maximum value 
before decreasing again going to larger values of $x$. Similar results are obtained for $\mathrm{H}_{4}(x)$ and $\mathrm{H}_{4}(x)$ if target mass corrections are included in the calculation of $\mathrm{F}_{2}^{\mathrm{LT}}$.

Instead of determining the values of $\mathrm{H}_{4}(x)$ for a limited number of $x$ bins, the data can be fitted directly by assuming a functional form for $H_{4}(x)$. Recent theoretical predictions [64] prefer an enhancement of the twist 4 relative to the leading twist by a factor of $1 /(1-x)$ as $x \rightarrow 1$ and $F_{2}\left(x, Q^{2}\right)$ is, therefore, parameterised as

$$
F_{2}\left(x, Q^{2}\right)=F_{2}{ }^{L T}\left(x, Q^{2}\right)\left(1+\frac{\mu_{4}{ }^{2} x^{\alpha}}{(1-x) Q^{2}}\right)
$$

allowing a factor of $x^{\alpha}$ ( $\alpha$ free) for the suppression of the twist 4 contribution within the $x$ range of the data. The SLAC-MIT dats [12] were again combined with the EMC data on $F_{2}\left(x, Q^{2}\right)$. The fit was performed to the region $x \geq 0.33$ and $Q^{2}>2 \mathrm{GeV}^{2}$ with $\overline{M S}$ and the relative normalisation between the EMC and SLAC-MIT data as free parameters.

The results of the fit are given in Table 17 . The relative normalisation factor between the two data sets was again found to be 0.925 and the value of $\Lambda$ MS close to that determined in section 8.2 for the pure next to leading order, nonsinglet, fit to the EMC data alone. Fig. 22 shows this fit compared to the data (solid curve) together with the next to leading order fit to the EMC data alone at high $Q^{2}$ (dashed curve).

The results of a pure next to leading order non-singlet fit to the SLAC-MIT and EMC data are also given in Table 17. It can be seen that an acceptable fit is only obtained when reasonable $1 / Q^{2}$ higher twist contributions are included. Furthermore, such a combined leading and higher twist fit gives a similar value of $\Lambda_{M S}$ to that obtained in the pure next to leading order non-singlet fit to the EMC data alone (section 8.2). This shows that there is 1ittle uncertainty due to higher twist contributions in such fits for the $x$ and $Q^{2}$ range of the EMC data within the quoted errors. 


\section{Conclusions}

Results have been presented for the measurement of the proton structure functions $F_{2}\left(x, Q^{2}\right)$ and $R\left(x, Q^{2}\right)$ in deep inelastic muon-proton scattering.

The ratio of the longitudinal to transverse virtual photon absorption cross sections, $R=\sigma_{L} / \sigma_{T}$, is found to be small within the kinematic range of the data presented with a global average value of $R=-0.010 \pm 0.037$ (stat) \pm 0.102 (syst). No significant variation with $Q^{2}, \nu$ or $x$ was observed.

The proton structure function, $F_{2}\left(x, Q^{2}\right)$, measured in the region $0.02 \leq x \leq 0.80$ and $3 \leq Q^{2} \leq 190 \mathrm{GeV}^{2}$, exhibits a clear pattern of scale breaking. Perturbative QCD gives a good description of the data. A next-to-leading order non-singlet QCD fit to the $F_{2}\left(x, Q^{2}\right)$ data for $x \geq 0.35$ results in a value for the scale parameter of QCD,

$$
\Lambda \overline{\mathrm{MS}}=10 \mathrm{~S}_{-45}^{+55} \text { (stat) } \stackrel{+85}{+45} \text { (syst) } \mathrm{MeV} \text {. }
$$

Furthermore, the fraction of the momentum of the nucleon carried by gluons is $\sim 56 \%$ at $Q^{2} \sim 22.5 \mathrm{GeV}^{2}$. The gluon density distribution was determined to be

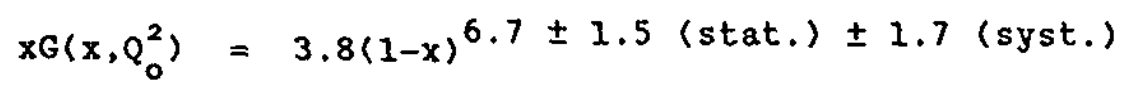

at $Q_{0}^{2}=5 \mathrm{GeV}^{2}$.

A consistent description of the data on $F_{2}\left(x, Q^{2}\right)$ presented in this paper, together with that measured for electron-proton scattering from SLAC-MIT [12] at lower $Q^{2}$, can only be achieved if additional $1 / Q^{2}$, or higher twist, contributions to $F_{2}\left(x, Q^{2}\right)$ are included. The $x$ dependence of the higher twist contribution can be parameterised as $x^{3} /(1-x)$. The value of $\Lambda$ MS remains unchanged from that determined with the EMC data alone showing that in the kinematic range of this experiment the effects of higher twist are small. 


\section{Acknowledgements}

We wish to thank all those people in our home institutions who have contributed to the construction and maintenance of the apparatus. In particular we thank D. Botterill, Y. Camp, B. Charles, G. Falley, G.von Holtey, G. Juban, A. Love11, A. Mazzari, M. Sproston, M.D. Rousseau, E. Watson, and V. White who did so much to make this experiment possible. In addition we thank the CERN directorate for its support, the SPS division for the provision of an excellent source of muons and the CERN DD division for its support and help. Finally we thank E. Cumiskey for typing this manuscript. 
Appendix 1 - Radiative Corrections

To determine $F_{2}\left(x, Q^{2}\right)$ and $R\left(x, Q^{2}\right)$ from the data, the cross-section due to single photon exchange, $\sigma I$, has to be extracted from the measured crosssection, $\sigma^{O B S}$, which contains additional electromagnetic contributions. In a given bin of $x$ and $Q^{2}, \sigma^{O B S}$ can be written as

$$
\sigma^{\mathrm{OBS}}=\sigma^{\mathrm{DI}}+\sigma^{\mathrm{IR}}+\sigma^{\mathrm{ER}}
$$

$\sigma^{I R}$, the inelastic radiative tail, is due to inelastic events where the incoming or outgoing muon has radiated a real photon and the real muon-prọton scattering kinematics are different from the apparent kinematics. This contribution to $\sigma$ OBS depends directly on the structure functions $F_{2}$ and $R$. $\sigma$, the elastic radiative tail, arises from elastic events which appear in the inelastic region of the $Q^{2}, v$ plane as a result of the radiation of real photons.

The diagrams contributing to $\left(\sigma^{I R}+\sigma^{E R}\right)$ in lowest order of the electromagnetic coupling constant are shown in Fig. 7. Of these only the diagrams for internal bremsstrahlung ( $F i g .7 a, b$ ) have a significant effect on the lepton current, and hence on the measured single arm kinematics. The vertex correction (Fig. 7c) and vacuum polarisation correction (Fig. 7d) are also included, as although they do not directly modify the single arm kinematics they do interfere with the leading order process (Fig. 1) and so modify $\sigma^{\mathrm{OBS}}$.

The contribution from two photon exchange (Fig. 7e) can be determined experimentally as the two photon exchange amplitude leads to a difference for the scattering of positively and negatively charged leptons. This arises from an interference between the single photon and two photon exchange amplitudes. Results on the measurement of the ratio $\mu^{+} / \mu^{-}\left(\mathrm{e}^{+} / \mathrm{e}^{-}\right)$\{38\} up to $\mathrm{Q}^{2} \sim 60 \mathrm{GeV}$ show that over this $Q^{2}$ range any deviation from unity is small and less than $3 \%$. The contribution from two photon exchange is, therefore, neglected. The contributions from the hadron lines (Fig. $7 f, g$ ) are also neglected since in the parton model they have been estimated to be very small [39]. 
In addition to the corrections shown in Fig. 7, which arise from photon radiation within the field of the proton with which the muon interacts, there is in principle also a correction due to photon radiation within the field of the other protons in the target material. This external bremsstrahlung or 'straggling'. correction is significant in electron scattering [41]. However for muon scattering it is negligible due to the larger mass of the muon, and was not considered in this analysis except as a standard energy loss correction to the incident and scattered muons in the target.

The elastic and inelastic radiative tail contributions to $\sigma$. W evaluated using the formulae of Tsai rather than the peaking approximation [37]. In addition the corrections corresponding to the second order diagrams of Fig. 8 were evaluated for inelastic scattering.

The inelastic tail determination used the iterative procedure of Mo and Tsai [42] in which $R\left(x, Q^{2}\right)=0.0$ and $F_{2}^{O L D}\left(x, Q^{2}\right)$ of Eqn. 4.6 .2 were used to parameterise the deep inelastic cross section. For the calculation of the elastic tail a modified dipole fit to the existing data [43] was used to parameterise the proton form factors, $G_{E}\left(Q^{2}\right)$ and $G_{M}\left(Q^{2}\right)$. The calculations were performed using the equations of reference [41]. 


\section{Appendix 2 - Combining the $\mathrm{F}_{2}\left(\mathrm{x}, \mathrm{Q}^{2}\right)$ Results}

For any particular data set, $F_{2}$ for a given bin in $x$ and $Q^{2}$ was evaluated using Eqn. 4.6.2. If the number of Monte Carlo events accepted after all cuts,

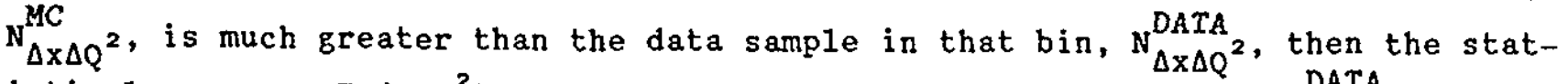
istical error on $F_{2}\left(x, Q^{2}\right)$ can be considered to come entirely from $N_{\triangle X \Delta Q^{2}}$.

If $F_{i}$ represents the measurement of $F_{2}\left(x, Q^{2}\right)$ and $n_{i}$ the number of events in the data sample in a given bin of the $i^{\text {th }}$ data set, then eqn. 4.6 .2 can be rewritten as

$$
F_{i}=a_{i} n_{i}
$$

where $a_{i}$ is a multiplicative factor which by comparison with eqn, 4.6 .2 is defined as

$$
a_{i}=\frac{F_{2}^{O L D}\left(x, Q^{2}\right)}{N_{\Delta x \Delta Q^{2}}^{M C}} .
$$

The error on $F_{i}$ is considered to be purely statisitical and due to poisson fluctuations in $n_{i}$, so that the error, $\sigma_{i}$, on $F_{i}$ can be defined as

$$
\sigma_{i}=a_{i} \vee n_{i}
$$

and hence $n_{i}=\frac{F_{i}{ }^{2}}{\sigma_{i}{ }^{2}}$

and

$$
a_{i}=\frac{\sigma_{i}^{2}}{F_{i}}
$$

Before combining these results from the different data sets $\sigma_{i}{ }^{2}$ is the best estimate of the variance of $F_{i}$. After combining the datasets, a better estimate, $s_{i}{ }^{2}$, is available where

$$
s_{i}{ }^{2}=a_{i}{ }^{2} N_{i}
$$

and

$$
\mathrm{N}_{i}=\frac{\mathrm{f}}{\mathrm{a}_{\mathrm{i}}}
$$


The quanitity $f$ is the combined value and $N_{i}$ is now the best estimate of the expected numbers of events for the $i^{\text {th }}$ dataset. Assuming that the values of $N_{i}$ are known, the best estimate of $f$ is then

$$
f=\frac{\sum F_{i} N_{i}}{\sum N_{i}}
$$

It should be noted that by using the $N_{i}$ instead of $n_{i}$ as the weight any incorrect bias towards downwards fluctuations is avoided.

From $A 2.1$ and $A 2.7$

$$
\frac{f}{F_{i}}=\frac{N_{i}}{n_{i}}
$$

and hence, using A2.4

$$
N_{i}=\frac{n_{i} f}{F_{i}}=\frac{f F_{i}}{\sigma_{i}^{2}}
$$

By substitution into $A 2.8$ for $N_{i}$ from $A 2.10$, an equation is found for $f$ in terms of $F_{i}$ and $\sigma_{i}$, respectively the values of $F_{2}\left(x, Q^{2}\right)$ from each dataset and their statistical errors.

$$
f=F_{2}\left(x, Q^{2}\right)=\frac{\sum_{i} F_{i}^{2} / \sigma_{i}^{2}}{\sum_{i} F_{i} / \sigma_{i}^{2}}
$$

To determine the error on $f$, we can rewrite $A 2.8$ using $A 2.7$ as

$$
f=\frac{\sum_{i} n_{i}}{\sum_{i} a_{i}^{-1}}
$$

It follows that the best estimate of the variance, $\sigma$, of $f$ is given by

$$
\sigma^{2}=\frac{\sum_{i} n_{i}}{\left(\sum_{i} a_{i}^{-1}\right)^{2}}=\frac{\left.\sum_{i} \frac{F_{i}^{2}}{\sigma_{i}}\right)}{\sum_{i}^{\left(\frac{F}{i}\right)}}
$$

The square root of $\sigma^{2}$ is the best estimate of the error on $F_{2}$. 
The best estimate of the $x^{2}$ for the combination is

$$
x^{2}=\sum \frac{\left(F_{i}-f\right)^{2}}{s_{i}{ }^{2}}=\sum \frac{\left(F_{i}-f\right)^{2}}{a_{i}{ }^{2} N_{i}}
$$

which can be rewritten using $A 2.5$ and $A 2.10$ as

$$
x^{2}=\sum \frac{F_{i}\left(F_{i}-f\right)^{2}}{\sigma_{i}^{2} f}
$$




\section{References}

[1] S.L. Wu, Phys. Rep. 107 (1984) 60.

[2] F.E. Close, An Introduction to Quarks and Partons, (Academic Press, 1979).

[3] S.D. Dre11 and J.D. Walecka, Ann. Phys. 28 (1964) 18.

[4] L.N. Hand, Phys. Rev. 129 (1963) 1834.

[5] R.E. Taylor, Proc. of the 4th Int. Symp. on Electron and Photon Interactions at High Energies, Liverpool (1969), eds. D.W. Braben and R.E. Rand.

W. Albrecht et a1., DESY 69/46, (1969).

[6] E.D. Bloom et a1., Phys, Rev. Lett. 23 (1969) 930.

M. Breidenbach et al., Phys, Rev. Lett. 23 (1969) 935.

[7] G. Miller et a1., Phys. Rev. D5 (1972) 528.

[8] J.D. Bjorken, Phys, Rev. 179 (1969) 1547.

[9] R.P. Feynman, Phys. Rev. Lett. 23 (1969) 1415;

R.P. Feynman, Photon-Hadron Interactions (Benjamin, Reading, MA, 1972).

[10] J.D. Bjorken and E.A. Paschos, Phys, Rev. 185 (1969) 1975.

[11] S. Stein et a1., Phys. Rev. D12 (1975) 1884.

W.B. Atwood et al., Phys. Lett. 64B (1976) 479.

M.D. Mestayer et al., Phys. Rev D27 (1983) 285.

[12] A. Bodek et a1., Phys. Rev. D20 (1979) 1471.

[13] D.J. Fox et a1., Phys. Rev. Lett. 33 (1974) 1504.

[14] Y. Watanabe et a1., Phys. Rev. Lett. 35 (1975) 898.

C. Chang et al., Phys. Rev. Lett. 35 (1975) 901. 
[15] B.A. Gordon et 21., Phys. Rev. D20 (1979) 2645.

[16] M.S. Chanowitz and S.D. Dre11, Phys. Rev. D9 (1974) 2078.

G.B. West and P. Zerwas, Phys. Rev. D10 (1974) 2130.

[17] O. Nachtmann, Nuc1. Phys. B63 (1973) 237.

H. Georgi and H.D. Politzer, Phys. Rev. D14 (1976) 1829.

R. Barbieri et a1., Nuc1. Phys. B117 (1976) 50.

[18] G. Parisi, Phys, Lett. 43B (1973) 207.

[19] H. Georgi and H.D. Politzer, Phys. Rev, D9 (1974) 416.

D.J. Gross and F. Wilczek, Phys. Rev. D9 (1974) 980.

[20] A.H, Mueller, Phys. Rep. 73, (1981), 195.

A.J. Buras, Rev. Mod. Phys. 52 (1980) 199.

[21] EMC, J.J. Aubert et a1., Phys. Lett. 105B (1981) 315.

[22] EMC, J.J. Aubert et a1., Phys. Lett. 214B (1982) 291.

[23] EMC; J.J. Aubert et a1., Phys. Lett 121B (1983) 87.

[24] S.J. Wimpenny, Ph.D. Thesis, University of Sheffield. RL PUB HEP/T/90 (1981).

[25] M. Leenen, Habilitation Thesis, University of Bonn, Bonn-IR-83-45 (1983).

[26] U. Pietrzyk, Dissertation, University of Wupperta1, WUB-DI 84-1 (1984).

[27] U. Landgraf, Dissertation, University of Freiburg, (1984).

[28] R. C1ifft and N. Doble, CERN/SPSC/74-12, (2974), unpublished.

[29] EMC, 0.C. A11kofer et a1., Nuc1. Instr. and Meth. 179 (1981) 445.

[30] D. Brahy and E. Rossa, Nuc1. Instr. and Meth. 158 (1979) 121. 
[31] J.J. Aubert et a1., Nuc1. Instr, and Meth. 159 (1979) 47.

[32] R. Mount et a1., Nuc1. Instr, and Meth. 160 (1979) 23.

[33] W. Flauger, Nuc1. Instr, and Meth. I65 (1979) 113.

[34] R.P. Mount, Nuc1, Instr, and Meth. 187 (1981) 401.

[35] H. Wind, Nuc1. Inst, and Meth. IIS (1974) 431.

[36] L. Page, Introduction to Theoretical Physics. (D. Van Nostrand Co., New York, 1935).

[37] Y.S. Tsai, SLAC-PUB -848 (1971).

[38] L.S. Rochester et a1., Phys. Rev. Lett. 36 (1976) 1284.

D.L. Fancher et al., Phys. Rev. Lett. 37 (1976) 1323.

S. Hartwig et al., Phys. Lett. 82B (1979) 297.

S. Hartwig et a1., Lett. Nuov. Cim. 12 (1975) 30.

H. Jöstlein et al., Phys. Lett. 52B (1974) 485.

K.W. Chen. Proc. 1975 EPS Int. Conf, on High Energy Physics, Palermo (1975), ed, A. Zichichi, p. 458.

[39] D. Yu. Bardin, N.M. Shumeiko, Sov. J. Nuc1. Phys. 29 (1979) 499.

[40] J. Drees, Wupperta1 University Report, Wu B 78-16 (1978).

[41] G. Miller, Ph.D. Thesis, SLAC-REPORT No. 129 (1971).

A. Bodek, Ph.D. Thesis, MIT LNS Report No. C00-3069-116 (1972).

[42] L.W. Mo and Y.S. Tsai, Rev.Mod. Phys. 41 (1969) 205.

[43] P.N. Kirk et al., Phys. Rev. D8 (1973) 63.

W.B. Atwood, Ph.D. Thesis, SLAC-REPORT No. 185 (1975).

M.D. Mestayer, Ph.D. Thesis, SLAC-REPORT No. 214 (1978).

[44] EMC, J.J. Aubert et a1., Z. Phys. C22 (1984) 341.

J.J. Aubert et a1., Z. Phys. C10 (1981) 101. 
[45] S. Brandt, Statistical and Computational Methods in Data Analysis, (North Holland Publishing Company, 1978).

[46] W.K. Tung, Phys. Rev. Dl2, (1975) 3613.

I. Hincheliffe and C.H. Llewellyn-Smith, Nuc1. Phys. B128 (1977) 93.

[47] G. Altare11i, Phys. Rep. 81 (1982), 1.

E. Reya, Phys. Rep. 69 (1981), 195.

A. Peterman, Phys. Rep 53 (1979), 158.

F.E. Close, Rep. Prog. Phys. 42 (1979), 1285.

[48] CDHS, H. Abramowicz et al., Z, Phys. Cl7 (1983) 283.

CHARM, F. Bergsma et al., Phys. Lett. 123B (1983) 269.

[49] CDHS, H. Abramowicz et al., Z. Phys. C12 (1982) 289.

CHARM, F. Bergsma et a1., Phys. Lett. 123B (1983) 269.

EMC, J.J. Aubert et a1., Nuc1. Phys. B213 (1983) 1.

[50] D. Amati et a1., Nuc1. Phys. B 173 (1980) 429.

G. Curci and M. Greco, Phys. Lett. 92B (1980) 175 .

[51] M. R. Pennington et al., Phys. Lett. 120B (1983) 204.

[52] E.G. Floratos, D.A. Ross and C.T. Sachrajda, Nuc1. Phys. B152 (1979) 493.

W.A. Bardeen, A.J. Buras, D.W. Duke and T. Muta, Phys. Rev. D18 (1978) 3998.

[53] EMC, J.J. Aubert et al., Nuc1. Phys B213 (1983) 31.

J.J. Aubert et al., Phys. Lett 110B (1982) 73.

[54] G. Altare11i and G. Parisi, Nuc1. Phys. BI26 (1977) 298.

[55] F. James and M. Roos, Comput. Phys. Commun. 10 (1975) 343.

[56] L.F. Abbott et a1., Phys. Rev. D22 (1980) 582.

[57] EMC, J.J. Aubert et a1., in preparation. 
[58] G. Altare11i and G. Martinelli, Phys. Lett. 76B (1978) 89.

[59] M. Gluck and E. Reya, Nuc1. Phys. B145 (1978) 24.

[60] J.M. Cornwa11 and R.E. Norton, Phys, Rev. 177, (1969) 2584.

[61] H.D. Politzer, Phys. Rep. 14C (1974) 129.

[62] J.L. Cortés and J. Sanchez-Guillén, Phys. Lett. 120B (1983) 396. R.X. E11is et a1., Nuc1. Phys. B212 (1983) 29.

S. Gottlieb, Nucl. Phys. B139 (1978) 125.

J. Gunion et al, Phys, Lett. 117B (1982) 353.

R.L. Jaffe and M. Soldate, Phys. Rev. D26 (1982) 49.

R.L. Jaffe, Nuc1. Phys. B229 (1983) 205.

S.P. Luttre11 and S. Wada, Nuc1. Phys. B197 (1982) 290.

M. Moshe, Phys. Lett. 988 (1981) 297.

M. Okawa, Nuc1. Phys. B187 (1981) 71.

E.V. Shuryak and A.I. Vainshtein, Nuc1. Phys. B201 (1982) 141.

S. Wada, Nuc1. Phys. B202 (1982) 201

[63] J. Drees, Proc. of the 1981 Int. Symp. on Lepton and Photon Interactions at High Energies, Bonn (1981), ed. W. Pfiel. (Remark from R. Jaffe).

A. de Rujula et al., Ann. Phys. 103 (1977) 311.

A. de Rujula et a1., Phys. Rev D15 (1977) 243.

[64] M. Soldate, Nuc1. Phys. B223 (1983) 61. J.F. Gunion et a1., Phys. Rev. D29 (1984) 2491. 


\section{List of Tables}

1) Definition of Kinematic Variables.

2) The Muon Track and Vertex Resolution Functions for the EMC spectrometer.

3) Typical Values for the Kinematic Cuts Applied to the Data.

4) Values of the Individual Systematic Errors on $F_{2}(\%)$, (a) $120 \mathrm{GeV}$, (b) $200 \mathrm{GeV}$, (c) $240, \mathrm{GeV}$ (d) $280 \mathrm{GeV}$. Columns 1 to 8 correspond to the errors arising from:

1. - the final acceptance after all cuts,

2. - the radiative corrections,

3. - the correction for the smearing of events from one bin to another,

4. - the correction for the loss of events due to detector inefficiencies,

5. - the correction introduced to determine $F_{2}$ at the bin centre,

6. - the measurement of the incoming beam energy,

7. - the measurement of the outgoing scattered muon energy,

8. - the measurement of the muon scattering angle.

5) Values of the Individual Systematic Errors on $F_{2}(\%)$ for the combined dataset. Columns 1 to 8 correspond to the same sources of error as in Table 4.

6) Requirements for an $\left(x, Q^{2}\right)$ bin to be accepted into the Final Data Sample.

7) Summary of Hydrogen Data Entering the Final $\mathrm{F}_{2}$ Sample.

8) The Relative Normalisation between the datasets at each energy.

9) Values of the Proton Structure Function $F_{2}$ extracted assuming that $R\left(x, Q^{2}\right)=0.0$ at incident muon energies of, (a) $120 \mathrm{Gev}$, (b) $200 \mathrm{GeV}$, (c) $240 \mathrm{GeV}$, (d) $280 \mathrm{GeV}$.

10) Values of the Proton Structure Function $F_{2}$ derived by combining the results from the four nominal beam energies. 
11) Values of the Radiatively Corrected Double Differential Cross-Section $\mathrm{d}^{2} \sigma / \mathrm{dQ}^{2} \mathrm{dx}$ for Deep Inelastic Muon-Proton Scattering, at incident muon energies of (a) $120 \mathrm{GeV}$, (b) $200 \mathrm{GeV}$, (c) $240 \mathrm{GeV}$, (d) $280 \mathrm{GeV}$.

12) Values of the Structure Function $R=\sigma_{L} / \sigma_{T}$ for Deep Inelastic Muon-Proton Scattering.

13) Values of $R=\sigma_{L} / \sigma_{T}$ as a function of $Q^{2}, v$ and $x$.

14) The Results of Non-Singlet QCD Fits to $F_{2}\left(x, Q^{2}\right)$ for $x \geq 0.35$

15) The Results of Singlet + Non-Singlet Fits to $F_{2}\left(x, Q^{2}\right)$ in Leading Order QCD.

16) The Results of Higher Twist Fits to the EMC and SLAC-MII Data for $\geq 0.35$ and $Q^{2}>2.0 \mathrm{GeV}^{2}$.

17) The Results of QCD and QCD + Higher Twist Fits to the EMC and SLAC-MIT Data for $x \geq 0.33$ and $Q^{2}>2.0 \mathrm{GeV}^{2}$. 


\section{Table 1}

\section{The Definition of Kinematic Variables}

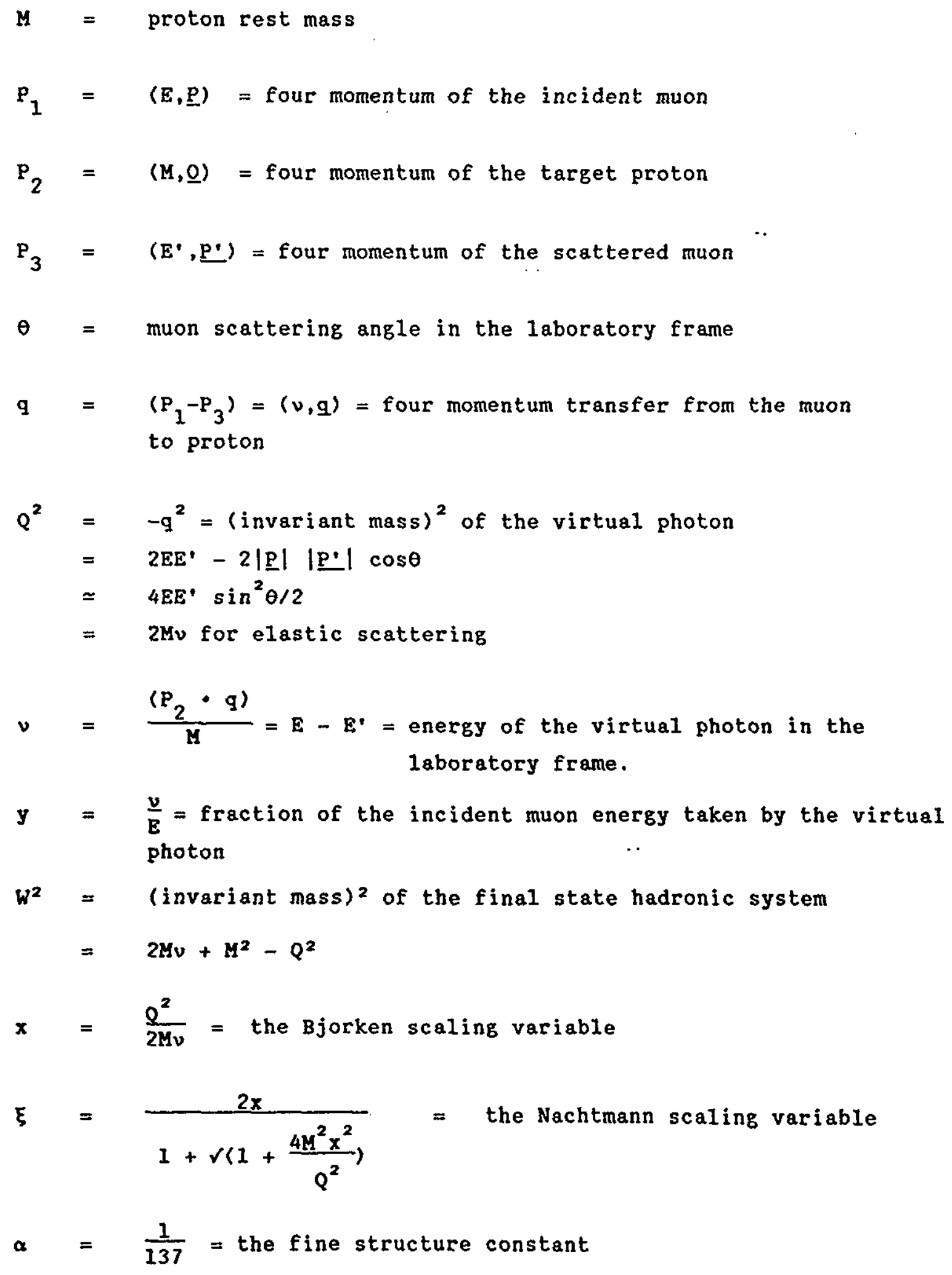




\section{Table 2}

The Muon Track and Vertex Resolution Functions for the EMC Spectrometer

a) Muon Vertex Resolution Function. (Applicable for all beam energies). $\sigma(x)=\frac{1}{\theta}\left(0.05+\frac{l}{p}\right) \frac{\pi}{180}$ metres. $\sigma(y)=6.1 \times 10^{-4}$ metres, $\sigma(z)=7.0 \times 10^{-4}$ metres.

b) Scattered Muon Momentum and Angle Resolution Functions.

$$
\sigma\left(\frac{1}{\mathrm{p}}\right)=\mathrm{K}\left(0.66+\frac{25.1}{\mathrm{P}}\right) \times 10^{-4} \mathrm{GeV}^{-1} \text {, }
$$$$
\sigma\left(\frac{P_{y}^{\prime}}{P^{\prime}}\right)=(0.67+11.7 F) \times 10^{-4} \text { radians, }
$$$$
\sigma\left(\frac{P_{z}^{\prime}}{P_{x}^{\prime}}\right)=(0.14+14.1 F) \times 10^{-4} \text { radians }
$$

$K=1$ for the 240 and $280 \mathrm{GeV}$ data

$=1.174$ for the $200 \mathrm{GeV}$ data

$=2.226$ for the $120 \mathrm{GeV}$ data

$F=\frac{(1+8 V L)}{P}$, where $L=$ total number of radiation lengths traversed by the scattered muon upstream of the FSM.

\begin{tabular}{|c|c|c|c|}
\hline$E_{\text {Beam }}(G e V)$ & $\begin{array}{l}\sigma\left(\frac{1}{\mathrm{P}}\right)(\mathrm{GeV})^{-1} \\
\times 10^{-5}\end{array}$ & $\begin{array}{l}\sigma\left(\frac{\mathrm{P}^{\prime}}{\mathrm{P}_{\mathrm{X}}^{\prime}}\right) \text { radians } \\
\times 10^{-4}\end{array}$ & $\begin{array}{l}\alpha\left(\frac{\mathrm{Z}}{\mathrm{P}_{\mathrm{X}}^{\prime}}\right) \text { radians } \\
\times 10^{-4}\end{array}$ \\
\hline 120 & 4.0 & 3.1 & 1.3 \\
\hline 200 & 2.4 & $1.1-0.024 \mathrm{x}_{\mathrm{v}}$ & $1.3-0.039 x_{y}$ \\
\hline 240 & 1.3 & $1.1-0.035 \mathrm{x}_{\mathrm{v}}$ & $1.2-0.030 \mathrm{x}_{\mathrm{v}}$ \\
\hline 280 & 1.3 & $1.1-0.035 \mathrm{x}_{\mathrm{v}}$ & $1.2-0.030 \mathrm{x}_{\mathrm{v}}$ \\
\hline
\end{tabular}

$x_{v}$ is the distance in metres of the vertex from the upstream edge of the target. $P^{\prime}$ is the momentum of the outgoing muon in GeV, $\theta$ is the scattering angle in radians. 
Tab1e 3

Iypical Values for the Kinematic Cuts Applied

to the Data

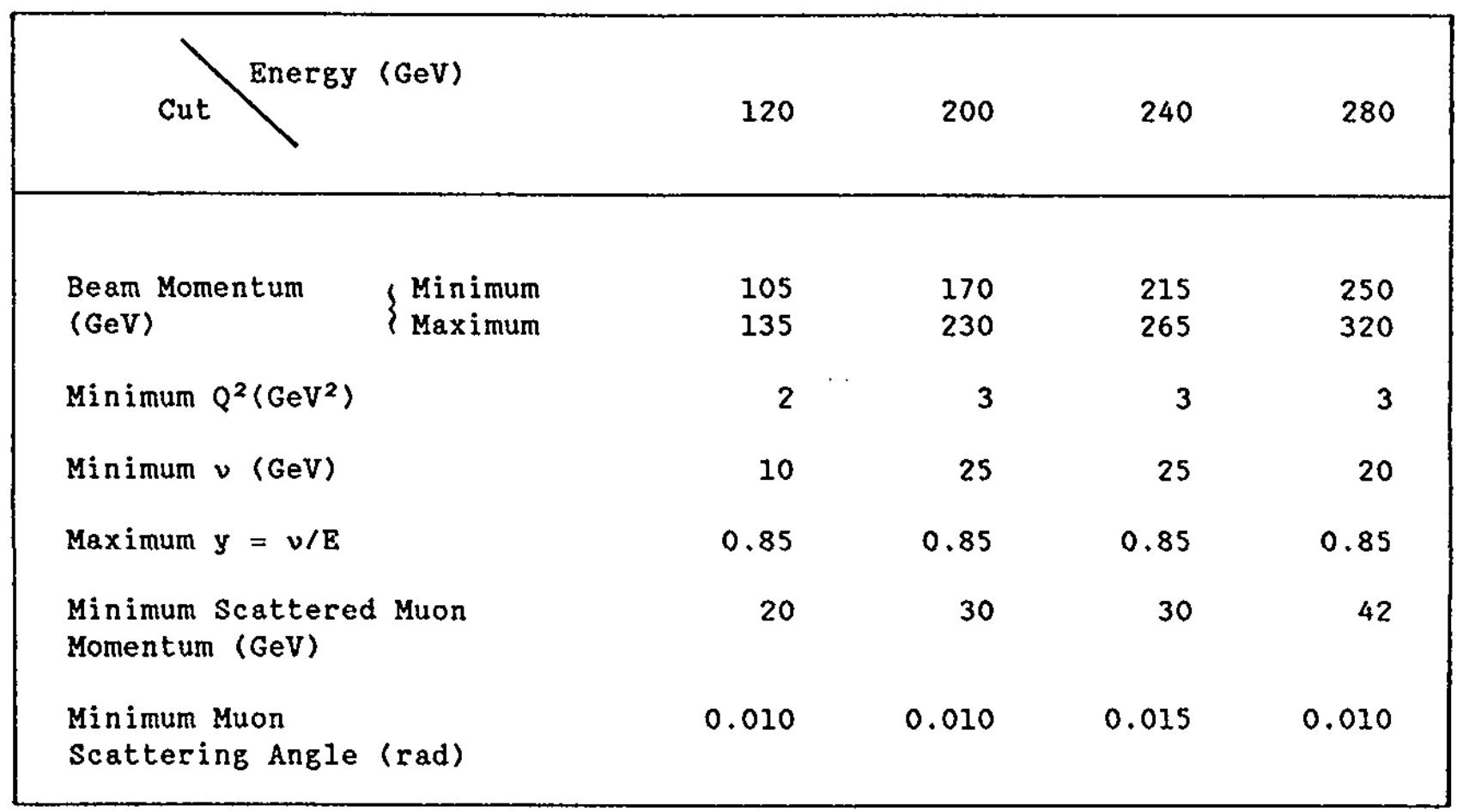


Table 4 a

\begin{tabular}{|c|c|c|c|c|c|c|c|c|c|}
\hline \multicolumn{10}{|c|}{$\begin{array}{l}\text { Values of the Individual Systematic Errors (\%) on } F 2 \\
\text { Beam Energy }=120 \mathrm{GeV}, \text { Target }=6 \mathrm{~m} \text { Hydrogen }\end{array}$} \\
\hline$x$ & $\left(G e^{Q^{2}}\right)$ & $\mathbf{I}$ & 2 & 3 & 4 & 5 & 6 & 7 & 8 \\
\hline $\begin{array}{l}0.030 \\
0.030 \\
0.030\end{array}$ & $\begin{array}{l}3.50 \\
4.50 \\
5.50\end{array}$ & $\begin{array}{l}3 \cdot 3 \\
2 \cdot 3 \\
2 \cdot 3\end{array}$ & $\begin{array}{l}2.6 \\
2.9 \\
3.1\end{array}$ & $\begin{array}{l}0.2 \\
0: 0 \\
0.2\end{array}$ & .3 .6 & $\begin{array}{l}0.1 \\
0: 0 \\
0.1\end{array}$ & $\begin{array}{l}1.1 \\
1: 0 \\
1.0\end{array}$ & $\begin{array}{l}0.0 \\
0.0 \\
0.1\end{array}$ & $\begin{array}{l}0.0 \\
0.0 \\
0.0\end{array}$ \\
\hline $\begin{array}{l}0.050 \\
0.050 \\
0.050 \\
0.050\end{array}$ & $\begin{array}{l}4.50 \\
5.50 \\
7.00 \\
9.00\end{array}$ & $\begin{array}{l}3.7 \\
2.0 \\
\frac{1}{2}: 3\end{array}$ & $\begin{array}{l}1.5 \\
1.8 \\
2.2 \\
2.7\end{array}$ & $\begin{array}{l}0.5 \\
0: 1 \\
0: 0 \\
0.0\end{array}$ & $\begin{array}{l}3.9 \\
3: 2 \\
2: 3 \\
1.4\end{array}$ & $\begin{array}{l}0.0 \\
0.0 \\
0.0 \\
0.0\end{array}$ & $\begin{array}{l}1.6 \\
\frac{1}{1}: \frac{3}{1} \\
\frac{1}{1} \cdot 0\end{array}$ & $\begin{array}{l}0.2 \\
0: 1 \\
0.0 \\
0.1\end{array}$ & $\begin{array}{l}0.0 \\
0: 0 \\
0.0 \\
0.0\end{array}$ \\
\hline $\begin{array}{l}0.080 \\
0.080 \\
0.080 \\
0.080 \\
0.080\end{array}$ & $\begin{array}{r}5.50 \\
7.00 \\
9.00 \\
11.50 \\
15.00\end{array}$ & $\begin{array}{l}3.3 \\
\frac{1}{1} \cdot 7 \\
\frac{1}{1} \cdot 3 \\
2.7\end{array}$ & $\begin{array}{l}1 \cdot 1 \\
1: 3 \\
1: 5 \\
1: 9 \\
2.2\end{array}$ & $\begin{array}{l}0.3 \\
0: 0 \\
0: \frac{1}{1} \\
0: \frac{1}{1} \\
0.1\end{array}$ & $\begin{array}{l}3 \cdot 8 \\
\frac{3}{3}: \frac{1}{1} \\
\frac{1}{1}: \frac{3}{3} \\
1: 0\end{array}$ & $\begin{array}{l}0.0 \\
0.0 \\
0.0 \\
0.0 \\
0.1\end{array}$ & $\begin{array}{l}1.9 \\
\frac{1}{1}: 6 \\
1.3 \\
1.1 \\
1.0\end{array}$ & $\begin{array}{l}0.4 \\
0.2 \\
0.1 \\
0.0 \\
0.1\end{array}$ & $\begin{array}{l}0.0 \\
0.0 \\
0.0 \\
0.0 \\
0.0\end{array}$ \\
\hline $\begin{array}{l}0.125 \\
0.125 \\
0: 125 \\
0.125 \\
0.125\end{array}$ & $\begin{array}{r}7.00 \\
9.00 \\
1150 \\
15.00 \\
20.00\end{array}$ & $\begin{array}{l}2 \cdot 3 \\
1: 3 \\
1: 3 \\
1: 3 \\
2: 0\end{array}$ & $\begin{array}{l}0.8 \\
0: 9 \\
1: 1 \\
1.7 \\
1.7\end{array}$ & $\begin{array}{l}0.9 \\
0: \frac{1}{1} \\
0.12 \\
0: \frac{1}{2} \\
0.2\end{array}$ & $\begin{array}{l}3.7 \\
2: 6 \\
2.1 \\
1.4 \\
1.0\end{array}$ & $\begin{array}{l}0.0 \\
0: 0 \\
0: 0 \\
0: 0 \\
0.1\end{array}$ & $\begin{array}{l}2.2 \\
1: 8 \\
1: 5 \\
1: 3 \\
1.1\end{array}$ & $\begin{array}{l}0.5 \\
0: 3 \\
0: 1 \\
0: 0 \\
0.1\end{array}$ & $\begin{array}{l}0.0 \\
0: 0 \\
0: 0 \\
0: 0 \\
0.0\end{array}$ \\
\hline $\begin{array}{l}0.175 \\
0: 175 \\
0.175 \\
0.175 \\
0.175 \\
0: 175\end{array}$ & $\begin{array}{r}7.00 \\
9.00 \\
11.50 \\
15.00 \\
20.00 \\
27.00\end{array}$ & $\begin{array}{l}2 \cdot 7 \\
1.7 \\
1.7 \\
1: 0 \\
\frac{1}{2} \cdot 3 \\
2.0\end{array}$ & $\begin{array}{l}0.4 \\
0.5 \\
0.7 \\
0.8 \\
1.0 \\
1.4\end{array}$ & $\begin{array}{l}0.6 \\
0.7 \\
0.8 \\
0.3 \\
0.1 \\
0.1\end{array}$ & $\begin{array}{l}4.0 \\
2: 9 \\
2.4 \\
1.7 \\
1.7 \\
0.8\end{array}$ & $\begin{array}{l}0.0 \\
0.0 \\
0.0 \\
0.0 \\
0.0 \\
0.0\end{array}$ & $\begin{array}{l}2.6 \\
2 \cdot 2 \\
1 \cdot 8 \\
1 \cdot 5 \\
1 \cdot 3 \\
1.0\end{array}$ & $\begin{array}{l}0.6 \\
0: 4 \\
0.3 \\
0.1 \\
0.0 \\
0.2\end{array}$ & $\begin{array}{l}0.0 \\
0.0 \\
0: 0 \\
0.0 \\
0.0 \\
0.0\end{array}$ \\
\hline $\begin{array}{l}0.250 \\
0.250 \\
0.250 \\
0.250 \\
0.250 \\
0.250 \\
0.250 \\
0.250\end{array}$ & $\begin{array}{r}7.00 \\
9.00 \\
11.50 \\
15.000 \\
20.00 \\
27.00 \\
36.00 \\
48.00\end{array}$ & $\begin{array}{l}3.7 \\
2: 0 \\
1: 3 \\
1=3 \\
1=0 \\
\frac{1}{1}: 3 \\
2: 0 \\
6: 7\end{array}$ & $\begin{array}{l}0.0 \\
0: 1 \\
0: 02 \\
0: 4 \\
0: 5 \\
0.7 \\
1: 0 \\
1.2\end{array}$ & $\begin{array}{l}1.2 \\
0: 4 \\
0: 1 \\
0: 4 \\
0: 3 \\
0: 0 \\
0: 3 \\
0: 3\end{array}$ & $\begin{array}{l}3.7 \\
3: 3 \\
2: 8 \\
2: 0 \\
1.3 \\
0: 9 \\
0.6 \\
0.6\end{array}$ & $\begin{array}{l}0.2 \\
0: 2 \\
0: 3 \\
0: 2 \\
0: 2 \\
0: 2 \\
0: 0 \\
1: 0\end{array}$ & $\begin{array}{l}2.4 \\
2.1 \\
12.9 \\
\frac{1}{1}: 6 \\
1.4 \\
\frac{1}{1}: 2 \\
0.9\end{array}$ & $\begin{array}{l}0.5 \\
0: 3 \\
0: 3 \\
0: 1 \\
0: 0 \\
0: \frac{1}{1} \\
0: 2 \\
0: 3\end{array}$ & $\begin{array}{l}0.0 \\
0: 0 \\
0: 0 \\
0: 0 \\
0: 0 \\
0: 0 \\
0: 0 \\
0.0\end{array}$ \\
\hline $\begin{array}{l}0.350 \\
0.350 \\
0.350 \\
0.350 \\
0.350 \\
0.350 \\
0.350\end{array}$ & $\begin{array}{r}9.00 \\
11.50 \\
15.00 \\
20.00 \\
27.00 \\
36.00 \\
48.00\end{array}$ & $\begin{array}{l}2 \cdot 3 \\
1: 3 \\
1: 3 \\
1: 0 \\
\frac{1}{1}: 3 \\
\frac{1}{2} \cdot 3\end{array}$ & $\begin{array}{l}0.3 \\
0: 2 \\
0: 1 \\
0.0 \\
0.2 \\
0.4 \\
0.7\end{array}$ & $\begin{array}{l}1.5 \\
2.4 \\
0: 6 \\
0: 2 \\
0: 3 \\
0: 1 \\
0.1\end{array}$ & $\begin{array}{l}3.3 \\
3: 1 \\
2: 3 \\
1.5 \\
1.5 \\
0.8 \\
0.6\end{array}$ & $\begin{array}{l}0: 5 \\
0: 3 \\
0: 5 \\
0: 3 \\
0: 3 \\
0: 3 \\
0.1\end{array}$ & $\begin{array}{l}0.8 \\
0.9 \\
1.0 \\
1.00 \\
1.00 \\
1.0 \\
0.9\end{array}$ & $\begin{array}{l}0.5 \\
0.4 \\
0: 4 \\
0.4 \\
0.4 \\
0.4 \\
0.4\end{array}$ & $\begin{array}{ll}0 & 0 \\
0 & 0 \\
0 & 0 \\
0 & 0 \\
0 & 0 \\
0 & 0 \\
0: 0 & 0\end{array}$ \\
\hline $\begin{array}{l}0.450 \\
0.450 \\
0.450 \\
0.450 \\
0.450 \\
0.450 \\
0.450\end{array}$ & $\begin{array}{l}11.50 \\
15.00 \\
20.00 \\
27.00 \\
36.00 \\
48.00 \\
65.00\end{array}$ & 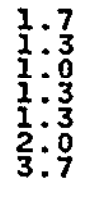 & $\begin{array}{l}0.5 \\
0.5 \\
0: 3 \\
0.2 \\
0.0 \\
0.2 \\
0.4\end{array}$ & $\begin{array}{l}1.7 \\
0.6 \\
2.1 \\
0.2 \\
0.5 \\
0.6 \\
0.2\end{array}$ & $\begin{array}{l}2.8 \\
1.7 \\
1.8 \\
1.3 \\
1.0 \\
0.7 \\
0.5\end{array}$ & $\begin{array}{l}0.7 \\
0.5 \\
0: 5 \\
0.5 \\
0.5 \\
0.5 \\
0.5\end{array}$ & $\begin{array}{l}1.2 \\
0.8 \\
0: 3 \\
0.1 \\
0.4 \\
0.6 \\
0.7\end{array}$ & $\begin{array}{l}1.6 \\
1.4 \\
1.1 \\
1.0 \\
0.8 \\
0.7 \\
0.7\end{array}$ & $\begin{array}{ll}0 & 0 \\
0 & 0 \\
0 & 0 \\
0 & 0 \\
0 & 0 \\
0 & 0 \\
0 & 0 \\
0 & 0\end{array}$ \\
\hline $\begin{array}{l}0.550 \\
0.550 \\
0.550 \\
0.550 \\
0.550 \\
0.550 \\
0.550\end{array}$ & $\begin{array}{l}11.50 \\
15.00 \\
20.00 \\
27.00 \\
36.00 \\
48.00 \\
65.00\end{array}$ & $\begin{array}{l}2: 3 \\
\frac{1}{1}: 3 \\
\frac{1}{1}: 3 \\
\frac{1}{1}: 3 \\
\frac{1}{2}: 7\end{array}$ & $\begin{array}{l}0.7 \\
0.7 \\
0.6 \\
0.5 \\
0.3 \\
0.2 \\
0.0\end{array}$ & $\begin{array}{l}2.3 \\
1: 2 \\
0: 7 \\
0: 4 \\
0: 1 \\
1: 0 \\
0: 0\end{array}$ & $\begin{array}{l}3.0 \\
1.9 \\
2: 2 \\
1.4 \\
1.2 \\
0.7 \\
0.7\end{array}$ & $\begin{array}{l}1.2 \\
0.6 \\
0.6 \\
0.7 \\
0.6 \\
0.6 \\
0.4\end{array}$ & $\begin{array}{l}3.9 \\
3.2 \\
2.4 \\
1.5 \\
0.8 \\
0.2 \\
0.2\end{array}$ & $\begin{array}{l}3.1 \\
2.8 \\
2.4 \\
2.0 \\
1.6 \\
1.3 \\
1.1\end{array}$ & $\begin{array}{l}0.0 \\
0: 0 \\
0: 0 \\
0: 0 \\
0: 0 \\
0: 0 \\
0: 0\end{array}$ \\
\hline $\begin{array}{l}0.650 \\
0.650 \\
0.650 \\
0.650 \\
0.650\end{array}$ & $\begin{array}{l}20.00 \\
27.00 \\
36.00 \\
48.00 \\
65.00\end{array}$ & $\begin{array}{l}\frac{1}{1} \cdot 3 \\
\frac{1}{1} \cdot 3 \\
\frac{1}{2}: \frac{3}{3}\end{array}$ & $\begin{array}{l}0.8 \\
0.7 \\
0.6 \\
0.5 \\
0.3\end{array}$ & $\begin{array}{l}0.5 \\
0.7 \\
0.2 \\
0.4 \\
0.5\end{array}$ & $\begin{array}{l}1.8 \\
1.4 \\
1.5 \\
0.8 \\
0.5\end{array}$ & $\begin{array}{l}0.7 \\
0: 9 \\
1: 2 \\
0.8 \\
1.0\end{array}$ & $\begin{array}{l}5.1 \\
4.0 \\
2.8 \\
1.6 \\
0.7\end{array}$ & $\begin{array}{l}3.9 \\
3.4 \\
2.9 \\
2.9 \\
1.9\end{array}$ & $\begin{array}{l}0.0 \\
0: 0 \\
0: 0 \\
0: 0 \\
0.0\end{array}$ \\
\hline $\begin{array}{l}0.750 \\
0.750 \\
0.750 \\
0.750\end{array}$ & $\begin{array}{l}27.00 \\
36.00 \\
48.00 \\
65.00\end{array}$ & $\begin{array}{l}\frac{1}{1} \cdot 3 \\
\frac{1}{2}: \frac{3}{2} \\
2 \cdot 0\end{array}$ & $\begin{array}{l}0.9 \\
0.9 \\
0.8 \\
0.6\end{array}$ & $\begin{array}{l}0.6 \\
0.7 \\
1.5 \\
0.5\end{array}$ & $\begin{array}{l}1.0 \\
0.9 \\
1.0 \\
1.0\end{array}$ & $\begin{array}{l}\frac{1}{1}: \frac{2}{3} \\
\frac{1}{1}: 4 \\
1 \cdot 5\end{array}$ & $\begin{array}{l}7.0 \\
5.6 \\
3.9 \\
2.5\end{array}$ & $\begin{array}{l}5.2 \\
4: 6 \\
3: 8 \\
3.2\end{array}$ & $\begin{array}{l}0.0 \\
0: 0 \\
0: 0 \\
0.0\end{array}$ \\
\hline
\end{tabular}


Table $4 \mathrm{~b}$

\begin{tabular}{|c|c|c|c|c|c|c|c|c|c|}
\hline$x$ & $\begin{array}{c}\text { Values of } \\
\text { Beam } \\
\left(G Q^{2}\right. \\
\left(G V^{2}\right)\end{array}$ & $\begin{array}{c}\text { he Ind } \\
\text { iergy } \\
1\end{array}$ & $\begin{array}{c}\text { ividus } \\
2000 \\
2\end{array}$ & $\frac{1}{e^{5}}$ & $\begin{array}{l}\text { ematj } \\
\text { arget } \\
\qquad 4\end{array}$ & $\begin{array}{l}\text { Err } \\
6 \mathrm{~m} \\
5\end{array}$ & $\begin{array}{l}\text { dio } \\
6\end{array}$ & $\begin{array}{c}\text { on } F 2 \\
\text { n } \\
7\end{array}$ & 8 \\
\hline $\begin{array}{l}0.030 \\
0.030\end{array}$ & $\begin{array}{l}7.00 \\
9.00\end{array}$ & $\begin{array}{l}2.8 \\
3.2\end{array}$ & $3 \cdot \frac{1}{3}$ & $\begin{array}{l}0.0 \\
0.0\end{array}$ & 2.6 & $\begin{array}{l}0.0 \\
0.0\end{array}$ & $\frac{1}{0.1}$ & 0.0 & $\begin{array}{l}0.0 \\
0.0\end{array}$ \\
\hline $\begin{array}{l}0.050 \\
0.050 \\
0.050\end{array}$ & $\begin{array}{r}9.00 \\
11.50 \\
15.00\end{array}$ & $\begin{array}{l}2.6 \\
\frac{1}{2}: 5 \\
\end{array}$ & $\begin{array}{l}\frac{1.9}{2} .4 \\
3.0\end{array}$ & $\begin{array}{l}0.0 \\
0.0 \\
0.0\end{array}$ & $\begin{array}{l}2.0 \\
1.0 \\
0.5\end{array}$ & $\begin{array}{l}0.0 \\
0: 0 \\
0.1\end{array}$ & $\begin{array}{l}1.4 \\
2.1 \\
0.9\end{array}$ & $\begin{array}{l}0.1 \\
0: 0 \\
0.1\end{array}$ & $\begin{array}{l}0.0 \\
0.0 \\
0.0\end{array}$ \\
\hline $\begin{array}{l}0.080 \\
0.080 \\
0.080 \\
0.080 \\
0.080\end{array}$ & $\begin{array}{r}9.00 \\
11: 50 \\
15: 00 \\
20.00 \\
27.00\end{array}$ & $\begin{array}{l}6.2 \\
2: 6 \\
1.5 \\
\frac{1}{4}: 4 \\
4.0\end{array}$ & $\begin{array}{l}\frac{7}{1} \cdot 2 \\
\frac{1}{1}: 7 \\
2.7 \\
2.6\end{array}$ & $\begin{array}{l}0.0 \\
0: 0 \\
0.0 \\
0: 0 \\
0: 0\end{array}$ & $\begin{array}{l}3.5 \\
1: 7 \\
0.8 \\
0.5 \\
0.3\end{array}$ & $\begin{array}{l}0.0 \\
0: 0 \\
0: 0 \\
0.0 \\
0.3\end{array}$ & $\begin{array}{l}2.0 \\
2.6 \\
1.3 \\
1.0 \\
0.9\end{array}$ & $\begin{array}{l}0.4 \\
0: 2 \\
0: \frac{1}{2} \\
0: \frac{1}{2} \\
0.2\end{array}$ & $\begin{array}{l}0.0 \\
0.0 \\
0.0 \\
0.0 \\
0.0\end{array}$ \\
\hline $\begin{array}{l}0.125 \\
0: 125 \\
0: 125 \\
0: 125 \\
0.125\end{array}$ & $\begin{array}{l}11.50 \\
15.00 \\
200.00 \\
27.00 \\
36.00\end{array}$ & $\begin{array}{l}3 \cdot 7 \\
2: \frac{1}{3} \\
1 \\
\frac{1}{2}: \frac{1}{2}\end{array}$ & $\begin{array}{l}0.8 \\
1: 0 \\
\frac{1}{1}: 2 \\
\frac{1}{2}: 0\end{array}$ & $\begin{array}{l}0.0 \\
0: 0 \\
0: 0 \\
0: 0 \\
0.0\end{array}$ & $\begin{array}{l}2.3 \\
1: 4 \\
0: 8 \\
0: 4 \\
0.3\end{array}$ & $\begin{array}{l}0.0 \\
0: 0 \\
0: 1 \\
0: 0 \\
0.2\end{array}$ & $\begin{array}{l}2.2 \\
1.8 \\
\frac{1}{1}: 5 \\
0.2\end{array}$ & $\begin{array}{l}0.5 \\
0: 3 \\
0: 1 \\
0: 0 \\
0.2\end{array}$ & $\begin{array}{l}0.0 \\
0: 0 \\
0: 0 \\
0.0 \\
0.0\end{array}$ \\
\hline $\begin{array}{l}0.175 \\
0.175 \\
0.175 \\
0.175 \\
0.175 \\
0.175\end{array}$ & $\begin{array}{l}11.50 \\
15.00 \\
20.00 \\
27.00 \\
36.00 \\
48.00\end{array}$ & $\begin{array}{l}4 \cdot 9 \\
2: 2 \\
\frac{1}{1}: 5 \\
\frac{1}{1}: 2 \\
\frac{1}{2}: 0\end{array}$ & $\begin{array}{l}0.5 \\
0.6 \\
0.8 \\
1.0 \\
\frac{1}{1} .2\end{array}$ & $\begin{array}{l}0.1 \\
0: \frac{1}{1} \\
0: 0 \\
0: 0 \\
0.0 \\
0.0\end{array}$ & $\begin{array}{l}3.2 \\
1: 7 \\
10 \\
0: 5 \\
0: 4 \\
0.3\end{array}$ & $\begin{array}{l}0.1 \\
0: \frac{1}{1} \\
0: \frac{1}{1} \\
0 \\
0: \frac{1}{1} \\
0: \frac{1}{1}\end{array}$ & $\begin{array}{l}2.6 \\
2.1 \\
1.7 \\
\frac{1}{1}: 4 \\
\frac{1}{1} \cdot 0\end{array}$ & $\begin{array}{l}0.6 \\
0.4 \\
0.2 \\
0.0 \\
0.1 \\
0.2\end{array}$ & $\begin{array}{l}0.0 \\
0.0 \\
0.0 \\
0.0 \\
0.0 \\
0.0\end{array}$ \\
\hline $\begin{array}{l}0.250 \\
0.250 \\
0.250 \\
0.250 \\
0.250 \\
0.250 \\
0.250\end{array}$ & $\begin{array}{l}11.50 \\
15.00 \\
20.00 \\
27.00 \\
36.00 \\
48.00 \\
65.00\end{array}$ & $\begin{array}{l}6 \cdot 1 \\
2: 7 \\
1 \\
1 \\
\frac{1}{1}: 2 \\
1 \\
\frac{1}{2}: 7 \\
2.2\end{array}$ & $\begin{array}{l}0.1 \\
0: \frac{1}{2} \\
0: 3 \\
0: 5 \\
0: 7 \\
0: 9 \\
1.2\end{array}$ & $\begin{array}{l}0.6 \\
0.2 \\
0: 2 \\
0: 1 \\
0: 1 \\
0.0 \\
0.0\end{array}$ & $\begin{array}{l}3.9 \\
1.8 \\
10.0 \\
0.6 \\
0.5 \\
0.4 \\
0.3\end{array}$ & $\begin{array}{l}0.3 \\
0: 3 \\
0: 3 \\
0: 3 \\
0: 3 \\
0: 3 \\
0: 1\end{array}$ & $\begin{array}{l}2.5 \\
2: 1 \\
1: 8 \\
1: 5 \\
1: 3 \\
1: 1 \\
1.0\end{array}$ & $\begin{array}{l}0.5 \\
0: 3 \\
0: 2 \\
0: 0 \\
0: \frac{1}{2} \\
0: \frac{2}{2} \\
0: 3\end{array}$ & $\begin{array}{l}0.0 \\
0: 0 \\
0: 0 \\
0: 0 \\
0: 0 \\
0: 0 \\
0.0\end{array}$ \\
\hline $\begin{array}{l}0.350 \\
0: 350 \\
0: 350 \\
0: 350 \\
0.350 \\
0.350 \\
0.350\end{array}$ & $\begin{array}{l}15.00 \\
20.00 \\
27.00 \\
36.00 \\
48.00 \\
65.00 \\
90.00\end{array}$ & $\begin{array}{l}3: 1 \\
1: 7 \\
\frac{1}{1}: 3 \\
\frac{1}{1}: \frac{1}{7} \\
\frac{1}{2}: 8 \\
2.5\end{array}$ & $\begin{array}{l}0.4 \\
0: 2 \\
0: \frac{1}{1} \\
0: \frac{1}{3} \\
0: 3 \\
0.6 \\
0.9\end{array}$ & $\begin{array}{l}0.9 \\
0: 3 \\
0: 3 \\
0: 2 \\
0: 1 \\
0: 1 \\
0: 0\end{array}$ & $\begin{array}{l}2.1 \\
1: 3 \\
0: 7 \\
0: 4 \\
0: 5 \\
0: 3 \\
0.1\end{array}$ & $\begin{array}{l}0.6 \\
0.6 \\
0: 5 \\
0.5 \\
0.4 \\
0.3 \\
0.1\end{array}$ & $\begin{array}{l}0.7 \\
0.8 \\
0.9 \\
0.9 \\
0.9 \\
0.9 \\
0.9\end{array}$ & $\begin{array}{l}0.5 \\
0.4 \\
0: 4 \\
0.4 \\
0.3 \\
0.3 \\
0.4\end{array}$ & $\begin{array}{l}0.0 \\
0.0 \\
0.0 \\
0.0 \\
0.0 \\
0.0 \\
0.0 \\
0.0\end{array}$ \\
\hline $\begin{array}{l}0.450 \\
0.450 \\
0.450 \\
0.450 \\
0.450 \\
0.450 \\
0.450\end{array}$ & $\begin{array}{l}15.00 \\
20.00 \\
27.00 \\
36.00 \\
48.00 \\
65.00 \\
90.00\end{array}$ & $\begin{array}{l}3.4 \\
2: 0 \\
1: 4 \\
1: 2 \\
\frac{1}{1}: \frac{1}{6} \\
1: .7\end{array}$ & $\begin{array}{l}0.7 \\
0: 0 \\
0: 5 \\
0: 3 \\
0: \frac{1}{1} \\
0.71 \\
0.4\end{array}$ & $\begin{array}{l}0.7 \\
0.7 \\
0: 4 \\
0.4 \\
0: 3 \\
0.1 \\
0.1\end{array}$ & $\begin{array}{l}1.6 \\
1.5 \\
1.5 \\
0.5 \\
0.4 \\
0.4 \\
0.3\end{array}$ & $\begin{array}{l}0.6 \\
0.8 \\
0.7 \\
0.5 \\
0.6 \\
0.5 \\
0.6\end{array}$ & $\begin{array}{l}2.8 \\
1: 7 \\
0: 9 \\
0: 3 \\
0: 1 \\
0: 5 \\
0.6\end{array}$ & $\begin{array}{l}2.4 \\
1.9 \\
1.5 \\
1.2 \\
1.0 \\
0: 7 \\
0.7\end{array}$ & $\begin{array}{l}0.0 \\
0.0 \\
0.0 \\
0.0 \\
0.0 \\
0.0 \\
0.0\end{array}$ \\
\hline $\begin{array}{l}0.550 \\
0.5550 \\
0.550 \\
0.550 \\
0.550\end{array}$ & $\begin{array}{l}27.00 \\
36.00 \\
48.00 \\
65.00 \\
90.00\end{array}$ & $\begin{array}{l}1 \cdot 3 \\
1: 2 \\
1: 2 \\
1: 7 \\
1: 9\end{array}$ & $\begin{array}{l}0.7 \\
0: 6 \\
0: 5 \\
0: 3 \\
0: 1\end{array}$ & $\begin{array}{l}0.8 \\
0.6 \\
0: 2 \\
0.2 \\
0.1\end{array}$ & $\begin{array}{l}0.8 \\
0: 7 \\
0.5 \\
0: 5 \\
0.3\end{array}$ & $\begin{array}{l}0.8 \\
1.0 \\
1.0 \\
0.7 \\
0.7\end{array}$ & $\begin{array}{l}4.2 \\
2: 7 \\
1: 5 \\
0.6 \\
0.0\end{array}$ & $\begin{array}{l}3.3 \\
2.6 \\
2.0 \\
\frac{1}{1} .4\end{array}$ & $\begin{array}{l}0.0 \\
0.0 \\
0.0 \\
0.0 \\
0.0\end{array}$ \\
\hline $\begin{array}{l}0.650 \\
0.650 \\
0.650 \\
0.650 \\
0.650\end{array}$ & $\begin{array}{r}36.00 \\
48.00 \\
65.00 \\
90.00 \\
125.00\end{array}$ & $\begin{array}{l}1 \cdot \frac{1}{2} \\
\frac{1}{1} \cdot \frac{5}{1} \\
\frac{1}{2} \cdot 8 \\
\end{array}$ & $\begin{array}{l}0.9 \\
0.8 \\
0.6 \\
0.4 \\
0.2\end{array}$ & $\begin{array}{l}2.6 \\
0.8 \\
0.4 \\
0.1 \\
0.1\end{array}$ & $\begin{array}{l}0.5 \\
0.4 \\
0.5 \\
0.4 \\
0.4\end{array}$ & $\begin{array}{l}1.2 \\
1.5 \\
1.5 \\
0: 9 \\
0.8\end{array}$ & $\begin{array}{l}6.6 \\
4.4 \\
2.8 \\
1.1 \\
0.4\end{array}$ & $\begin{array}{l}4.8 \\
3.7 \\
2.8 \\
1.8 \\
1.2\end{array}$ & $\begin{array}{l}0.0 \\
0.0 \\
0.0 \\
0.0 \\
0.0\end{array}$ \\
\hline $\begin{array}{l}0.750 \\
0.750 \\
0.750\end{array}$ & $\begin{array}{r}65.00 \\
90.00 \\
125.00\end{array}$ & $\begin{array}{l}\frac{1}{3} .8 \\
\frac{3}{2} .9\end{array}$ & $\begin{array}{l}0.9 \\
0.8 \\
0.5\end{array}$ & $\begin{array}{l}2.4 \\
0.8 \\
0.3\end{array}$ & $\begin{array}{l}0.4 \\
0.4 \\
0.3\end{array}$ & $\begin{array}{l}\frac{1}{1} .4 \\
\frac{1}{1} .6\end{array}$ & $\begin{array}{l}4.9 \\
3: 6 \\
1.3\end{array}$ & $\begin{array}{l}3.5 \\
2.7 \\
1.4\end{array}$ & $\begin{array}{l}0.0 \\
0.0 \\
0.0\end{array}$ \\
\hline
\end{tabular}


Table $4 \mathrm{c}$

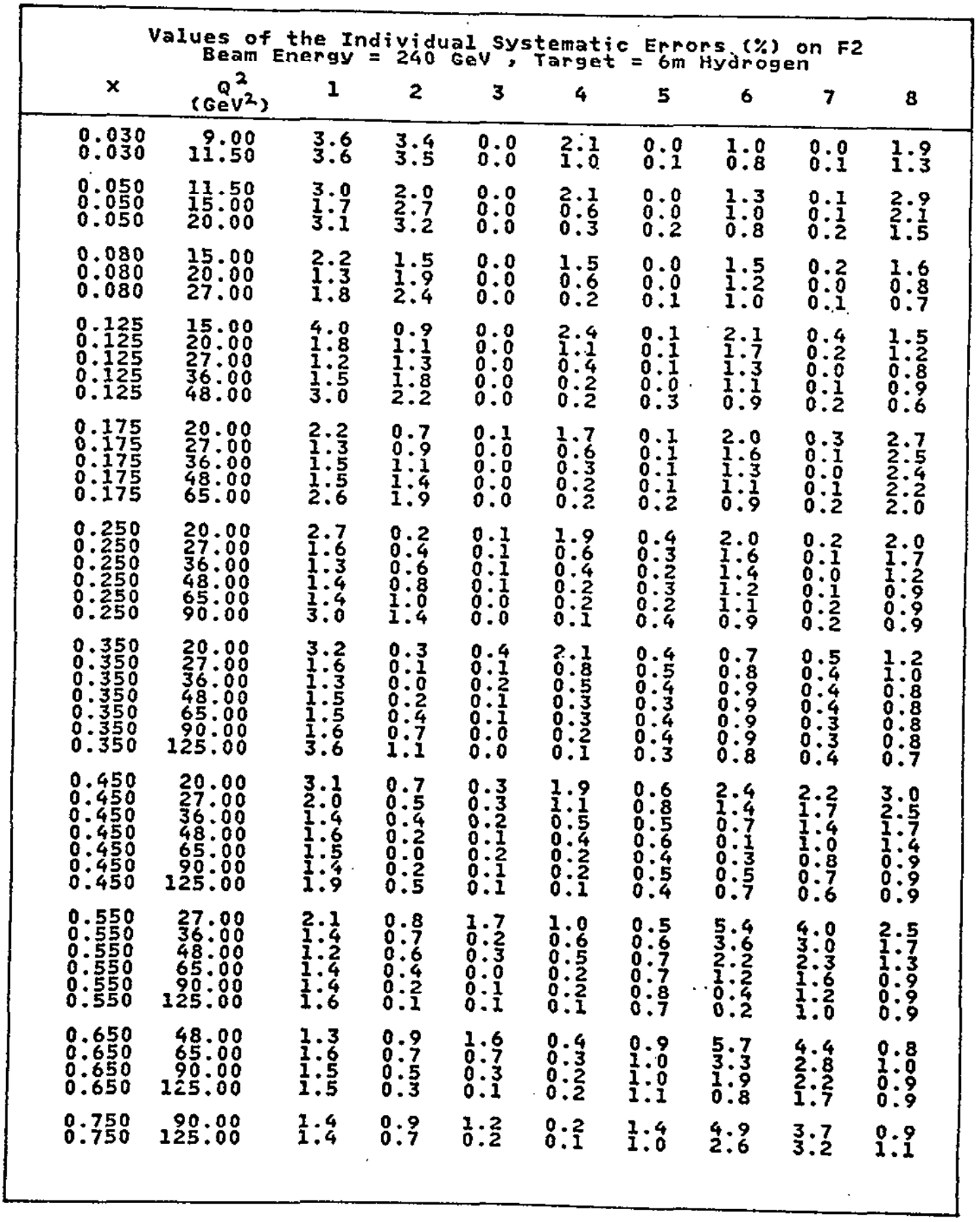


rable $4 d$

\begin{tabular}{|c|c|c|c|c|c|c|c|c|c|}
\hline \multirow[b]{2}{*}{$x$} & \multicolumn{9}{|c|}{$\begin{array}{c}\text { Values of the Individual systematic Errors }(\%) \text { on } F 2 \\
\text { Beam Energy }=280 \text { Gev } \text { Target }=6 \mathrm{~m} \text { Hydrogen }\end{array}$} \\
\hline & $\left(G e^{2} V^{2}\right)$ & 1 & 2 & 3 & 4 & 5 & 6 & 7 & 8 \\
\hline $\begin{array}{l}0.030 \\
0.030 \\
0.030\end{array}$ & $\begin{array}{r}7.00 \\
9.00 \\
11.50\end{array}$ & $\frac{3}{2} \cdot \frac{5}{2} \cdot \frac{1}{2}$ & $\begin{array}{l}2.2 \\
2.8 \\
3.1\end{array}$ & 0.21 & $\begin{array}{l}0.9 \\
0.8 \\
0.8\end{array}$ & $\begin{array}{l}0.0 \\
0.0 \\
0.1\end{array}$ & $\begin{array}{l}1.3 \\
1: 1 \\
1.0\end{array}$ & $\begin{array}{l}0.1 \\
0.0 \\
0.0\end{array}$ & $\begin{array}{l}3.0 \\
2: 5 \\
2.0\end{array}$ \\
\hline $\begin{array}{l}0.050 \\
0.050 \\
0.050 \\
0.050 \\
0.050\end{array}$ & $\begin{array}{r}7.00 \\
9.00 \\
11.50 \\
15.00 \\
20.00\end{array}$ & $\begin{array}{l}6.0 \\
2.7 \\
1.9 \\
1.4 \\
1.7\end{array}$ & $\begin{array}{l}1.3 \\
1 \cdot 4 \\
\frac{1}{2}: 7 \\
2.2\end{array}$ & $\begin{array}{l}0.3 \\
0: 2 \\
0.2 \\
0.2 \\
0.2\end{array}$ & $\begin{array}{l}1.0 \\
0: 9 \\
0: 9 \\
0.8 \\
0.7\end{array}$ & $\begin{array}{l}0.0 \\
0.0 \\
0.0 \\
0.0 \\
0.1\end{array}$ & $\begin{array}{l}2.0 \\
1.7 \\
1.4 \\
1.2 \\
1.0\end{array}$ & $\begin{array}{l}0.3 \\
0: 2 \\
0: \frac{1}{1} \\
0: 0 \\
0: 0\end{array}$ & $\begin{array}{l}3 \cdot 5 \\
3: 3 \\
3: 0 \\
2: 8 \\
2.5\end{array}$ \\
\hline $\begin{array}{l}0.080 \\
0.080 \\
0.080 \\
0.080 \\
0.080 \\
0.080\end{array}$ & $\begin{array}{r}9.00 \\
11.50 \\
15.00 \\
20.00 \\
27.00 \\
36.00\end{array}$ & $\begin{array}{l}3 \cdot 2 \\
2: 1 \\
1 \\
\frac{1}{1} \cdot 5 \\
\frac{1}{2} \cdot 4 \\
2.1\end{array}$ & $\begin{array}{l}\frac{1}{1} \cdot 0 \\
\frac{1}{1} \cdot \frac{1}{3} \\
\frac{1}{2} \cdot 6 \\
\frac{2}{2} \cdot \frac{2}{5}\end{array}$ & $\begin{array}{l}0.6 \\
0.4 \\
0.3 \\
0.2 \\
0.2 \\
0.2\end{array}$ & $\begin{array}{l}0.9 \\
0.8 \\
1.0 \\
0.8 \\
0.6 \\
0.5\end{array}$ & $\begin{array}{l}0.0 \\
0: 0 \\
0: 0 \\
0: 1 \\
0.0 \\
0.3\end{array}$ & $\begin{array}{l}2.4 \\
2.0 \\
13 \\
\frac{1}{1}: 3 \\
\frac{1}{0}: 9\end{array}$ & $\begin{array}{l}1.2 \\
0: 5 \\
0: 2 \\
0: 0 \\
0: 0 \\
0.0\end{array}$ & $\begin{array}{l}4.0 \\
3.0 \\
2.0 \\
1.0 \\
1.0 \\
1.0\end{array}$ \\
\hline $\begin{array}{l}0.125 \\
0: 125 \\
0: 125 \\
0: 125 \\
0: 1255 \\
0: 1255 \\
0.125\end{array}$ & $\begin{array}{r}9.00 \\
11.50 \\
15.00 \\
20.00 \\
27.00 \\
36.00 \\
48.00\end{array}$ & $\begin{array}{l}3.8 \\
2.4 \\
1.8 \\
1.6 \\
1.4 \\
1.3 \\
1.5\end{array}$ & $\begin{array}{l}0.5 \\
0: 7 \\
0.8 \\
1.0 \\
1.2 \\
1.5 \\
2.0\end{array}$ & $\begin{array}{l}0.6 \\
10: 1 \\
0: 2 \\
0: 2 \\
0.2 \\
0.2 \\
0.1\end{array}$ & $\begin{array}{l}1.2 \\
0.8 \\
0.9 \\
0.9 \\
0.8 \\
0.6 \\
0.5\end{array}$ & $\begin{array}{l}0.0 \\
0.0 \\
0: 0 \\
0: 0 \\
0.01 \\
0.11 \\
0.1\end{array}$ & $\begin{array}{l}3.2 \\
2: 7 \\
2: 2 \\
1: 8 \\
1 \cdot 5 \\
1.2 \\
1.0\end{array}$ & $\begin{array}{l}2 \cdot 2 \\
1: 2 \\
0: 7 \\
0: 3 \\
0: \frac{1}{1} \\
0: 0 \\
0: 0\end{array}$ & $\begin{array}{l}4.0 \\
2.8 \\
2.0 \\
1.5 \\
\frac{1}{1} .0 \\
1.0 \\
1.0\end{array}$ \\
\hline $\begin{array}{l}0.175 \\
0.1175 \\
0: 175 \\
0: 175 \\
0.175 \\
0: 1755 \\
0: 1755 \\
0.175\end{array}$ & $\begin{array}{r}9.00 \\
11.50 \\
15.00 \\
20.00 \\
27.00 \\
36.00 \\
48.00 \\
65.00\end{array}$ & $\begin{array}{l}3.8 \\
2.6 \\
2.0 \\
1.6 \\
1.5 \\
1.5 \\
1.2 \\
1.4\end{array}$ & $\begin{array}{l}0.1 \\
0.3 \\
0.4 \\
0.6 \\
0.8 \\
1.0 \\
1.2 \\
1.6\end{array}$ & $\begin{array}{l}2.5 \\
0.77 \\
0.7 \\
0.7 \\
0.4 \\
0.5 \\
0.2 \\
0.2\end{array}$ & $\begin{array}{l}0.7 \\
0.7 \\
0: 9 \\
0: 9 \\
0.9 \\
0.8 \\
0.6 \\
0.5\end{array}$ & $\begin{array}{l}0.0 \\
0: 1 \\
0: 1 \\
0: 0 \\
0: 1 \\
0: \frac{1}{1} \\
0: \frac{1}{1} \\
0.1\end{array}$ & $\begin{array}{l}3.8 \\
3.2 \\
2.6 \\
2: 1 \\
1: 7 \\
1: 4 \\
1.2 \\
1.0\end{array}$ & $\begin{array}{l}2.9 \\
1: 9 \\
\frac{1}{0}: \frac{1}{5} \\
0: 2 \\
0: 0 \\
0: 0 \\
0: 1\end{array}$ & $\begin{array}{l}3.9 \\
3: 8 \\
3.5 \\
3: 2 \\
3: 0 \\
3: 0 \\
3.0 \\
3.0\end{array}$ \\
\hline $\begin{array}{l}0.250 \\
0.250 \\
0.250 \\
0.250 \\
0.250 \\
0.250 \\
0.250 \\
0.250\end{array}$ & $\begin{array}{l}11.50 \\
15.00 \\
20.00 \\
27.00 \\
36.00 \\
48.00 \\
65: 00 \\
90.00\end{array}$ & $\begin{array}{l}2.9 \\
2: 0 \\
1: 7 \\
1: 5 \\
1.5 \\
1.2 \\
1.2 \\
1.6\end{array}$ & $\begin{array}{l}0.1 \\
0: 0 \\
0: 2 \\
0: 3 \\
0: 5 \\
0: 7 \\
0: 9 \\
1.2\end{array}$ & $\begin{array}{l}2.0 \\
0: 09 \\
0: 6 \\
0: 3 \\
0: 5 \\
0.2 \\
0: 1 \\
0.2\end{array}$ & $\begin{array}{l}0.7 \\
0.9 \\
1.00 \\
0.9 \\
0.6 \\
0.7 \\
0.5 \\
0.5\end{array}$ & $\begin{array}{l}0.4 \\
0: 3 \\
0: 3 \\
0: 3 \\
0: 3 \\
0: 3 \\
0: 3 \\
0: 1\end{array}$ & $\begin{array}{l}3: 1 \\
2: 5 \\
2: 1 \\
1: 8 \\
1: 5 \\
1: 3 \\
1=1 \\
1.0\end{array}$ & 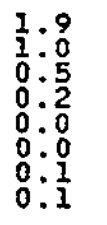 & $\begin{array}{l}4: 0 \\
3: 5 \\
3: 0 \\
2: 0 \\
1: 5 \\
1: 0 \\
1: 0 \\
1: 0\end{array}$ \\
\hline $\begin{array}{l}0.350 \\
0.350 \\
0.350 \\
0.350 \\
0.350 \\
0.350 \\
0.350 \\
0.350\end{array}$ & $\begin{array}{r}15.00 \\
20.00 \\
27.00 \\
36.00 \\
48.00 \\
65.00 \\
90.00 \\
125.00\end{array}$ & $\begin{array}{l}2.6 \\
1.8 \\
1.6 \\
1.4 \\
1.4 \\
1.2 \\
1.2 \\
1.9\end{array}$ & $\begin{array}{l}0.4 \\
0: 3 \\
0: 2 \\
0: \frac{1}{3} \\
0: \frac{1}{2} \\
0: 3 \\
0: 8 \\
0: 9\end{array}$ & $\begin{array}{l}2.3 \\
0: 9 \\
1: 0 \\
0: 4 \\
0: 7 \\
0: 3 \\
0: 2 \\
0.3\end{array}$ & $\begin{array}{l}0.8 \\
0.9 \\
1.0 \\
0: 8 \\
0: 9 \\
0.5 \\
0.4 \\
0.5\end{array}$ & $\begin{array}{l}0.7 \\
0.4 \\
0.4 \\
0: 4 \\
0.4 \\
0.4 \\
0.4 \\
0.3\end{array}$ & $\begin{array}{l}0.8 \\
0: 7 \\
0: 9 \\
0: 9 \\
0: 9 \\
1.0 \\
0: 99 \\
0.9\end{array}$ & $\begin{array}{l}0.7 \\
0.7 \\
0.4 \\
0: 3 \\
0: 3 \\
0.2 \\
0: 2 \\
0.1\end{array}$ & $\begin{array}{l}2: 0 \\
1: 0 \\
\frac{1}{1}: 0 \\
\frac{1}{1}: 0 \\
\frac{1}{1}: 0 \\
\frac{1}{1}: 0 \\
1.0\end{array}$ \\
\hline $\begin{array}{l}0.450 \\
0.450 \\
0.450 \\
0.450 \\
0.450 \\
0.450 \\
0.450 \\
0.450\end{array}$ & $\begin{array}{r}20.00 \\
27.00 \\
36.00 \\
48.00 \\
65.00 \\
90.00 \\
125.00 \\
170.00\end{array}$ & $\begin{array}{l}2.2 \\
\frac{1}{1}: 8 \\
\frac{1}{1}: 5 \\
1: 5 \\
\frac{1}{1}: 2 \\
\frac{1}{3}: 4 \\
3.0\end{array}$ & $\begin{array}{l}0.7 \\
0.6 \\
0: 5 \\
0.3 \\
0.1 \\
0.7 \frac{1}{1} \\
0.4 \\
0.7\end{array}$ & $\begin{array}{l}1.9 \\
2: 0 \\
0: 9 \\
1: 0 \\
0: 4 \\
0: 5 \\
0: 3 \\
0.3\end{array}$ & $\begin{array}{l}1.2 \\
1.2 \\
1.0 \\
0.6 \\
0.6 \\
0.6 \\
0.5 \\
0.6\end{array}$ & $\begin{array}{l}0.8 \\
0.6 \\
0.5 \\
0.6 \\
0.5 \\
0.6 \\
0.5 \\
0.4\end{array}$ & $\begin{array}{l}2.7 \\
1.8 \\
0.9 \\
0.3 \\
0: 1 \\
0.4 \\
0.6 \\
0.7\end{array}$ & $\begin{array}{l}3 \cdot 2 \\
2: 1 \\
1: 5 \\
1: 0 \\
0: 7 \\
0: 5 \\
0: 3 \\
0: 2\end{array}$ & $\begin{array}{l}4.0 \\
3.0 \\
2.0 \\
1.5 \\
1.0 \\
1.0 \\
1.0 \\
1.0\end{array}$ \\
\hline
\end{tabular}


Table $4 d$ (cont'd.)

\begin{tabular}{|c|c|c|c|c|c|c|c|c|c|}
\hline \multicolumn{10}{|c|}{$\begin{array}{c}\text { Values of the Individual Systematic Eriors (\%) on } F 2 \\
\text { Beam Energy }=280 \mathrm{GeV}, \text { Target }^{2}=6 \mathrm{~m} H \mathrm{H} \text { drogen }\end{array}$} \\
\hline$x$ & $\left(G^{Q^{2}} v^{2}\right)$ & 1 & 2 & 3 & 4 & 5 & 6 & 7 & 8 \\
\hline $\begin{array}{l}0: 550 \\
0: 550 \\
0: 550 \\
0: 550 \\
0: 550 \\
0: 550 \\
0: 550\end{array}$ & $\begin{array}{r}27.00 \\
36: 000 \\
48: 00 \\
65000 \\
90000 \\
125000 \\
170.00\end{array}$ & $\begin{array}{l}1 \\
\frac{1}{1}: 7 \\
\frac{1}{3}: 5 \\
\frac{1}{1}: 3 \\
\frac{1}{1}: 2 \\
\frac{1}{1}: 3\end{array}$ & $\begin{array}{l}0.8 \\
0: 8 \\
0: 6 \\
0: 4 \\
0: 3 \\
0: \frac{1}{2} \\
0.2\end{array}$ & $\begin{array}{l}1.4 \\
1: 4 \\
1: 1 \\
0: 7 \\
0: 6 \\
0: 3 \\
0: 3\end{array}$ & $\begin{array}{l}0.9 \\
0.2 \\
0: 7 \\
0: 5 \\
0: 5 \\
0: 5 \\
0.4\end{array}$ & $\begin{array}{l}0.8 \\
0: 7 \\
0: 9 \\
0: 7 \\
0: 9 \\
0.8\end{array}$ & $\begin{array}{l}6.6 \\
4: 4 \\
2: 7 \\
1.6 \\
0: 7 \\
0: 7 \\
0.4\end{array}$ & $\begin{array}{l}6: 1 \\
4: 2 \\
2: 2 \\
1: 6 \\
1: 0 \\
0: 7 \\
0: 5\end{array}$ & $\begin{array}{l}3: 0 \\
2: 0 \\
1: 5 \\
1: 0 \\
1: 0 \\
\frac{1}{1}: 0\end{array}$ \\
\hline $\begin{array}{l}0.650 \\
0.650 \\
0.650 \\
0.650 \\
0.650 \\
0.650\end{array}$ & $\begin{array}{r}36.00 \\
48.00 \\
65.00 \\
90.00 \\
125.00 \\
170.00\end{array}$ & $\begin{array}{l}1: 6 \\
1: 4 \\
1: 2 \\
\frac{1}{1}: 2 \\
\frac{1}{1}: 2 \\
1: 5\end{array}$ & $\begin{array}{l}1.0 \\
0.9 \\
0.8 \\
0.6 \\
0.4 \\
0.2\end{array}$ & $\begin{array}{l}0.9 \\
1: 0 \\
1 \\
0: 4 \\
0: 43 \\
0: 3\end{array}$ & $\begin{array}{l}1: 1 \\
0: 8 \\
0: 6 \\
0: 6 \\
0: 3 \\
0.2\end{array}$ & $\begin{array}{l}1: 0 \\
0: 9 \\
1: 7 \\
\frac{1}{1}: \frac{1}{5} \\
\frac{1}{2}: 1\end{array}$ & $\begin{array}{r}10.8 \\
7.1 \\
4.4 \\
2.7 \\
10.3 \\
0.4\end{array}$ & $\begin{array}{l}9: 3 \\
5: 4 \\
3: 0 \\
2: 1 \\
3: 4 \\
0: 8\end{array}$ & $\begin{array}{r}2.0 \\
1: 0 \\
\frac{1}{1}: 0 \\
\cdot \frac{1}{1}: 0 \\
1: 0\end{array}$ \\
\hline $\begin{array}{l}0.750 \\
0.750 \\
0.750 \\
0.750 \\
0.750\end{array}$ & $\begin{array}{r}48.00 \\
65.00 \\
90.00 \\
125.00 \\
170.00\end{array}$ & $\begin{array}{l}1: 6 \\
3: 2 \\
1: 2 \\
1: 2 \\
1: 5\end{array}$ & $\begin{array}{l}1.1 \\
1.0 \\
0: 9 \\
0: 7 \\
0.5\end{array}$ & $\begin{array}{l}1: 8 \\
0: 5 \\
1: \frac{1}{3} \\
0: 3 \\
0.3\end{array}$ & $\begin{array}{l}0.7 \\
0: 4 \\
0: 2 \\
0: 2 \\
0.2\end{array}$ & $\begin{array}{l}\frac{1}{1}: 5 \\
\frac{1}{1}: 6 \\
\frac{1}{1}: 2 \\
\frac{2}{2}: 6\end{array}$ & $\begin{array}{r}14.3 \\
9: 5 \\
6: 3 \\
3: 9 \\
1.6\end{array}$ & $\begin{array}{l}7.9 \\
5: 5 \\
3: 9 \\
2: 7 \\
1.5\end{array}$ & $\begin{array}{l}1: 0 \\
\frac{1}{1}: 0 \\
\frac{1}{1}: 0 \\
1: 0\end{array}$ \\
\hline
\end{tabular}


rable 5

\begin{tabular}{|c|c|c|c|c|c|c|c|c|c|}
\hline \multicolumn{10}{|c|}{$\begin{array}{l}\text { Values of the Individual systematic Errors }(\%) \text { on } F 2 \\
\text { AlI Energies combined }\end{array}$} \\
\hline$x$ & $\left(G e^{2} v^{2}\right)$ & 1 & 2 & 3 & 4 & 5 & 6 & 7 & 8 \\
\hline $\begin{array}{l}0.030 \\
0.030 \\
0.030 \\
0.030 \\
0.030 \\
0.030\end{array}$ & $\begin{array}{r}3.50 \\
4.50 \\
5.50 \\
7.00 \\
9.00 \\
11.50\end{array}$ & $\begin{array}{l}3 \cdot 3 \\
2 \cdot 3 \\
2 \cdot 3 \\
2 \cdot 3 \\
2 \cdot 8 \\
2 \cdot \frac{1}{2}\end{array}$ & $\begin{array}{l}2.6 \\
2: 9 \\
3: 1 \\
3: 1 \\
2.8 \\
3.1\end{array}$ & $\begin{array}{l}0.2 \\
0.0 \\
0.2 \\
0.0 \\
0.1 \\
0.1\end{array}$ & $\begin{array}{l}3.6 \\
2.7 \\
2.3 \\
2.6 \\
0.8 \\
0.8\end{array}$ & $\begin{array}{l}0.1 \\
0.0 \\
0.1 \\
0.0 \\
0.0 \\
0.1\end{array}$ & $\begin{array}{l}1 \cdot \frac{1}{1} \\
\frac{1}{1}: 0 \\
\frac{1}{1}: \frac{1}{1} \\
\frac{1}{1} \cdot 0\end{array}$ & $\begin{array}{l}0.0 \\
0: 0 \\
0: 1 \\
0: 0 \\
0.00 \\
0.0 .\end{array}$ & $\begin{array}{l}0.0 \\
0.0 \\
0.0 \\
0.0 \\
2.5 \\
2.0\end{array}$ \\
\hline $\begin{array}{l}0.050 \\
0.050 \\
0.050 \\
0.050 \\
0.050 \\
0.050 \\
0.050\end{array}$ & $\begin{array}{r}4.50 \\
5.50 \\
7.00 \\
9.00 \\
11.50 \\
15.00 \\
20.00\end{array}$ & $\begin{array}{l}3.7 \\
2.0 \\
1.3 \\
2.5 \\
\frac{1}{1} \cdot 7 \\
1.8\end{array}$ & $\begin{array}{l}1.5 \\
1.8 \\
2.2 \\
2.2 \\
2.1 \\
2.6 \\
2.9\end{array}$ & $\begin{array}{l}0.5 \\
0.15 \\
0.00 \\
0.2 \\
0.2 \\
0.2 \\
0.2\end{array}$ & $\begin{array}{l}3.9 \\
3: 2 \\
2: 3 \\
1: 6 \\
0: 9 \\
0: 7 \\
0.7\end{array}$ & $\begin{array}{l}0.0 \\
0.0 \\
0.0 \\
0.0 \\
0.0 \\
0.1 \\
0.1\end{array}$ & $\begin{array}{l}1 \cdot 6 \\
\frac{1}{1} \cdot 3 \\
\frac{1}{1} \cdot \frac{1}{4} \\
\frac{1}{1} \cdot \frac{3}{3} \\
\frac{1}{1} \cdot 0\end{array}$ & $\begin{array}{l}0: 2 \\
0: 1 \\
0: 0 \\
0: 1 \\
0: \frac{1}{1} \\
0: 01 \\
0: 0\end{array}$ & $\begin{array}{l}0.0 \\
0.0 \\
0.0 \\
3.3 \\
3.0 \\
2.6 \\
2.5\end{array}$ \\
\hline $\begin{array}{l}0.080 \\
0.080 \\
0.080 \\
0.080 \\
0.080 \\
0.080 \\
0.080 \\
0.080\end{array}$ & $\begin{array}{r}5.50 \\
7.00 \\
91000 \\
1150 \\
15.00 \\
20.00 \\
27.00 \\
36.00\end{array}$ & $\begin{array}{l}3.3 \\
1: 7 \\
11: 3 \\
2: 1 \\
11: 9 \\
1.4 \\
1: 5 \\
2.1\end{array}$ & $\begin{array}{l}1: \frac{1}{3} \\
\frac{1}{1}: 5 \\
\frac{1}{1}: 6 \\
\frac{1}{1}: 6 \\
\frac{1}{2}: 9 \\
2: 5\end{array}$ & $\begin{array}{l}0.3 \\
0: 0 \\
0: 1 \\
0: 3 \\
0.3 \\
0.2 \\
0.2 \\
0.2\end{array}$ & $\begin{array}{l}3: 8 \\
3: 1 \\
2: 1 \\
1: \frac{1}{1} \\
1 \\
0: \frac{1}{7} \\
0: 6 \\
0: 5\end{array}$ & $\begin{array}{l}0: 0 \\
0: 0 \\
0: 0 \\
0: 0 \\
0: 01 \\
0: \frac{1}{1} \\
0: \frac{1}{3} \\
0.3\end{array}$ & 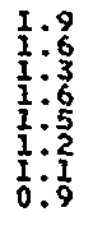 & $\begin{array}{l}0: 4 \\
0: 42 \\
0: \frac{1}{1} \\
0: 4 \\
0: 2 \\
0:: 1 \\
0: 1 \\
0: 0\end{array}$ & $\begin{array}{l}0.0 \\
0: 0 \\
0: 0 \\
3: 0 \\
1: 0 \\
0: 9 \\
1: 0 \\
1.0\end{array}$ \\
\hline $\begin{array}{l}0.125 \\
0.125 \\
0: 125 \\
0.125 \\
0.125 \\
0.125 \\
0.125 \\
0.125\end{array}$ & $\begin{array}{r}7.00 \\
9.00 \\
12: 50 \\
15000 \\
20.00 \\
27.00 \\
36: 00 \\
48.00\end{array}$ & $\begin{array}{l}2.3 \\
1.3 \\
11: 8 \\
11.8 \\
11: 6 \\
11: 3 \\
11.5\end{array}$ & $\begin{array}{l}0.8 \\
0: 9 \\
1: 0 \\
1: 1 \\
1: 2 \\
1: 3 \\
13: 6 \\
2: 0\end{array}$ & $\begin{array}{l}0.9 \\
0: 1 \\
1: 0 \\
0: 2 \\
0: 2 \\
0: 2 \\
0: 2 \\
0.1\end{array}$ & $\begin{array}{l}3: 7 \\
2: 6 \\
1: 9 \\
1: 3 \\
0: 9 \\
0: 7 \\
0: 5 \\
0: 5\end{array}$ & $\begin{array}{l}0.0 \\
0: 0 \\
0: 0 \\
0: 0 \\
0: 1 \\
0: \frac{1}{1} \\
0: \frac{1}{1} \\
0.1\end{array}$ & $\begin{array}{l}2.2 \\
1.8 \\
2: 1 \\
1.9 \\
1.6 \\
11.4 \\
1.2 \\
1.0\end{array}$ & $\begin{array}{l}0.5 \\
0: 3 \\
1: 1 \\
0: 6 \\
0: 2 \\
0: \frac{1}{1} \\
0: 0\end{array}$ & $\begin{array}{l}0.0 \\
0: 0 \\
2: 8 \\
2: 0 \\
1: 0 \\
0: 0 \\
1: 0 \\
1.0\end{array}$ \\
\hline $\begin{array}{l}0.175 \\
0.175 \\
0.175 \\
0.175 \\
0.175 \\
0.175 \\
0.175 \\
0.175 \\
0.175\end{array}$ & $\begin{array}{r}7.00 \\
9.00 \\
11.50 \\
15.00 \\
20.00 \\
27.00 \\
36.00 \\
48.00 \\
65.00\end{array}$ & $\begin{array}{l}2.7 \\
1.7 \\
1.3 \\
1.9 \\
1.7 \\
1.5 \\
1.5 \\
1.4 \\
1.8\end{array}$ & $\begin{array}{l}0.4 \\
0.5 \\
0.7 \\
0.6 \\
0.8 \\
1.0 \\
1.1 \\
1.3 \\
1.7\end{array}$ & $\begin{array}{l}0.6 \\
0.7 \\
0.8 \\
0: 5 \\
0.5 \\
0.4 \\
0.5 \\
0.2 \\
0.2\end{array}$ & $\begin{array}{l}4.0 \\
2.9 \\
2.4 \\
1.5 \\
1: 2 \\
0.8 \\
0.7 \\
0.5 \\
0.5\end{array}$ & $\begin{array}{l}0: 0 \\
0: 0 \\
0: 0 \\
0: \frac{1}{1} \\
0: \frac{1}{1} \\
00: \frac{1}{1} \\
00: \frac{1}{1} \\
0.1\end{array}$ & $\begin{array}{l}2.6 \\
2.2 \\
1.8 \\
2.2 \\
\frac{1}{1} \cdot 9 \\
\frac{1}{1} \cdot 6 \\
1.3 \\
1.0\end{array}$ & $\begin{array}{l}0.6 \\
0.4 \\
0: 3 \\
0: 9 \\
0: 4 \\
0: 2 \\
0: \frac{1}{1} \\
0: \frac{1}{1} \\
0.1\end{array}$ & $\begin{array}{l}0.0 \\
0.0 \\
0.0 \\
3.5 \\
3.1 \\
2.8 \\
2.8 \\
2.8 \\
2.8\end{array}$ \\
\hline $\begin{array}{l}0.250 \\
0.250 \\
0.250 \\
0.250 \\
0.250 \\
0.250 \\
0.250 \\
0.250 \\
0.250 \\
0.250\end{array}$ & $\begin{array}{r}7.00 \\
9: 00 \\
11: 500 \\
15: 00 \\
20.00 \\
27: 00 \\
36: 00 \\
48: 00 \\
65.00 \\
90.00\end{array}$ & $\begin{array}{l}3.7 \\
2.0 \\
1.3 \\
2.0 \\
1.8 \\
1.4 \\
1.5 \\
1.4 \\
1.4 \\
1.6\end{array}$ & $\begin{array}{l}0.0 \\
0.11 \\
0.02 \\
0: 4 \\
0.4 \\
0.5 \\
0.5 \\
0.8 \\
1.0 \\
1.2\end{array}$ & $\begin{array}{l}1: 2 \\
0: 4 \\
0: 1 \\
0: 7 \\
0: 4 \\
0: 2 \\
0: 4 \\
0: \frac{4}{2} \\
0: \frac{1}{2} \\
0.2\end{array}$ & $\begin{array}{l}3.7 \\
3: 3 \\
2.8 \\
1.7 \\
1.3 \\
0: 8 \\
0: 6 \\
0.6 \\
0.4 \\
0.5\end{array}$ & $\begin{array}{l}0: 2 \\
0: 2 \\
0: 3 \\
0: 3 \\
0: 3 \\
0: 3 \\
0: 3 \\
0: 3 \\
0: 3 \\
0.1\end{array}$ & $\begin{array}{l}2.4 \\
2: 1 \\
\frac{1}{2}: 9 \\
2: \frac{1}{1} \\
\frac{1}{1}: 9 \\
\frac{1}{1}: 4 \\
\frac{1}{1}: \frac{2}{1} \\
1.0\end{array}$ & $\begin{array}{l}0.5 \\
0: 3 \\
0: 2 \\
0: 8 \\
0: 4 \\
0: 2 \\
0: \frac{1}{2} \\
0: 2 \\
0: 2 \\
0.1\end{array}$ & $\begin{array}{l}0.0 \\
0: 0 \\
0.0 \\
3: 5 \\
2.8 \\
1.9 \\
1.4 \\
1: 0 \\
1.0 \\
1.0\end{array}$ \\
\hline $\begin{array}{l}0.350 \\
0.350 \\
0.350 \\
0.350\end{array}$ & $\begin{array}{r}9.00 \\
11.50 \\
15.00 \\
20.00\end{array}$ & $\begin{array}{l}2 \cdot 3 \\
\frac{1}{2} \cdot 3 \\
1 \cdot 0\end{array}$ & $\begin{array}{l}0.3 \\
0.2 \\
0.3 \\
0.3\end{array}$ & $\begin{array}{l}1.5 \\
2.4 \\
1.8 \\
0.7\end{array}$ & $\begin{array}{l}\frac{3}{3} \cdot \frac{3}{1} \\
\frac{2}{1} \cdot \frac{1}{3}\end{array}$ & $\begin{array}{l}0.5 \\
0.3 \\
0.6 \\
0.4\end{array}$ & $\begin{array}{l}0.8 \\
0: 9 \\
0.9 \\
0.9\end{array}$ & $\begin{array}{l}0.5 \\
0.54 \\
0.6 \\
0.6\end{array}$ & $\begin{array}{l}0.0 \\
0.0 \\
2.0 \\
1.0\end{array}$ \\
\hline
\end{tabular}


Table 5 (cont'd,

\begin{tabular}{|c|c|c|c|c|c|c|c|c|c|}
\hline \multicolumn{10}{|c|}{$\begin{array}{l}\text { Values of the Individual Systematic Errors (\%) on F2 } \\
\text { A1 } 1 \text { Energies Combined } \text { Target }=6 \mathrm{~m} \text { Hydrogen }\end{array}$} \\
\hline$x$ & $\left(G e^{2} v^{2}\right)$ & 1 & 2 & 3 & 4 & 5 & 6 & 7 & 8 \\
\hline $\begin{array}{l}0.350 \\
0: 350 \\
0: 350 \\
0: 350 \\
0: 350 \\
0.350\end{array}$ & $\begin{array}{r}27.00 \\
36.00 \\
48.00 \\
65000 \\
90.00 \\
125.00\end{array}$ & $\begin{array}{l}\frac{1}{3}: 5 \\
\frac{1}{1}: \frac{4}{4} \\
\frac{1}{3}: 6 \\
\frac{1}{1}: 5 \\
1: 9\end{array}$ & $\begin{array}{l}0: 2 \\
0: 2 \\
0: 3 \\
0: 4 \\
0: 7 \\
0.9\end{array}$ & $\begin{array}{l}0.8 \\
0: 3 \\
0: 8 \\
0: 3 \\
0: 3 \\
0.3\end{array}$ & $\begin{array}{l}1.0 \\
0: 7 \\
0: 6 \\
0: 4 \\
0: 4 \\
0.5\end{array}$ & $\begin{array}{l}0.4 \\
0: 4 \\
0: 3 \\
0: 4 \\
0: 4 \\
0.3\end{array}$ & $\begin{array}{l}0.9 \\
0: 9 \\
0: 9 \\
0: 0 \\
0: 9\end{array}$ & $\begin{array}{l}0: 4 \\
0: 4 \\
0: 3 \\
0: 3 \\
0: 3 \\
0.1\end{array}$ & $\begin{array}{l}1.0 \\
0: 9 \\
0: 9 \\
\frac{1}{1}: 0 \\
1: 0\end{array}$ \\
\hline $\begin{array}{l}0.450 \\
0: 450 \\
0: 450 \\
0: 450 \\
0: 450 \\
0.450 \\
0: 450 \\
0: 450 \\
0.450\end{array}$ & $\begin{array}{r}11.50 \\
15000 \\
20000 \\
27.00 \\
36.00 \\
48.00 \\
65000 \\
90000 \\
125.00\end{array}$ & $\begin{array}{l}\frac{1}{1}: 7 \\
\frac{1}{1}: 6 \\
\frac{1}{1}: 6 \\
\frac{1}{1}: 4 \\
1: 5 \\
\frac{1}{1}: 4 \\
\frac{1}{3}: 3 \\
1.6\end{array}$ & $\begin{array}{l}0.5 \\
0: 5 \\
0: 5 \\
0: 5 \\
0: 5 \\
0: 3 \\
0: \frac{1}{2} \\
0: \frac{2}{2} \\
0: 4\end{array}$ & $\begin{array}{l}1: 7 \\
0: 8 \\
1: 8 \\
1: 5 \\
0: 7 \\
0: 9 \\
0: 4 \\
0: 5 \\
0: 3\end{array}$ & $\begin{array}{l}2.8 \\
1: 7 \\
1: 7 \\
1: 2 \\
0: 9 \\
0: 6 \\
0: 5 \\
0: 5 \\
0.5\end{array}$ & $\begin{array}{l}0: 7 \\
0: 5 \\
0: 7 \\
0: 6 \\
0: 5 \\
0: 6 \\
0: 5 \\
0: 6 \\
0: 5\end{array}$ & $\begin{array}{l}1: 2 \\
0: 8 \\
0: 4 \\
1: 4 \\
0: 7 \\
0: 3 \\
0: 3 \\
0: 5 \\
0: 6\end{array}$ & $\begin{array}{l}1: 6 \\
\frac{1}{1}: 4 \\
\frac{1}{3}: 6 \\
\frac{1}{1}: 6 \\
\frac{1}{1}: 0 \\
0: 7 \\
0: 6 \\
0: 4\end{array}$ & $\begin{array}{l}0.0 \\
0: 0 \\
0: 0 \\
2: 8 \\
.1: 9 \\
1: 5 \\
1: 0 \\
1: 0 \\
1: 0 \\
1.0\end{array}$ \\
\hline $\begin{array}{l}0.550 \\
0: 550 \\
0: 550 \\
0: 550 \\
0: 550 \\
0: 550 \\
0: 550 \\
0: 550 \\
0: 550 \\
0.550\end{array}$ & $\begin{array}{r}11: 50 \\
15: 00 \\
20000 \\
27: 00 \\
36: 00 \\
48: 00 \\
65000 \\
190000 \\
125000 \\
170: 00\end{array}$ & $\begin{array}{l}2: 3 \\
\frac{1}{3}: 3 \\
\frac{1}{3}: 0 \\
\frac{1}{1}: 3 \\
1: 3 \\
\frac{1}{1}: 5 \\
\frac{1}{1}: 5 \\
\frac{1}{1}: 4 \\
1: 9\end{array}$ & $\begin{array}{l}0.7 \\
0: 7 \\
0: 6 \\
0: 6 \\
0: 6 \\
0: 6 \\
0: 4 \\
0: 3 \\
0: \frac{1}{2} \\
0.2\end{array}$ & $\begin{array}{l}2: 3 \\
1: 2 \\
0: 7 \\
0: 7 \\
0: 5 \\
1: 0 \\
0: 6 \\
0: 5 \\
0: 3 \\
0: 3\end{array}$ & $\begin{array}{l}3.0 \\
1: 9 \\
2: 2 \\
1: 2 \\
0: 9 \\
0: 7 \\
0: 5 \\
0: 4 \\
0: 5 \\
0: 4\end{array}$ & $\begin{array}{l}1: 2 \\
0: 6 \\
0: 6 \\
0: 7 \\
0: 8 \\
0: 9 \\
0: 7 \\
0: 8 \\
0: 8 \\
0: 7\end{array}$ & $\begin{array}{l}3: 9 \\
3: 2 \\
2: 4 \\
3: 4 \\
2: 9 \\
2: 5 \\
1: 4 \\
0: 6 \\
0: 2 \\
0: 4\end{array}$ & $\begin{array}{l}3: 1 \\
2: 8 \\
2: 4 \\
2: 8 \\
2: 5 \\
2: 1 \\
1: 5 \\
1: 1 \\
0: 8 \\
0: 5\end{array}$ & 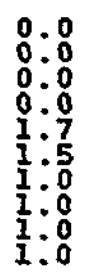 \\
\hline $\begin{array}{l}0.650 \\
0.650 \\
0.650 \\
0.650 \\
0.650 \\
0.650 \\
0.650 \\
0.650\end{array}$ & $\begin{array}{r}20.00 \\
27.00 \\
36.00 \\
48.00 \\
65.00 \\
90.00 \\
125.00 \\
170.00\end{array}$ & $\begin{array}{l}1: 3 \\
\frac{1}{1}: 3 \\
1: 3 \\
\frac{1}{1}: 7 \\
\frac{1}{1}: 6 \\
\frac{1}{1}: 4 \\
1: 5\end{array}$ & $\begin{array}{l}0.8 \\
0: 7 \\
0: 6 \\
0: 5 \\
0: 6 \\
0: 6 \\
0: 4 \\
0.2\end{array}$ & $\begin{array}{l}0.5 \\
0: 7 \\
0: 2 \\
0: 4 \\
0: 6 \\
0: 4 \\
0: 3 \\
0.3\end{array}$ & $\begin{array}{l}1: 8 \\
\frac{1}{3}: 4 \\
1: \frac{1}{1} \\
0: 8 \\
0: 4 \\
0: 53 \\
0: 2\end{array}$ & $\begin{array}{l}0.7 \\
0: 9 \\
1: 2 \\
0: 8 \\
1: 0 \\
1: 0 \\
1 \\
2: 1\end{array}$ & $\begin{array}{l}5: 1 \\
4: 0 \\
2: 8 \\
1: 6 \\
2: 9 \\
2: 4 \\
1: 2 \\
0: 4\end{array}$ & $\begin{array}{l}3: 9 \\
3: 4 \\
2: 9 \\
2: 3 \\
2: 7 \\
2: 1 \\
1: 5 \\
0.8\end{array}$ & $\begin{array}{l}0.0 \\
0: 0 \\
0: 0 \\
0: 0 \\
1: 0 \\
\frac{1}{1}: 0 \\
\frac{1}{3}: 0 \\
: 0\end{array}$ \\
\hline $\begin{array}{l}0.750 \\
0: 750 \\
0: 750 \\
0: 750 \\
0: 750 \\
0: 750 \\
0.750\end{array}$ & $\begin{array}{r}27: 00 \\
36: 00 \\
48000 \\
65000 \\
90000 \\
125000 \\
170: 00\end{array}$ & $\begin{array}{l}\frac{1}{1}: 3 \\
\frac{3}{1}: 3 \\
2: 7 \\
\frac{1}{3}: 9 \\
\frac{3}{1}: 5 \\
1: 5\end{array}$ & $\begin{array}{l}0.9 \\
0: 9 \\
0: 8 \\
0: 6 \\
0: 8 \\
0: 7 \\
0: 5\end{array}$ & $\begin{array}{l}0.6 \\
0: 7 \\
1: 5 \\
0: 5 \\
0: 8 \\
0: 2 \\
0.3\end{array}$ & $\begin{array}{l}1: 0 \\
0: 9 \\
1: 0 \\
1: 0 \\
0: 4 \\
0: 2 \\
0: 2\end{array}$ & $\begin{array}{l}\frac{1}{1}: \frac{2}{3} \\
\frac{1}{3}: 4 \\
\frac{1}{4}: 5 \\
\frac{1}{1}: 6 \\
\frac{1}{2}: 6\end{array}$ & $\begin{array}{l}7: 0 \\
5: 6 \\
3: 9 \\
2: 5 \\
3: 6 \\
3: 1 \\
1: 6\end{array}$ & $\begin{array}{l}5: 2 \\
4: 6 \\
3: 8 \\
3: 2 \\
2: 7 \\
3: 0 \\
1: 5\end{array}$ & $\begin{array}{l}0.0 \\
0: 0 \\
0: 0 \\
0: 0 \\
0: 0 \\
1: 1 \\
1: 0\end{array}$ \\
\hline
\end{tabular}


Table 6

Requirements for an $\left(x_{2} Q^{2}\right)$ bin to be Accepted into the Final Data Sample

\begin{tabular}{|c|c|c|}
\hline Condition & Requireme & ent \\
\hline $\begin{array}{l}\text { Final acceptance for a bin after } \\
\text { all cuts }\end{array}$ & $>15 \%$ & $\therefore$ \\
\hline Radiative corrections in the bin & $<25 \%$ & \\
\hline $\begin{array}{l}\text { Correction for smearing of events } \\
\text { in and out of the bin }\end{array}$ & $<15 \%$ & \\
\hline $\begin{array}{l}\text { Correction for the inability to } \\
\text { reconstruct tracks due to detector } \\
\text { inefficiencies }\end{array}$ & $<20 \%$ & \\
\hline $\begin{array}{l}\text { Correction for the centring of } F_{2} \text { at } \\
\text { the bin centre from the mean } x \text { and } Q^{2} \\
\text { of the bin }\end{array}$ & $<15 \%$ & \\
\hline$y=v / E$ at bin centre & $\leqq 0.95$ & \\
\hline
\end{tabular}


Table 7

Summary of Hydrogen Data Entering the

Einal E Sample

\begin{tabular}{|cccc|}
\hline Period Muon FIux $\times 10^{-12}$ & $\begin{array}{c}\text { Number of Events } \\
\text { in } \mathrm{F}_{2} \text { Sample }\end{array}$ & $\begin{array}{c}\text { Total Events for } \\
\text { each Energy }\end{array}$ \\
\hline H120-1 & 2.60 & 100,000 & $\cdots 100,000$ \\
& & & \\
H200-1 & 2.78 & 57,000 & 72,000 \\
H200-2 & 4.32 & 15,100 & \\
& & & 55,700 \\
H240-1 & 3.01 & 35,800 & \\
H240-2 & 3.16 & 19,900 & \\
& & & \\
H280-1 & 0.56 & 12,900 & \\
H280-2 & 1.04 & 24,300 & \\
H280-3 & 2.08 & 53,000 & \\
H280-4 & 2.18 & 45,600 & \\
H280-5 & 1.90 & 14,500 & \\
H280-6 & 2.00 & 13,000 & \\
H280-7 & 3.77 & 19,400 & \\
& & & \\
\hline
\end{tabular}




\section{Table 8}

The Relative Normalisation between the Datasets at each Energy

\begin{tabular}{|cc|}
\hline Energy (GeV) & $\begin{array}{c}\text { Normalisation } \\
\text { factor }\end{array}$ \\
\hline 120 & $\cdots$ \\
200 & 1.001 \\
240 & 0.969 \\
280 & 1.013 \\
\end{tabular}


Table 9 a

\begin{tabular}{|c|c|c|c|c|}
\hline \multicolumn{5}{|c|}{ 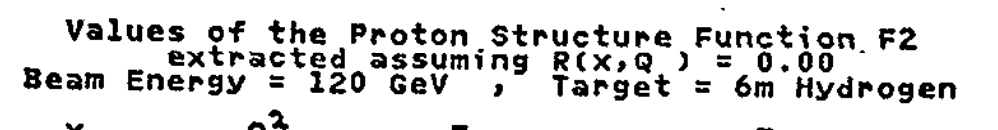 } \\
\hline $\begin{array}{l}0.030 \\
0.030 \\
0.030\end{array}$ & $\begin{array}{l}3.50 \\
4: 50 \\
5.50\end{array}$ & $\begin{array}{l}0.3039 \\
0.3092 \\
0.3313\end{array}$ & $\begin{array}{l}0.0050 \\
0.0055 \\
0.0072\end{array}$ & $\begin{array}{l}0.0172 \\
0.01145 \\
0.0153\end{array}$ \\
\hline $\begin{array}{l}0.050 \\
0: 050 \\
0: 050 \\
0.050\end{array}$ & $\begin{array}{l}4.50 \\
5: 50 \\
7: 00 \\
9: 00\end{array}$ & $\begin{array}{l}0.3090 \\
0: 3.149 \\
0: 3447 \\
0.3462\end{array}$ & $\begin{array}{l}0.0089 \\
0: 0074 \\
0: 8058 \\
0.0094\end{array}$ & $\begin{array}{l}0.0180 \\
0: 0138 \\
0.0124 \\
0.0137\end{array}$ \\
\hline $\begin{array}{l}0.080 \\
0.080 \\
0.080 \\
0.080 \\
0.080\end{array}$ & $\begin{array}{r}5.50 \\
7.00 \\
11.00 \\
15.50 \\
15.00\end{array}$ & $\begin{array}{l}0.3359 \\
0: 3402 \\
0.3412 \\
0: 3553 \\
0.3663\end{array}$ & $\begin{array}{l}0.0078 \\
0.0060 \\
0.0063 \\
0.0069 \\
0.0121\end{array}$ & $\begin{array}{l}0.0185 \\
0.0139 \\
0.0108 \\
0.0102 \\
0.0138\end{array}$ \\
\hline $\begin{array}{l}0.125 \\
0: 125 \\
0: 125 \\
0: 125 \\
0: 125\end{array}$ & $\begin{array}{r}7.00 \\
9.00 \\
1150 \\
15000 \\
20.00\end{array}$ & $\begin{array}{l}0.3355 \\
0.3323 \\
0: 3402 \\
0.3291 \\
0.3533\end{array}$ & $\begin{array}{l}0.0066 \\
0.0076 \\
0.0070 \\
0.0077 \\
0.0110\end{array}$ & $\begin{array}{l}0.0169 \\
0.0118 \\
0.0105 \\
0.0087 \\
0.0107\end{array}$ \\
\hline $\begin{array}{l}0.175 \\
0: 175 \\
0: 175 \\
0: 175 \\
0: 175 \\
0.175\end{array}$ & $\begin{array}{r}7.00 \\
9: 00 \\
115000 \\
15000 \\
20: 00 \\
27.00\end{array}$ & $\begin{array}{l}0.3032 \\
0: 3144 \\
0: 3229 \\
0: 3282 \\
0: 3347 \\
0.3017\end{array}$ & $\begin{array}{l}0.0082 \\
0: 0082 \\
0.0074 \\
0.0089 \\
0: 0102 \\
0.0145\end{array}$ & $\begin{array}{l}0.0169 \\
0.0130 \\
0.0111 \\
0.0086 \\
0.0079 \\
0.0083\end{array}$ \\
\hline $\begin{array}{l}0.250 \\
0.250 \\
0.250 \\
0.250 \\
0.250 \\
0.250 \\
0.250 \\
0.250\end{array}$ & $\begin{array}{r}7.00 \\
9: 00 \\
11.50 \\
15000 \\
20.00 \\
27.000 \\
36.00 \\
48.00\end{array}$ & $\begin{array}{l}0.2996 \\
0.2880 \\
0.2972 \\
0.2739 \\
0.2814 \\
0.2845 \\
0.2530 \\
0.2367\end{array}$ & $\begin{array}{l}0.0077 \\
0.0069 \\
0.0062 \\
0.0068 \\
0.0072 \\
0.0095 \\
0.00139 \\
0.0331\end{array}$ & $\begin{array}{l}0.0177 \\
0.0128 \\
0.0108 \\
0.0080 \\
0.0063 \\
0.0060 \\
0.0064 \\
0.0165\end{array}$ \\
\hline $\begin{array}{l}0.350 \\
0: 350 \\
0: 350 \\
0: 350 \\
0: 350 \\
0: 350 \\
0: 350\end{array}$ & $\begin{array}{rl}9 & 00 \\
11: 50 \\
15 & 00 \\
20 & 00 \\
27 & 00 \\
36: 00 \\
48: 00\end{array}$ & $\begin{array}{l}0.2163 \\
0: 2264 \\
0: 2132 \\
0: 2052 \\
0: 2056 \\
0: 2033 \\
0.1959\end{array}$ & $\begin{array}{l}0.0076 \\
0: 0006 \\
0: 0072 \\
0: 0072 \\
0: 0088 \\
0: 0118 \\
0.01772\end{array}$ & $\begin{array}{l}0.0096 \\
0: 0096 \\
0: 0063 \\
0: 0044 \\
0: 0044 \\
000045 \\
0.0052\end{array}$ \\
\hline $\begin{array}{l}8.450 \\
0: 450 \\
0: 450 \\
0: 450 \\
0: 450 \\
0: 450 \\
0.450\end{array}$ & $\begin{array}{l}115: 50 \\
15: 00 \\
20: 00 \\
27: 00 \\
36: 00 \\
48: 00 \\
65: 00\end{array}$ & $\begin{array}{l}0.1392 \\
0: 1446 \\
0: 11514 \\
0: 1385 \\
0: 11512 \\
0: 1275 \\
0.1618\end{array}$ & $\begin{array}{l}0.0060 \\
0: 0068 \\
0: 0071 \\
000078 \\
0: 0108 \\
0: 0131 \\
0.0268\end{array}$ & $\begin{array}{l}0.0060 \\
000041 \\
0: 0049 \\
000030 \\
0: 0030 \\
0000031 \\
0.0063\end{array}$ \\
\hline $\begin{array}{l}0.550 \\
0: 550 \\
0: 550 \\
0: 550 \\
0: 550 \\
0: 550 \\
0.550\end{array}$ & $\begin{array}{l}11.50 \\
15: 000 \\
20: 00 \\
27000 \\
36: 000 \\
48000 \\
65: 00\end{array}$ & $\begin{array}{l}0.0935 \\
0: 0861 \\
0: 0731 \\
000744 \\
0: 0759 \\
0: 0650 \\
0.0826\end{array}$ & $\begin{array}{l}0.0060 \\
0: 0058 \\
000052 \\
0: 0062 \\
0: 0081 \\
0: 0098 \\
0.0173\end{array}$ & $\begin{array}{l}0.0064 \\
0: 0044 \\
0: 0032 \\
000024 \\
0.0020 \\
0.0017 \\
0.0025\end{array}$ \\
\hline $\begin{array}{l}0.650 \\
0.650 \\
0: 650 \\
0.650 \\
0.650\end{array}$ & $\begin{array}{l}20.00 \\
27: 00 \\
36: 00 \\
48: 00 \\
65: 00\end{array}$ & $\begin{array}{l}0.0434 \\
0.0371 \\
0.0438 \\
0.0343 \\
0.0469\end{array}$ & $\begin{array}{l}0.0042 \\
0.0046 \\
0.0064 \\
0.0072 \\
0.0126\end{array}$ & $\begin{array}{l}0.0030 \\
0.0021 \\
0.0020 \\
0.0012 \\
0.0016\end{array}$ \\
\hline $\begin{array}{l}0.750 \\
0: 750 \\
0: 750 \\
0.750\end{array}$ & $\begin{array}{l}27.00 \\
36: 00 \\
48: 00 \\
65: 00\end{array}$ & $\begin{array}{l}0.0198 \\
0.0127 \\
0.0190 \\
0.0108\end{array}$ & $\begin{array}{l}0.0035 \\
0: 0036 \\
0: 0055 \\
0.0062\end{array}$ & $\begin{array}{l}0.0018 \\
0: 0018 \\
0: 0012 \\
0: 0005\end{array}$ \\
\hline
\end{tabular}


Table 9 b

\begin{tabular}{|c|c|c|c|c|c|}
\hline \multicolumn{6}{|c|}{ 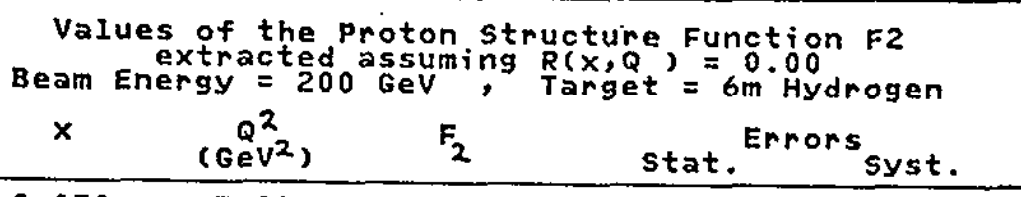 } \\
\hline $\begin{array}{l}0.030 \\
0.030\end{array}$ & $\begin{array}{l}7.00 \\
9.00\end{array}$ & 0.31133 & $\begin{array}{l}0.0055 \\
0.0077\end{array}$ & 0.0157 & \\
\hline $\begin{array}{l}0.050 \\
0.050 \\
0.050\end{array}$ & $\begin{array}{r}9.00 \\
11.50 \\
15.00\end{array}$ & $\begin{array}{l}0.3325 \\
0.3372 \\
0.3578\end{array}$ & $\begin{array}{l}0.0095 \\
0.0073 \\
0.0097\end{array}$ & $\begin{array}{l}0.0134 \\
0.0108 \\
0.0140\end{array}$ & \\
\hline $\begin{array}{l}0.080 \\
0.080 \\
0.080 \\
0.080 \\
0.080\end{array}$ & $\begin{array}{r}9.00 \\
11.50 \\
15.00 \\
20.00 \\
27.00\end{array}$ & $\begin{array}{l}0.3365 \\
0: 3291 \\
0.3617 \\
0.3425 \\
0.3618\end{array}$ & $\begin{array}{l}0.0126 \\
0.0077 \\
0.0073 \\
0.0075 \\
0.0112\end{array}$ & $\begin{array}{l}0.0252 \\
0.0124 \\
0: 0099 \\
0.0097 \\
0.0176\end{array}$ & \\
\hline $\begin{array}{l}0.125 \\
0.125 \\
0.125 \\
0: 125 \\
0: 125\end{array}$ & $\begin{array}{l}11.50 \\
15.00 \\
20.00 \\
27.00 \\
36.00\end{array}$ & $\begin{array}{l}0.3360 \\
0.3207 \\
0.3250 \\
0.3372 \\
0.3022\end{array}$ & $\begin{array}{l}0.0114 \\
0.0086 \\
0.0077 \\
0.0090 \\
0.0137\end{array}$ & $\begin{array}{l}0.0167 \\
0.0105 \\
0.0080 \\
0.0078 \\
0.0095\end{array}$ & \\
\hline 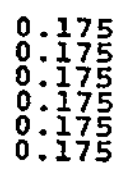 & $\begin{array}{l}11.50 \\
15.00 \\
20000 \\
27.00 \\
36: 00 \\
48.00\end{array}$ & $\begin{array}{l}0.2926 \\
0: 3061 \\
0: 3306 \\
0: 3242 \\
0: 2994 \\
0.3002\end{array}$ & $\begin{array}{l}0.0144 \\
0.0105 \\
0.0098 \\
0.0103 \\
0.0120 \\
0.0175\end{array}$ & $\begin{array}{l}0.0189 \\
0.0109 \\
0.0088 \\
0.0070 \\
0.0064 \\
0.0085\end{array}$ & \\
\hline $\begin{array}{l}0.250 \\
0.250 \\
0.250 \\
0.250 \\
0.250 \\
0.250 \\
0.250\end{array}$ & $\begin{array}{l}11.50 \\
15.00 \\
200.00 \\
27.00 \\
36.00 \\
48.00 \\
65.00\end{array}$ & $\begin{array}{l}0.2581 \\
0.2688 \\
0.2733 \\
0.2912 \\
0.2581 \\
0.2545 \\
0.2529\end{array}$ & $\begin{array}{l}0.0124 \\
0.0090 \\
0.0075 \\
0.0081 \\
0.0089 \\
0.0077 \\
0.0161\end{array}$ & $\begin{array}{l}0.0199 \\
0.0105 \\
0.0073 \\
0.0061 \\
0.0050 \\
0.00558 \\
0.0069\end{array}$ & \\
\hline $\begin{array}{l}0.350 \\
0.350 \\
0.350 \\
0.350 \\
0.350 \\
0.350 \\
0.350\end{array}$ & $\begin{array}{l}15.00 \\
20: 00 \\
27.00 \\
36.00 \\
48.00 \\
65.00 \\
90.00\end{array}$ & $\begin{array}{l}0.2265 \\
0.2246 \\
0: 2201 \\
0.2050 \\
0.1251 \\
0.1997 \\
0.2052\end{array}$ & $\begin{array}{l}0.0112 \\
0.0086 \\
0.0084 \\
0.0092 \\
0.0076 \\
0.0095 \\
0.0210\end{array}$ & $\begin{array}{l}0.0091 \\
0.0054 \\
0.0041 \\
0.0033 \\
0.0044 \\
0.0043 \\
0.0058\end{array}$ & \\
\hline $\begin{array}{l}0.450 \\
0.450 \\
0.450 \\
0.450 \\
0.450 \\
0.450 \\
0.450\end{array}$ & $\begin{array}{l}15.00 \\
20.00 \\
27.00 \\
36.00 \\
48.00 \\
65.00 \\
90.00\end{array}$ & $\begin{array}{l}0.1738 \\
0: 1546 \\
0.1728 \\
0.1414 \\
0.1242 \\
0.1287 \\
0.1209\end{array}$ & $\begin{array}{l}0.0121 \\
0.0082 \\
0.0089 \\
0.0087 \\
0.0089 \\
0.0081 \\
0.0152\end{array}$ & $\begin{array}{l}0.0094 \\
0.0058 \\
0.0047 \\
0.0027 \\
0.0021 \\
0.0025 \\
0.0025\end{array}$ & \\
\hline $\begin{array}{l}0.550 \\
0.550 \\
0.550 \\
0.550 \\
0.550\end{array}$ & $\begin{array}{l}27.00 \\
36.00 \\
48.00 \\
65.00 \\
90.00\end{array}$ & $\begin{array}{l}0.0894 \\
0.0892 \\
0.0867 \\
0.0707 \\
0.0469\end{array}$ & $\begin{array}{l}0.0067 \\
0.0074 \\
0.0083 \\
0.0065 \\
0.0064\end{array}$ & $\begin{array}{l}0.0051 \\
0.0038 \\
0.0026 \\
0.0017 \\
0.0011\end{array}$ & \\
\hline $\begin{array}{l}0.650 \\
0.650 \\
0.650 \\
0.650 \\
0.650\end{array}$ & $\begin{array}{r}36.00 \\
48.00 \\
65.00 \\
90.00 \\
125.00\end{array}$ & $\begin{array}{l}0.0458 \\
0.0335 \\
0.0352 \\
0.0372 \\
0.0418\end{array}$ & $\begin{array}{l}0.0057 \\
0.0057 \\
0.0048 \\
0.0060 \\
0.0121\end{array}$ & $\begin{array}{l}0.0040 \\
0.0021 \\
0.0015 \\
0.0011 \\
0.0013\end{array}$ & \\
\hline $\begin{array}{l}0.750 \\
0.750 \\
0.750\end{array}$ & $\begin{array}{r}65.00 \\
90.00 \\
125.00\end{array}$ & $\begin{array}{l}0.0144 \\
0.0115 \\
0.0160\end{array}$ & $\begin{array}{l}0.0032 \\
0.0046 \\
0.0062\end{array}$ & $\begin{array}{l}0.0010 \\
0.0006 \\
0.0005\end{array}$ & \\
\hline
\end{tabular}


Table $9 \mathrm{c}$

\begin{tabular}{|c|c|c|c|c|}
\hline \multicolumn{2}{|c|}{$\begin{array}{l}\text { Values of the P } \\
\text { extracted } \\
\text { Beam Energy }=240 \\
\times \quad Q^{2} \\
\left(\mathrm{GeV}^{2}\right)\end{array}$} & \multicolumn{3}{|c|}{$\begin{array}{c}\text { roton structure Function F2 } \\
\text { assuming R(X,Q })=0.00 \\
\text { GeV },=6 \text { Target }=6 \mathrm{~m} \text { Hydrogen } \\
F_{2}\end{array}$} \\
\hline $\begin{array}{l}0.030 \\
0.030\end{array}$ & $\begin{array}{r}9.00 \\
11.50\end{array}$ & $\begin{array}{l}0.3486 \\
0.4042\end{array}$ & $\begin{array}{l}0.0088 \\
0.0105\end{array}$ & $\begin{array}{l}0.0202 \\
0.0216\end{array}$ \\
\hline $\begin{array}{l}0.050 \\
0.050 \\
0.050\end{array}$ & $\begin{array}{l}11.50 \\
15: 00 \\
20.00\end{array}$ & $\begin{array}{l}0.3235 \\
0: 3723 \\
0.3736\end{array}$ & $\begin{array}{l}0.0107 \\
0.0094 \\
0.0133\end{array}$ & $\begin{array}{l}0.0170 \\
0.0149 \\
0.0179\end{array}$ \\
\hline $\begin{array}{l}0.080 \\
0.080 \\
0.080\end{array}$ & $\begin{array}{l}15.00 \\
20.00 \\
27.00\end{array}$ & $\begin{array}{l}0.3157 \\
0.3493 \\
0.3933\end{array}$ & $\begin{array}{l}0.0091 \\
0.0079 \\
0.0107\end{array}$ & $\begin{array}{l}0.0119 \\
0.0097 \\
0.0128\end{array}$ \\
\hline $\begin{array}{l}0.125 \\
0: 125 \\
0: 125 \\
0.125 \\
0.125\end{array}$ & $\begin{array}{l}15.00 \\
20.00 \\
27.00 \\
36.00 \\
48.00\end{array}$ & $\begin{array}{l}0.3079 \\
0.3130 \\
0.3255 \\
0.3659 \\
0.3795\end{array}$ & $\begin{array}{l}0.0137 \\
0.0097 \\
0.0092 \\
0.0090 \\
0.0153\end{array}$ & $\begin{array}{l}0.0167 \\
0.0099 \\
0.0077 \\
0.0101 \\
0.0148\end{array}$ \\
\hline $\begin{array}{l}0.175 \\
0: 175 \\
0: 175 \\
0.175 \\
0.175\end{array}$ & $\begin{array}{l}20.00 \\
27.00 \\
36.00 \\
48.00 \\
65.00\end{array}$ & $\begin{array}{l}0.2908 \\
0: 2871 \\
0: 3063 \\
0: 3285 \\
0.2900\end{array}$ & $\begin{array}{l}0.0121 \\
0.0105 \\
0.0095 \\
0.0113 \\
0.0165\end{array}$ & $\begin{array}{l}0.0129 \\
0.0098 \\
0.0102 \\
0.0106 \\
0.0113\end{array}$ \\
\hline $\begin{array}{l}0.250 \\
0.250 \\
0.250 \\
0.250 \\
0.250 \\
0.250\end{array}$ & $\begin{array}{l}20.00 \\
27.00 \\
36.00 \\
48.00 \\
65.00 \\
90.00\end{array}$ & $\begin{array}{l}0.2580 \\
0.2736 \\
0.2871 \\
0.2807 \\
0.2592 \\
0.3154\end{array}$ & $\begin{array}{l}0.0106 \\
0.0094 \\
0.0102 \\
0.0085 \\
0.0094 \\
0.0181\end{array}$ & $\begin{array}{l}0.0113 \\
0.0080 \\
0.0068 \\
0.0063 \\
0.0059 \\
0.0113\end{array}$ \\
\hline $\begin{array}{l}0 \cdot 350 \\
0: 350 \\
0: 350 \\
0: 350 \\
0: 350 \\
0: 350 \\
0.350\end{array}$ & $\begin{array}{r}20.00 \\
27.00 \\
36.00 \\
48.00 \\
65.00 \\
90.00 \\
125.00\end{array}$ & $\begin{array}{l}0.1993 \\
0.2181 \\
0: 1961 \\
0: 2091 \\
0.2081 \\
0.1929 \\
0.2213\end{array}$ & $\begin{array}{l}0.0122 \\
0.0100 \\
0.0097 \\
0.0086 \\
0.0098 \\
0.0113 \\
0.0235\end{array}$ & $\begin{array}{l}0.0083 \\
0.0050 \\
0.0038 \\
0.0042 \\
0.0043 \\
0.0042 \\
0.0087\end{array}$ \\
\hline $\begin{array}{l}0.450 \\
0.450 \\
0.450 \\
0.450 \\
0.450 \\
0.450 \\
0.450\end{array}$ & $\begin{array}{r}20.00 \\
27.00 \\
36.00 \\
48.00 \\
65.00 \\
90.00 \\
125.00\end{array}$ & $\begin{array}{l}0.1377 \\
0: 1586 \\
0: 1465 \\
0: 1409 \\
0: 1434 \\
0: 1187 \\
0.1129\end{array}$ & $\begin{array}{l}0.0116 \\
0.0108 \\
0.0101 \\
0.0078 \\
0.0090 \\
0.0091 \\
0.0132\end{array}$ & $\begin{array}{l}0.0080 \\
0.0066 \\
0.0041 \\
0.0035 \\
0.0029 \\
0.0023 \\
0.0027\end{array}$ \\
\hline $\begin{array}{l}0.550 \\
0.550 \\
0 \cdot 550 \\
0.550 \\
0.550 \\
0.550\end{array}$ & $\begin{array}{r}27.00 \\
36.00 \\
48.00 \\
65.00 \\
90.00 \\
125.00\end{array}$ & $\begin{array}{l}0.1024 \\
0.0864 \\
0.0909 \\
0.0734 \\
0.0644 \\
0.0411\end{array}$ & $\begin{array}{l}0.0098 \\
0.0084 \\
0.0091 \\
0.0068 \\
0.0073 \\
0.0083\end{array}$ & $\begin{array}{l}0.0080 \\
0.0046 \\
0.0035 \\
0.0020 \\
0.0015 \\
0.0009\end{array}$ \\
\hline $\begin{array}{l}0.650 \\
0.650 \\
0.650 \\
0.650\end{array}$ & $\begin{array}{r}48.00 \\
65.00 \\
90.00 \\
125.00\end{array}$ & $\begin{array}{l}0.0473 \\
0.0347 \\
0.0515 \\
0.0303\end{array}$ & $\begin{array}{l}0.0077 \\
0.0052 \\
0.0072 \\
0.0071\end{array}$ & $\begin{array}{l}0.0036 \\
0.0017 \\
0.0018 \\
0.0009\end{array}$ \\
\hline $\begin{array}{l}0.750 \\
0.750\end{array}$ & $\begin{array}{r}90.00 \\
125.00\end{array}$ & 0.0223 & $\begin{array}{l}0.0038 \\
0.0025\end{array}$ & $\begin{array}{l}0.0008 \\
0.0002\end{array}$ \\
\hline
\end{tabular}


Table $9 \mathrm{~d}$

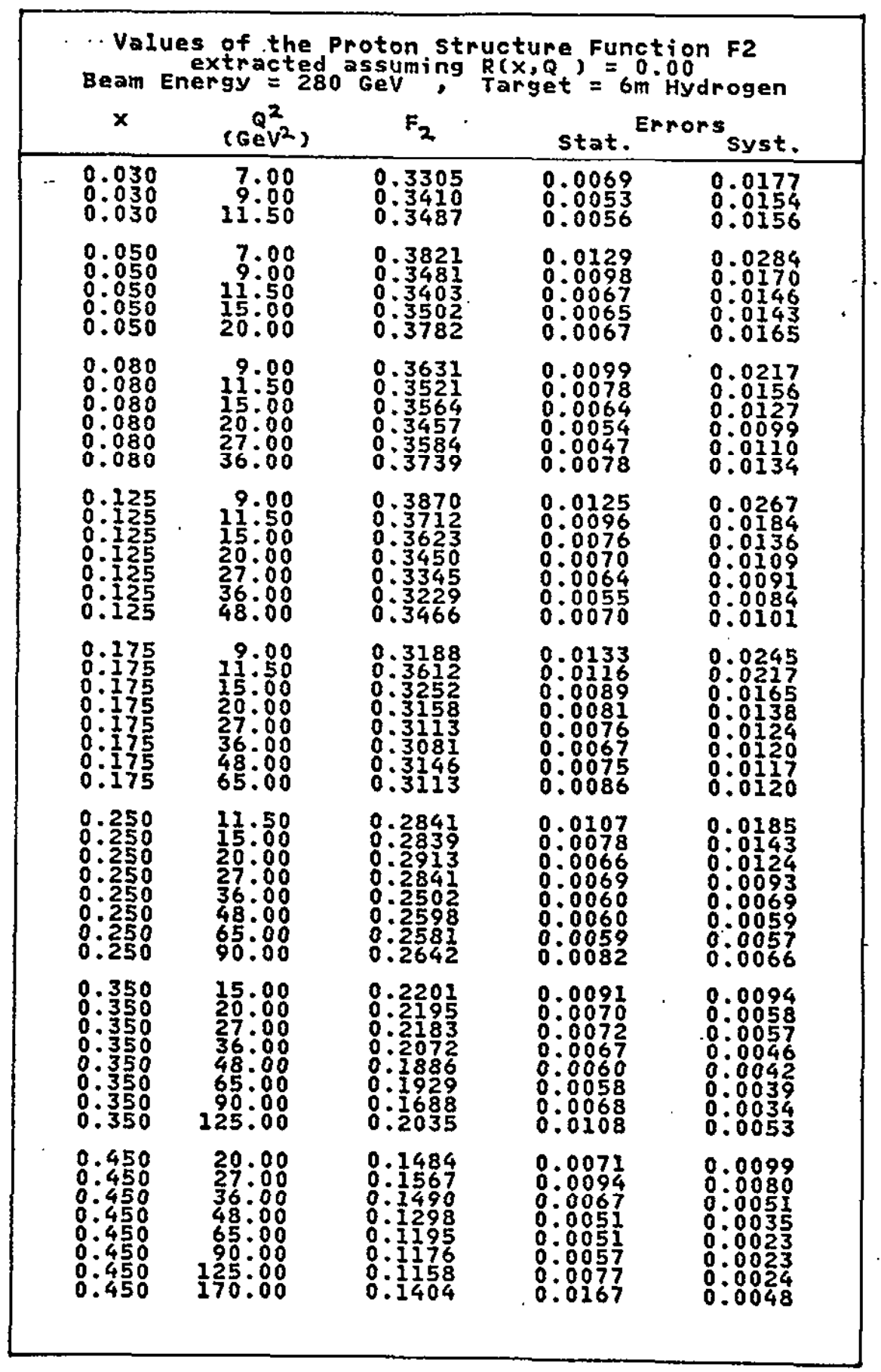


Table 9 d (cont'd.)

\begin{tabular}{|c|c|c|c|c|}
\hline \multicolumn{5}{|c|}{ 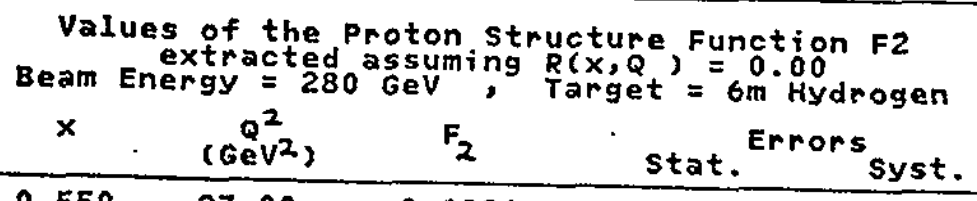 } \\
\hline $\begin{array}{l}0.550 \\
0: 550 \\
0: 550 \\
0: 550 \\
0: 550 \\
0: 550 \\
0.550\end{array}$ & $\begin{array}{r}27.00 \\
36.00 \\
48.00 \\
65.00 \\
90.00 \\
125.00 \\
170.00\end{array}$ & $\begin{array}{l}0.0926 \\
0.0672 \\
0.0649 \\
0.0785 \\
0.0671 \\
0.0642 \\
0.0550\end{array}$ & $\begin{array}{l}0.0060 \\
0.0068 \\
0.0042 \\
0.0045 \\
0.0046 \\
0.0660 \\
0.0088\end{array}$ & $\begin{array}{l}0.0091 \\
0.0046 \\
0.0029 \\
0.0024 \\
0.0016 \\
0.0013 \\
0.0013\end{array}$ \\
\hline $\begin{array}{l}0.650 \\
0.650 \\
0.650 \\
0.650 \\
0.650 \\
0.650\end{array}$ & $\begin{array}{r}36.00 \\
48.00 \\
65.00 \\
90.00 \\
125.00 \\
170.00\end{array}$ & $\begin{array}{l}0.0477 \\
0.0403 \\
0.0299 \\
0.0384 \\
0.0370 \\
0.0230\end{array}$ & $\begin{array}{l}0.0046 \\
0.0045 \\
0.0029 \\
0.0037 \\
0.0048 \\
0.0056\end{array}$ & $\begin{array}{l}0.0070 \\
0.0037 \\
0.0018 \\
0.0015 \\
0.00191 \\
0.0007\end{array}$ \\
\hline $\begin{array}{l}0.750 \\
0.750 \\
0.750 \\
0.750 \\
0.750\end{array}$ & $\begin{array}{r}48.00 \\
65.00 \\
90.00 \\
125.00 \\
170.00\end{array}$ & $\begin{array}{l}0.0145 \\
0.0178 \\
0.0172 \\
0.0177 \\
0.0107\end{array}$ & $\begin{array}{l}0.0024 \\
0.0025 \\
0.0028 \\
0.0036 \\
0.0038\end{array}$ & $\begin{array}{l}0.0024 \\
0.0020 \\
0.0013 \\
0.0009 \\
0.0004\end{array}$ \\
\hline
\end{tabular}


Table 10

\begin{tabular}{|c|c|c|c|c|c|}
\hline \multicolumn{5}{|c|}{ 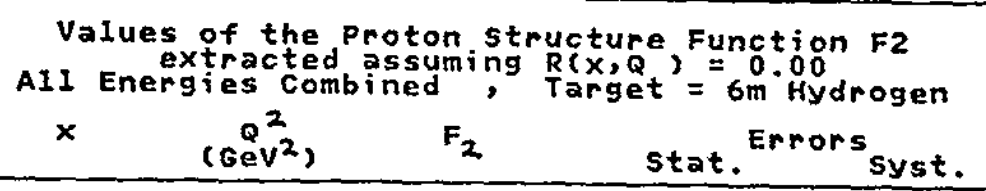 } & \\
\hline $\begin{array}{l}0.030 \\
0.030 \\
0.030 \\
0.030 \\
0.030 \\
0.030\end{array}$ & $\begin{array}{r}3.50 \\
4.50 \\
5.50 \\
7.00 \\
9.00 \\
11.50\end{array}$ & $\begin{array}{l}0.3039 \\
0.3092 \\
0.3313 \\
0.3113 \\
0.3410 \\
0.3487\end{array}$ & $\begin{array}{l}0.0057 \\
0.0058 \\
0.0082 \\
0.0063 \\
0.0060 \\
0.0064\end{array}$ & $\begin{array}{l}0.0172 \\
0.0175 \\
0.0153 \\
0.0157 \\
0.0154 \\
0.0156\end{array}$ & \\
\hline $\begin{array}{l}0.050 \\
0.050 \\
0.050 \\
0.050 \\
0.050 \\
0.050 \\
0.050\end{array}$ & $\begin{array}{r}4.50 \\
5.50 \\
7.00 \\
9.00 \\
11.50 \\
15.00 \\
20.00\end{array}$ & $\begin{array}{l}0.3090 \\
0.3149 \\
0.3447 \\
0.3435 \\
0.3389 \\
0.3556 \\
0.3782\end{array}$ & $\begin{array}{l}0.0101 \\
0.0084 \\
0.0066 \\
0.0070 \\
0.0054 \\
0.0092 \\
0.0076\end{array}$ & $\begin{array}{l}0.0180 \\
0.0138 \\
0.0124 \\
0.0177 \\
0.0147 \\
0.0153 \\
0.0165\end{array}$ & \\
\hline $\begin{array}{l}0.080 \\
0.080 \\
0.080 \\
0.080 \\
0.080 \\
0.080 \\
0.080 \\
0.080\end{array}$ & $\begin{array}{r}5.50 \\
7.00 \\
9.00 \\
1150 \\
15.00 \\
20.00 \\
27.00 \\
36.00\end{array}$ & $\begin{array}{l}0.3359 \\
0.3402 \\
0: 3412 \\
0: 3518 \\
0: 3587 \\
0: 3457 \\
0: 3595 \\
0.3739\end{array}$ & $\begin{array}{l}0.0088 \\
0.0068 \\
0.0072 \\
0.0056 \\
0.0054 \\
0.0043 \\
0.0068 \\
0.0088\end{array}$ & $\begin{array}{l}0.0185 \\
0.0139 \\
0.0108 \\
0.0160 \\
0.0131 \\
0.0100 \\
0.0112 \\
0.0134\end{array}$ & \\
\hline $\begin{array}{l}0.125 \\
0: 125 \\
0: 125 \\
0: 125 \\
0: 125 \\
0: 1255 \\
001225 \\
0.125\end{array}$ & $\begin{array}{r}7.00 \\
9.00 \\
11.50 \\
15000 \\
20.00 \\
27.00 \\
36.00 \\
48.00\end{array}$ & $\begin{array}{l}0.3355 \\
0: 3323 \\
0: 3433 \\
0: 3279 \\
0: 3400 \\
0: 3334 \\
0: 3226 \\
0.3466\end{array}$ & $\begin{array}{l}0.0075 \\
0.0086 \\
0.0250 \\
0.0088 \\
0.0082 \\
0.0053 \\
0.0063 \\
0.0079\end{array}$ & $\begin{array}{l}0.0169 \\
0.01118 \\
0.0162 \\
0.0123 \\
0.0104 \\
0.0086 \\
0.0089 \\
0.0101\end{array}$ & \\
\hline $\begin{array}{l}0.175 \\
0: 175 \\
0: 175 \\
0: 175 \\
0: 175 \\
0: 175 \\
0: 175 \\
0: 175 \\
0.175\end{array}$ & $\begin{array}{r}7.00 \\
9.00 \\
21.50 \\
75.00 \\
20.00 \\
27.00 \\
36.00 \\
48.00 \\
65.00\end{array}$ & $\begin{array}{l}0.3032 \\
0.3144 \\
0.3229 \\
0.3239 \\
0.3232 \\
0.3098 \\
0.3062 \\
0.3160 \\
0.3080\end{array}$ & $\begin{array}{l}0.0093 \\
0.0093 \\
0.0084 \\
0.0067 \\
0.0094 \\
0.0074 \\
0.0054 \\
0.0082 \\
0.0089\end{array}$ & $\begin{array}{l}0.0169 \\
0.0130 \\
0.0111 \\
0.00160 \\
0.0140 \\
0.0118 \\
0.011 \\
0.0115 \\
0.01120\end{array}$ & - \\
\hline $\begin{array}{l}0.250 \\
0: 250 \\
0: 250 \\
0: 250 \\
0: 250 \\
0.250 \\
0.250 \\
0.250 \\
0: 250 \\
0.250\end{array}$ & $\begin{array}{r}7.00 \\
9.00 \\
11.50 \\
15.00 \\
20.00 \\
27.00 \\
36.00 \\
48.00 \\
65000 \\
90.00\end{array}$ & $\begin{array}{l}0.2996 \\
0.2880 \\
0.2972 \\
0.2751 \\
0.2793 \\
0.22844 \\
0.2541 \\
0.2598 \\
0.2579 \\
0.2642\end{array}$ & $\begin{array}{l}0.0087 \\
0.0078 \\
0.0070 \\
0.0064 \\
0.0071 \\
0.0051 \\
0.0069 \\
0.0063 \\
0.0051 \\
0.0093\end{array}$ & $\begin{array}{l}0.0177 \\
0.0128 \\
0.0108 \\
0.0137 \\
0.0115 \\
0.0086 \\
0.0068 \\
0.0061 \\
0.0060 \\
0.0066\end{array}$ & \\
\hline $\begin{array}{l}0.350 \\
0.350 \\
0: 350 \\
0.350\end{array}$ & $\begin{array}{r}9.00 \\
11.50 \\
15.00 \\
20.00\end{array}$ & $\begin{array}{l}0.2163 \\
0.2264 \\
0.2158 \\
0.2182\end{array}$ & $\begin{array}{l}0.0086 \\
0.0075 \\
0.0069 \\
0.0062\end{array}$ & $\begin{array}{l}0.0096 \\
0.0096 \\
0.0090 \\
0.0058\end{array}$ & \\
\hline
\end{tabular}


Table 10 (contid.)

\begin{tabular}{|c|c|c|c|c|c|}
\hline \multicolumn{5}{|c|}{ 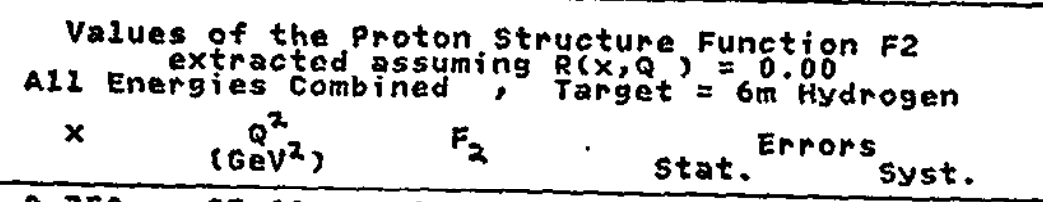 } & \\
\hline $\begin{array}{l}0.350 \\
0.350 \\
0.350 \\
0.350 \\
0: 350 \\
0.350\end{array}$ & $\begin{array}{r}27.00 \\
36.00 \\
48.00 \\
65.00 \\
90.00 \\
125.00\end{array}$ & $\begin{array}{l}0.2169 \\
0.2042 \\
0: 1939 \\
001971 \\
0.1751 \\
0.2035\end{array}$ & $\begin{array}{l}0.0050 \\
0.0050 \\
0.0069 \\
0.0072 \\
0.0217 \\
0.0122\end{array}$ & $\begin{array}{l}0.0053 \\
0.0043 \\
0.0044 \\
0.0042 \\
0.0039 \\
0.0053\end{array}$ & $\because$ \\
\hline $\begin{array}{l}0.450 \\
0.450 \\
0.450 \\
0.450 \\
0.450 \\
0.450 \\
0.450 \\
0.450 \\
0.450\end{array}$ & $\begin{array}{r}11.50 \\
15.00 \\
20.00 \\
27.00 \\
36.00 \\
48.00 \\
65.00 \\
90.00 \\
225.00\end{array}$ & $\begin{array}{l}0.1392 \\
0.1446 \\
0: 1528 \\
0: 1575 \\
0: 1472 \\
0.1302 \\
0: 1245 \\
0.11182 \\
0.1151\end{array}$ & $\begin{array}{l}0.0068 \\
0.0077 \\
0.0059 \\
0.0081 \\
0.0049 \\
0.0049 \\
0.0089 \\
0.0050 \\
0.0071\end{array}$ & $\begin{array}{l}0.0060 \\
0.0041 \\
0.0057 \\
0.0069 \\
0.0045 \\
0.0035 \\
0.0026 \\
0.0024 \\
0.0025\end{array}$ & $\cdots$ \\
\hline $\begin{array}{l}0.550 \\
0.550 \\
0.550 \\
0.550 \\
0.550 \\
0.550 \\
0.550 \\
0.550 \\
0.550 \\
0.550\end{array}$ & $\begin{array}{r}11.50 \\
15.00 \\
20.00 \\
27.00 \\
36.00 \\
48.00 \\
65.00 \\
90.00 \\
125.00 \\
170.00\end{array}$ & $\begin{array}{l}0.0935 \\
0.0861 \\
0.0731 \\
0.0802 \\
0.0850 \\
0.0673 \\
0.0757 \\
0.0648 \\
0.0612 \\
0.0550\end{array}$ & $\begin{array}{l}0.0068 \\
0.0066 \\
0.0059 \\
0.0107 \\
0.0059 \\
0.0090 \\
0.0040 \\
0.0043 \\
0.0066 \\
0.0100\end{array}$ & $\begin{array}{l}0.0064 \\
0.0044 \\
0.0032 \\
0.0039 \\
0.0039 \\
0.0028 \\
0.0022 \\
0.0016 \\
0.0013 \\
0.0013\end{array}$ & \\
\hline $\begin{array}{l}0.650 \\
0.650 \\
0.650 \\
0.650 \\
0.650 \\
0.650 \\
0.650 \\
0.650\end{array}$ & $\begin{array}{r}20.00 \\
27.00 \\
36.00 \\
48.00 \\
65.00 \\
90.00 \\
125.00 \\
170.00\end{array}$ & $\begin{array}{l}0.0434 \\
0.0371 \\
0.0438 \\
0.0343 \\
0.0356 \\
0.0390 \\
0.0359 \\
0.0230\end{array}$ & $\begin{array}{l}0.0048 \\
0.0052 \\
0.0073 \\
0.0082 \\
0.0039 \\
0.0040 \\
0.0044 \\
0.0064\end{array}$ & $\begin{array}{l}0.0030 \\
0.0021 \\
0.0020 \\
0.0012 \\
0.0016 \\
0.0015 \\
0.0011 \\
0.0007\end{array}$ & \\
\hline $\begin{array}{l}0.750 \\
0: 750 \\
0.750 \\
0: 750 \\
0: 750 \\
0: 750 \\
0.750\end{array}$ & $\begin{array}{r}27.00 \\
36.00 \\
48.00 \\
65.00 \\
90.00 \\
125.00 \\
170.00\end{array}$ & $\begin{array}{l}0.0198 \\
0.0127 \\
0.00190 \\
0.0108 \\
0.0115 \\
0.0076 \\
0.0107\end{array}$ & $\begin{array}{l}0.0040 \\
0.0041 \\
0.0063 \\
0.0070 \\
0.0052 \\
0.0060 \\
0.0043\end{array}$ & $\begin{array}{l}0.0018 \\
0.0010 \\
0.0012 \\
0.0005 \\
0.0006 \\
0.0004 \\
0.0004\end{array}$ & \\
\hline & & & & $\cdots$ & \\
\hline
\end{tabular}


Table Il a

\begin{tabular}{|c|c|c|c|c|c|}
\hline \multicolumn{4}{|c|}{ 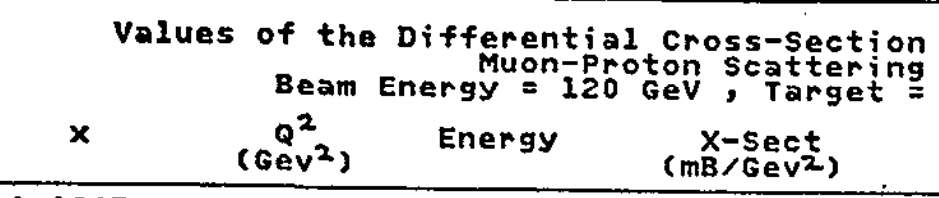 } & \multicolumn{2}{|c|}{$\begin{array}{l}\text { for Deep Inelastic } \\
6 m \text { Hydrogen }\end{array}$} \\
\hline $\begin{array}{l}0.0267 \\
0.0302 \\
0.0338\end{array}$ & $\begin{array}{l}3.54 \\
4.46 \\
5.43\end{array}$ & $\begin{array}{l}119: 1 \\
120: 0 \\
120: 5\end{array}$ & $\begin{array}{l}0.1377 E-03 \\
0: 7498 E-04 \\
0.4702 E-04\end{array}$ & $\begin{array}{l}0.2266 \mathrm{E}-05 \\
0: 1237 \mathrm{E}-05 \\
0.1022 \mathrm{E}-05\end{array}$ & $\begin{array}{l}0.7807 E-05 \\
0.3519 E-05 \\
0.2163 E-05\end{array}$ \\
\hline $\begin{array}{l}0.0484 \\
0.0488 \\
0.0493 \\
0.0533\end{array}$ & $\begin{array}{l}4.53 \\
5.50 \\
6.93 \\
8.76\end{array}$ & $\begin{array}{l}118.9 \\
119.2 \\
119.9 \\
121.0\end{array}$ & $\begin{array}{l}0.5411 E-04 \\
0.3460 E-04 \\
0.2161 E=04 \\
0.1 I 85 E-04\end{array}$ & $\begin{array}{l}0.1559 E-05 \\
0.8131 E-06 \\
0.3636 E-06 \\
0.3217 E-06\end{array}$ & $\begin{array}{l}0.3159 E-05 \\
0.1517 E-05 \\
0.7810 E=06 \\
0.4679 E-06\end{array}$ \\
\hline $\begin{array}{l}0.0769 \\
0.0774 \\
0.0783 \\
0.0803 \\
0.0883\end{array}$ & $\begin{array}{r}5.51 \\
6: 98 \\
8.93 \\
11.25 \\
14.36\end{array}$ & $\begin{array}{l}119: 1 \\
119: 4 \\
119: 7 \\
120: 4 \\
121.1\end{array}$ & $\begin{array}{l}0.2732 E-04 \\
0: 1592 E=04 \\
0.8840 E=05 \\
0.5208 E=05 \\
0.2814 E-05\end{array}$ & $\begin{array}{l}0.6343 E-06 \\
0.2807 E-06 \\
0: 1632 E-06 \\
0.1011 E-06 \\
0.9296 E-07\end{array}$ & $\begin{array}{l}0.1509 E-05 \\
0.6529 E=06 \\
0.2805 E=06 \\
0.1494 E-06 \\
0.1066 E-06\end{array}$ \\
\hline $\begin{array}{l}0.1224 \\
0: 1234 \\
0: 1233 \\
0: 1242 \\
0.1281\end{array}$ & $\begin{array}{r}7.01 \\
8: 97 \\
11: 38 \\
14: 73 \\
19.18\end{array}$ & $\begin{array}{l}119 \cdot 1 \\
119: 5 \\
119: 7 \\
120: 2 \\
120: 8\end{array}$ & $\begin{array}{l}0.1128 E-04 \\
0.6363 \mathrm{E}-05 \\
0.3741 \mathrm{E}-05 \\
0.1951 \mathrm{E}-05 \\
0.1086 \mathrm{E}-05\end{array}$ & $\begin{array}{l}0.2219 E-06 \\
0.1455 E-06 \\
0.7697 E-07 \\
0.4565 E-07 \\
0.3382 E-07\end{array}$ & $\begin{array}{l}0.5694 E-06 \\
0.2257 E-06 \\
0.1157 E-06 \\
0.5173 E-07 \\
0.3299 E-07\end{array}$ \\
\hline $\begin{array}{l}0.1726 \\
0: 1727 \\
0: 1739 \\
0: 1739 \\
0: 1738 \\
0.1763\end{array}$ & $\begin{array}{r}6 \cdot 99 \\
9 \cdot 00 \\
11 \cdot 41 \\
14 \cdot 81 \\
19 \cdot 52 \\
25 \cdot 76\end{array}$ & $\begin{array}{l}119 \cdot 1 \\
119: 4 \\
11998 \\
120: 0 \\
12002 \\
120: 5\end{array}$ & $\begin{array}{l}0.7841 E-05 \\
0.4667 E-05 \\
0.2798 E-05 \\
0.7559 E=05 \\
0.8269 E-06 \\
0.3778 E-06\end{array}$ & $\begin{array}{l}0.2121 E-06 \\
0.1217 E-06 \\
0: 6411 E-07 \\
0: 4227 E=07 \\
0: 2520 E-07 \\
0.1816 E-07\end{array}$ & $\begin{array}{l}0.4350 E-06 \\
0: 1922 E-06 \\
0: 9639 E-07 \\
0: 4081 E=07 \\
0: 1952 E=07 \\
0.1046 E-07\end{array}$ \\
\hline $\begin{array}{l}0.2423 \\
0.2439 \\
0.2445 \\
0: 2454 \\
0.2462 \\
0.2468 \\
0.2526 \\
0.2671\end{array}$ & $\begin{array}{r}7.05 \\
9.00 \\
11: 42 \\
14.82 \\
19: 58 \\
26: 41 \\
34: 70 \\
44.91\end{array}$ & $\begin{array}{l}119.1 \\
119: 4 \\
119: 6 \\
120.0 \\
120: 1 \\
119: 8 \\
12004 \\
121.1\end{array}$ & $\begin{array}{l}0.5781 E-05 \\
0.32685-05 \\
0.1999 E-05 \\
0.1028 E-05 \\
0.5570 \mathrm{E}=06 \\
0.2770 \mathrm{E}=06 \\
0.1246 \mathrm{E}=06 \\
0.5881 \mathrm{E}=07\end{array}$ & $\begin{array}{l}0.1486 E-06 \\
0.7829 E-07 \\
0.4169 E-07 \\
0.2552 E-07 \\
0: 1425 E-07 \\
0.9250 E-08 \\
0.6847 E-08 \\
0.8224 E-08\end{array}$ & $\begin{array}{l}0.3364 E-06 \\
0: 1429 E-06 \\
0.7208 E-07 \\
0: 2986 E-07 \\
0.1237 E-07 \\
0: 5812 E-08 \\
0: 3188 E-08 \\
0.4269 E-08\end{array}$ \\
\hline $\begin{array}{l}0.3449 \\
0: 3432 \\
0: 3449 \\
0: 3449 \\
0: 3465 \\
0: 3438 \\
0.3477\end{array}$ & $\begin{array}{r}9.02 \\
11.46 \\
14.85 \\
19.86 \\
26.32 \\
34.81 \\
46.14\end{array}$ & $\begin{array}{l}119.1 \\
119: 5 \\
119: 9 \\
119: 9 \\
120: 1 \\
120: 2 \\
121: 0\end{array}$ & $\begin{array}{l}0.1817 E-05 \\
0.1155 E-05 \\
0.6143 E-06 \\
0: 3182 E=06 \\
0.1629 E-06 \\
0.8488 E-07 \\
0.4094 E-07\end{array}$ & $\begin{array}{l}0.6385 E-07 \\
0: 3366 E-07 \\
0: 2074 E-07 \\
0: 1117 E=07 \\
0.6973 E=08 \\
0.4927 E=08 \\
0.3594 E-08\end{array}$ & $\begin{array}{l}0.7928 E-07 \\
0.4813 \mathrm{E}=07 \\
0.1778 \mathrm{E}-07 \\
0: 6660 \mathrm{E}-08 \\
0.3414 \mathrm{E}-08 \\
0.1846 \mathrm{E}-08 \\
0.1081 \mathrm{E}-08\end{array}$ \\
\hline $\begin{array}{l}0.4434 \\
0.4446 \\
0.4420 \\
0.4437 \\
0.4423 \\
0.4474 \\
0.4433\end{array}$ & $\begin{array}{l}11.45 \\
14.77 \\
19.54 \\
26 \cdot 38 \\
35.15 \\
46.44 \\
61.07\end{array}$ & $\begin{array}{l}119.2 \\
119: 7 \\
120: 0 \\
120: 0 \\
120: 3 \\
120: 0 \\
120: 5\end{array}$ & $\begin{array}{l}0.5727 E-06 \\
0: 3435 E-06 \\
0: 1996 \mathrm{E}=06 \\
0: 9279 \mathrm{E}=07 \\
0.5304 \mathrm{E}-07 \\
0.2256 \mathrm{E}-07 \\
0.1524 \mathrm{E}-07\end{array}$ & $\begin{array}{l}0.2468 E-07 \\
0.1615 E-07 \\
0.9363 E=08 \\
0.5226 E=08 \\
0.3788 E=08 \\
0.2318 E-08 \\
0.2524 E-08\end{array}$ & $\begin{array}{l}0.2384 E-07 \\
0.9502 E-08 \\
0.6174 E-08 \\
0.1958 E-08 \\
0.1011 E=08 \\
0.5372 E-09 \\
0.5733 E-09\end{array}$ \\
\hline $\begin{array}{l}0.5405 \\
0.5445 \\
0.5434 \\
0.5415 \\
0.5460 \\
0.5439 \\
0.5451\end{array}$ & $\begin{array}{l}11.59 \\
14.97 \\
19.59 \\
26.75 \\
35.47 \\
46.31 \\
62.91\end{array}$ & $\begin{array}{l}119.3 \\
120.0 \\
119.8 \\
120: 3 \\
121: 1 \\
120.6 \\
119.4\end{array}$ & $\begin{array}{l}0.3213 E-06 \\
0.1678 E-06 \\
0.8092 \mathrm{E}-07 \\
0.4226 \mathrm{E}-07 \\
0.2226 \mathrm{E}-07 \\
0.1047 \mathrm{E}-07 \\
0.6361 \mathrm{E}-08\end{array}$ & $\begin{array}{l}0.2062 E-07 \\
0.1131 E-07 \\
0.5756 E-08 \\
0.3522 E-08 \\
0.2376 E-08 \\
0.1578 E-08 \\
0.1332 E-08\end{array}$ & $\begin{array}{l}0.2077 \mathrm{E}-07 \\
0.8249 \mathrm{E}=08 \\
0.355 \mathrm{E}=08 \\
0.1325 \mathrm{E}=08 \\
0.5669 \mathrm{E}=09 \\
0.2575 \mathrm{E}-09 \\
0.1871 \mathrm{E}-09\end{array}$ \\
\hline $\begin{array}{l}0.6457 \\
0.6395 \\
0.6444 \\
0.6435 \\
0.6383\end{array}$ & $\begin{array}{l}19.49 \\
26: 42 \\
35: 39 \\
46: 73 \\
62.00\end{array}$ & $\begin{array}{l}120.1 \\
120: 4 \\
120: 0 \\
128.6 \\
120.0\end{array}$ & $\begin{array}{l}0.4163 \mathrm{E}-07 \\
0.1945 \mathrm{E}=07 \\
0.1156 \mathrm{E}=07 \\
0.4845 \mathrm{E}-08 \\
0.3583 \mathrm{E}-08\end{array}$ & $\begin{array}{l}0.4029 E-08 \\
0.2405 E-08 \\
001689 E=08 \\
0: 1017 E=08 \\
0.9625 E-09\end{array}$ & $\begin{array}{l}0.2783 E-08 \\
0: 1037 E=08 \\
0: 5095 E=09 \\
0: 1632 \mathrm{E}=09 \\
0.1094 \mathrm{E}-09\end{array}$ \\
\hline $\begin{array}{l}0.7394 \\
0.7476 \\
0.7400 \\
0.7430\end{array}$ & $\begin{array}{l}26 \cdot 49 \\
35: 18 \\
46: 50 \\
61 \cdot 55\end{array}$ & $\begin{array}{l}119.6 \\
120.2 \\
118.9 \\
118.0\end{array}$ & $\begin{array}{l}0.9290 \mathrm{E}-08 \\
0.2978 \mathrm{E}-08 \\
0.2560 \mathrm{E}-08 \\
0.7426 \mathrm{E}-0.9\end{array}$ & $\begin{array}{l}0.1642 E-08 \\
0.8442 E-09 \\
0.7409 E-09 \\
0.4263 E-09\end{array}$ & $\begin{array}{l}0.7653 E-09 \\
0.2218 E=09 \\
0.2455 E=09 \\
0.3439 E-10\end{array}$ \\
\hline
\end{tabular}


Table 11 b

\begin{tabular}{|c|c|c|c|c|c|c|}
\hline Va & $\begin{array}{c}\text { os of the } \\
\text { Beam } \\
Q^{2} \\
\left(\operatorname{Gev}^{2}\right)\end{array}$ & $\begin{array}{c}\text { Differenti } \\
\text { Muon- } \\
\text { Energy }=20 \\
\text { Energy }\end{array}$ & $\begin{array}{c}\text { ial cross-sectio } \\
\text { Proton scatterin } \\
\text { oo Gev , Target } \\
\text { X-sect } \\
\text { (mB/Gev') }\end{array}$ & $\begin{array}{l}\text { on } \\
\text { ng } \\
=\end{array}$ & $\begin{array}{l}\text { for Deep .Ine } \\
\text { 6m Hydrogen } \\
\text { Stat. Erro }\end{array}$ & rs syst. \\
\hline 0.0281 & $\begin{array}{l}6.94 \\
8.90\end{array}$ & $\begin{array}{l}198.2 \\
198.9\end{array}$ & $\begin{array}{l}0.3331 E-04 \\
0.1834 E-04\end{array}$ & & $\begin{array}{l}0.5885 E-06 \\
0.4116 E-06\end{array}$ & $\begin{array}{l}0.1683 E-05 \\
0.8835 E-06\end{array}$ \\
\hline $\begin{array}{l}0.0484 \\
0.0488 \\
0.0525\end{array}$ & $\begin{array}{r}9.09 \\
11.46 \\
14.47\end{array}$ & $\begin{array}{l}197 \cdot 3 \\
198: \frac{1}{19}\end{array}$ & $\begin{array}{l}0.1348 E-04 \\
0: 7783 E-05 \\
0.4517 E-05\end{array}$ & & $\begin{array}{l}0.3851 E-06 \\
0: 1685 E-06 \\
0.1225 E-06\end{array}$ & $\begin{array}{l}0.5445 E-06 \\
0.2488 E-06 \\
0.1778 E-06\end{array}$ \\
\hline $\begin{array}{l}0.0765 \\
0.0768 \\
0.0775 \\
0.0800 \\
0.0890\end{array}$ & $\begin{array}{r}9 \cdot 11 \\
11: 55 \\
14: 96 \\
19: 42 \\
25.43\end{array}$ & $\begin{array}{l}196.4 \\
197.6 \\
198.5 \\
198.8 \\
200.4\end{array}$ & $\begin{array}{l}0.1007 E-04 \\
0.5672 E-05 \\
0.3351 E=05 \\
0.1658 E=05 \\
0.8554 E-06\end{array}$ & & $\begin{array}{l}0.3771 E-06 \\
0.1344 E-06 \\
0.6763 E-07 \\
0.3630 E=07 \\
0.2648 E-07\end{array}$ & $\begin{array}{l}0.7552 E-06 \\
0.2136 E-06 \\
0.9155 E-07 \\
0.4713 E-07 \\
0.4226 E-07\end{array}$ \\
\hline $\begin{array}{l}0.1218 \\
0: 1225 \\
0: 1231 \\
0: 1237 \\
0.1296\end{array}$ & $\begin{array}{l}11.62 \\
14.98 \\
19.81 \\
26.60 \\
34.45\end{array}$ & $\begin{array}{l}197.1 \\
198.0 \\
198.4 \\
198.8 \\
200.1\end{array}$ & $\begin{array}{l}0.4137 E-05 \\
0.2210 E-05 \\
0.1161 E=05 \\
0.5932 E=06 \\
0.2759 E-06\end{array}$ & & $\begin{array}{l}0.1404 E-06 \\
0.5926 \mathrm{E}-07 \\
0.2752 \mathrm{E}=07 \\
0.1583 \mathrm{E}=07 \\
0.1251 \mathrm{E}-07\end{array}$ & $\begin{array}{l}0.2052 E-06 \\
0.7213 E-07 \\
0: 2849 E-07 \\
0.1372 E=07 \\
0.8709 E-08\end{array}$ \\
\hline $\begin{array}{l}0.1726 \\
0: 1729 \\
0: 1740 \\
0: 1735 \\
0: \frac{1}{73} 9 \\
0.1748\end{array}$ & $\begin{array}{l}11.68 \\
15.03 \\
19.75 \\
26.61 \\
35.42 \\
45.84\end{array}$ & $\begin{array}{l}196 \cdot 5 \\
197: 5 \\
198: 3 \\
198: 8 \\
199: 2 \\
200: 1\end{array}$ & $\begin{array}{l}0.2706 E-05 \\
0.1624 E-05 \\
0.9428 E=06 \\
0.4646 E=06 \\
0.2164 E=06 \\
0.1164 E-06\end{array}$ & & $\begin{array}{l}0.1332 E-06 \\
0.5572 E=07 \\
0.2795 E=07 \\
0.1476 E=07 \\
0.8675 E=08 \\
0.6788 E-08\end{array}$ & $\begin{array}{l}0.1741 E-06 \\
0.5767 E-07 \\
0.2497 E=07 \\
0.9999 E-08 \\
0.4580 E=08 \\
0.3294 E-08\end{array}$ \\
\hline $\begin{array}{l}0.2412 \\
0.2433 \\
0: 2447 \\
0.2460 \\
0.2425 \\
0.2449 \\
0.2542\end{array}$ & $\begin{array}{l}11.64 \\
14: 97 \\
19: 89 \\
26: 76 \\
35.53 \\
46.87 \\
61.95\end{array}$ & $\begin{array}{l}196.9 \\
197.5 \\
197.9 \\
198: 6 \\
199: 4 \\
199: 1 \\
199.6\end{array}$ & $\begin{array}{l}0.1839 \mathrm{E}-05 \\
0.1105 \mathrm{E}-05 \\
0.5995 \mathrm{E}-06 \\
0.3266 \mathrm{E}=06 \\
0.1534 \mathrm{E}-06 \\
0.7738 \mathrm{E}-07 \\
0.3762 \mathrm{E}-07\end{array}$ & & $\begin{array}{l}0.8836 E-07 \\
0: 3701 E-07 \\
0.1645 E-07 \\
0.9084 E-08 \\
0.5289 E-08 \\
0.2341 E-08 \\
0.2395 E-08\end{array}$ & $\begin{array}{l}0.1392 E-06 \\
0.4247 E-07 \\
0.1574 E-07 \\
0.6784 E-08 \\
0.2915 E=08 \\
0.1740 E-08 \\
0.1036 E=08\end{array}$ \\
\hline $\begin{array}{l}0.3437 \\
0: 3449 \\
0: 3450 \\
0: 3438 \\
0.3448 \\
0.3465 \\
0.3567\end{array}$ & $\begin{array}{l}15 \cdot 18 \\
19: 86 \\
26: 78 \\
35: 54 \\
47: 11 \\
63.68 \\
86.15\end{array}$ & $\begin{array}{l}197.8 \\
198: 1 \\
198: 5 \\
199: 2 \\
198: 9 \\
198: 8 \\
199.4\end{array}$ & $\begin{array}{l}0.6750 E-06 \\
0.3752 \mathrm{E}-06 \\
0: 1918 \mathrm{E}-06 \\
0: 9576 \mathrm{E}-07 \\
0.4747 \mathrm{E}-07 \\
0.2361 \mathrm{E}-07 \\
0.1116 \mathrm{E}-07\end{array}$ & & $\begin{array}{l}0.3338 E-07 \\
0.1437 E-07 \\
0.7320 E-08 \\
0.4298 E-08 \\
0.1849 E-08 \\
0.1123 E-08 \\
0.1142 E-08\end{array}$ & $\begin{array}{l}0.2655 E-07 \\
0.8935 E-08 \\
0.3528 E-08 \\
0.1523 E=08 \\
0.9660 E-09 \\
0.5045 E-09 \\
0.3228 E-09\end{array}$ \\
\hline $\begin{array}{l}0.4447 \\
0.4423 \\
0.4449 \\
0.4449 \\
0.4450 \\
0.4435 \\
0.4484\end{array}$ & $\begin{array}{l}15 \cdot 12 \\
19: 91 \\
26: 71 \\
35: 33 \\
47: 31 \\
62: 95 \\
85.33\end{array}$ & $\begin{array}{l}196.6 \\
198: 1 \\
197: 4 \\
198: 3 \\
199: 3 \\
198: 9 \\
199.5\end{array}$ & $\begin{array}{l}0.4156 E-06 \\
0.2107 E-06 \\
0.1236 E-06 \\
0.5501 E=07 \\
0.2515 E-07 \\
0.1362 E-07 \\
0.6065 E-08\end{array}$ & & $\begin{array}{l}0.2894 E-07 \\
0.1117 E-07 \\
0.6364 E-08 \\
0.3385 E-08 \\
0.1802 E-08 \\
0.8575 E=09 \\
0.7625 E-09\end{array}$ & $\begin{array}{l}0.2191 E-07 \\
0: 7685 E-08 \\
0: 3276 E-08 \\
0: 1036 E-08 \\
0.4142 E=09 \\
0.2551 E-09 \\
0.1252 E-09\end{array}$ \\
\hline $\begin{array}{l}0.5440 \\
0.5420 \\
0.5440 \\
0.5390 \\
0.5452\end{array}$ & $\begin{array}{l}26.82 \\
35.56 \\
47.53 \\
63.91 \\
85.83\end{array}$ & $\begin{array}{l}198.5 \\
198.1 \\
198.9 \\
197.6 \\
199.0\end{array}$ & $\begin{array}{l}0.5396 E-07 \\
0.2976 E-07 \\
0.1508 E-07 \\
0.6508 E-08 \\
0.2094 E-08\end{array}$ & & $\begin{array}{l}0.4044 E-08 \\
0.2469 E-08 \\
0.1444 E-08 \\
0.5984 E-09 \\
0.2858 E-09\end{array}$ & $\begin{array}{l}0.2981 E-08 \\
0: 1197 E-08 \\
0.4432 E=09 \\
0.1510 E=09 \\
0.4731 E-10\end{array}$ \\
\hline $\begin{array}{l}0.6426 \\
0.6411 \\
0.6447 \\
0.6404 \\
0.6233\end{array}$ & $\begin{array}{r}35.78 \\
46.63 \\
64.79 \\
88.07 \\
114.66\end{array}$ & $\begin{array}{l}198.6 \\
199.8 \\
198.4 \\
198.8 \\
196.3\end{array}$ & $\begin{array}{l}0.1315 \mathrm{E}-07 \\
0.5496 \mathrm{E}-08 \\
0.2693 \mathrm{E}-08 \\
0.1459 \mathrm{E}-08 \\
0.9986 \mathrm{E}-09\end{array}$ & & $\begin{array}{l}0.1636 \mathrm{E}-08 \\
0.9351 \mathrm{E}-09 \\
0.3672 \mathrm{E}-09 \\
0.2353 \mathrm{E}-09 \\
0.2891 \mathrm{E}-09\end{array}$ & $\begin{array}{l}0.1098 \mathrm{E}-08 \\
0: 3192 \mathrm{E}-09 \\
0.1088 \mathrm{E}=09 \\
0.4059 \mathrm{E}-10 \\
0.2669 \mathrm{E}-10\end{array}$ \\
\hline $\begin{array}{l}0.7352 \\
0.7424 \\
0.7280\end{array}$ & $\begin{array}{r}65.05 \\
83.56 \\
120.71\end{array}$ & $\begin{array}{l}199.2 \\
197: 3 \\
198: 4\end{array}$ & $\begin{array}{l}0.1080 E-08 \\
0.4606 E=09 \\
0.3097 E-09\end{array}$ & & $\begin{array}{l}0.2400 E-09 \\
0: 1843 \mathrm{E}-09 \\
0.1200 \mathrm{E}-09\end{array}$ & $\begin{array}{l}0.6628 E-10 \\
0.2266 E-10 \\
0.8838 E-11\end{array}$ \\
\hline
\end{tabular}


Table $11 \mathrm{c}$

\begin{tabular}{|c|c|c|c|c|c|}
\hline \multirow{2}{*}{$\frac{x}{0286}$} & \multicolumn{3}{|c|}{ 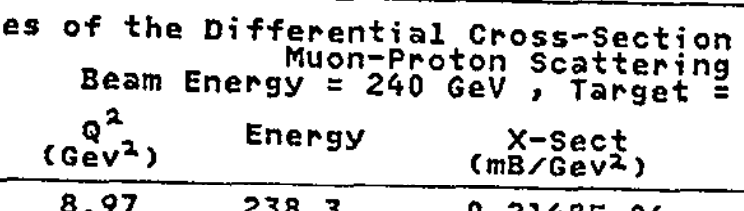 } & \multicolumn{2}{|c|}{$\begin{array}{l}\text { for Deep Inelastic } \\
\text { 6m Hydrogen } \\
\text { Stat. Errors Syst. }\end{array}$} \\
\hline & $\begin{array}{r}8.97 \\
11.28\end{array}$ & $\begin{array}{l}238.3 \\
240.1\end{array}$ & $\begin{array}{l}0.2148 E=04 \\
0.1309 E-04\end{array}$ & $\begin{array}{l}0.5423 E-06 \\
0.3403 E-06\end{array}$ & $\begin{array}{l}0.1245 E-05 \\
0.7017 E-06\end{array}$ \\
\hline $\begin{array}{l}0.0479 \\
0.0491 \\
0.0539\end{array}$ & $\begin{array}{l}11 \cdot 60 \\
14: 90 \\
18.88\end{array}$ & $\begin{array}{l}236 \cdot 8 \\
238.9 \\
242.1\end{array}$ & $\begin{array}{l}0.7897 E-05 \\
0.4915 E-05 \\
0.2648 E-05\end{array}$ & $\begin{array}{l}0.2612 E-06 \\
0.1241 E-06 \\
0.9427 E-07\end{array}$ & $\begin{array}{l}0.4139 E-06 \\
0.1964 E-06 \\
0.1277 E-06\end{array}$ \\
\hline $\begin{array}{l}0.0760 \\
0.0774 \\
0.0826\end{array}$ & $\begin{array}{l}15.06 \\
19.93 \\
26.09\end{array}$ & $\begin{array}{l}237 \cdot 2 \\
238.8 \\
241.0\end{array}$ & $\begin{array}{l}0.3127 E-05 \\
0.175 I E-05 \\
0.9899 E-06\end{array}$ & $\begin{array}{l}0.9015 E-07 \\
0.3960 E-07 \\
0.2693 E-07\end{array}$ & $\begin{array}{l}0.1175 E-06 \\
0.4862 E-07 \\
0.3230 E-07\end{array}$ \\
\hline $\begin{array}{l}0.1216 \\
0: 1223 \\
0: 1225 \\
0: 1232 \\
0: 1334\end{array}$ & $\begin{array}{l}15.16 \\
19.97 \\
26.79 \\
35.48 \\
45.50\end{array}$ & $\begin{array}{l}235.3 \\
238: 5 \\
239: 0 \\
239: 9 \\
242.7\end{array}$ & $\begin{array}{l}0.2182 E-05 \\
0.1177 E-05 \\
0: 6113 E-06 \\
0.3484 E-06 \\
0.1875 E-06\end{array}$ & $\begin{array}{l}0.9710 E-07 \\
0.3647 E-07 \\
0: 1728 E-07 \\
0.8569 E-08 \\
0.7560 E-08\end{array}$ & $\begin{array}{l}0.1180 E-06 \\
0.3718 E-07 \\
0.1446 E-07 \\
0.9553 E=08 \\
0.7419 E-08\end{array}$ \\
\hline $\begin{array}{l}0.1731 \\
0: 1738 \\
0: 1730 \\
0: 1742 \\
0.1785\end{array}$ & $\begin{array}{l}19.99 \\
26.89 \\
35.58 \\
47.20 \\
60.60\end{array}$ & $\begin{array}{l}238.0 \\
238.8 \\
238: 6 \\
240.1 \\
242.2\end{array}$ & $\begin{array}{l}0.8512 \mathrm{E}-06 \\
0.4263 \mathrm{E}-06 \\
0.2365 \mathrm{E}-06 \\
0.1281 \mathrm{E}-06 \\
0.6101 \mathrm{E}-07\end{array}$ & $\begin{array}{l}0.3542 E-07 \\
0.1559 E-07 \\
0.7334 E-08 \\
0.4408 E-08 \\
0.3471 E-08\end{array}$ & $\begin{array}{l}0.3759 E-07 \\
0.1454 E-07 \\
0.7814 E-08 \\
0.4108 E-08 \\
0.2400 E-08\end{array}$ \\
\hline $\begin{array}{l}0.2429 \\
0.2438 \\
0.2446 \\
0.2462 \\
0.2482 \\
0.2586\end{array}$ & $\begin{array}{l}20.01 \\
26.81 \\
35.54 \\
47.51 \\
63.80 \\
84.06\end{array}$ & $\begin{array}{l}237.0 \\
238.6 \\
239.0 \\
239 \cdot 5 \\
240: 3 \\
241.7\end{array}$ & $\begin{array}{l}0.5843 E-06 \\
0: 3239 E=06 \\
0: 1789 E-06 \\
0: 8812 E=07 \\
0: 3984 E-07 \\
0.2386 \mathrm{E}-07\end{array}$ & $\begin{array}{l}0.2401 E-07 \\
0.1113 E-07 \\
0.6355 E-08 \\
0.2669 E-08 \\
0.1445 E-08 \\
0.1369 E-08\end{array}$ & $\begin{array}{l}0.2517 E-07 \\
0.9383 E-08 \\
0.4198 E-08 \\
0.1951 E-08 \\
0.8947 E-09 \\
0.8694 E-09\end{array}$ \\
\hline $\begin{array}{l}0.3430 \\
0: 3434 \\
0: 3434 \\
0: 3457 \\
0: 3435 \\
0: 3480 \\
0: 3496\end{array}$ & $\begin{array}{r}20.15 \\
26: 82 \\
35.75 \\
47.55 \\
63.62 \\
87.42 \\
115.38\end{array}$ & $\begin{array}{l}238.6 \\
237: 2 \\
239: 6 \\
239: 3 \\
239: 1 \\
238: 7 \\
241: 9\end{array}$ & $\begin{array}{l}0.3346 \mathrm{E}-06 \\
0: 1976 \mathrm{E}-06 \\
0: 9471 \mathrm{E}-07 \\
0: 5243 \mathrm{E}-07 \\
0.2686 \mathrm{E}-07 \\
0: 1138 \mathrm{E}-07 \\
0.6715 \mathrm{E}-08\end{array}$ & $\begin{array}{l}0.2048 E-07 \\
0.9061 E-08 \\
0.4685 E-08 \\
0.2156 E-08 \\
0.1265 E-08 \\
0.6669 E-09 \\
0.7131 E-09\end{array}$ & $\begin{array}{l}0.1359 E-07 \\
0.4437 E=08 \\
0.1793 E=08 \\
0.1044 E=08 \\
0.5382 E=09 \\
0.2469 E=09 \\
0.2628 E=09\end{array}$ \\
\hline $\begin{array}{l}0.4454 \\
0.4463 \\
0.4436 \\
0.4427 \\
0.4449 \\
0.4432 \\
0.4504 \\
0.544\end{array}$ & $\begin{array}{r}20.08 \\
26.83 \\
35.79 \\
47.22 \\
64.06 \\
87.59 \\
121.70\end{array}$ & $\begin{array}{l}236: 3 \\
239: 0 \\
239: 7 \\
238: 9 \\
238: 9 \\
239: 5 \\
241: 6 \\
274\end{array}$ & $\begin{array}{l}0.1842 E-06 \\
0: 1144 E-06 \\
0.5782 E=07 \\
0.3039 E-07 \\
0.1531 E-07 \\
0.6173 E-08 \\
0.2568 E-08\end{array}$ & $\begin{array}{l}0.1551 E-07 \\
0: 7792 E-08 \\
0: 3986 E-08 \\
0: 1682 E-08 \\
0.9611 E-09 \\
0: 4733 E-09 \\
0.3003 E-09\end{array}$ & $\begin{array}{l}0.1049 E-07 \\
0.4680 E-08 \\
0.1590 E-08 \\
0.7262 E-09 \\
0.3002 E-09 \\
0.1173 E-09 \\
0.6128 E-10\end{array}$ \\
\hline $\begin{array}{l}0.5442 \\
0.5476 \\
0.5420 \\
0.5443 \\
0.5407 \\
0.5406\end{array}$ & $\begin{array}{r}26 \cdot 87 \\
35.69 \\
47.37 \\
63.61 \\
88.51 \\
122.67\end{array}$ & $\begin{array}{l}236.9 \\
239: 7 \\
238: 1 \\
237: 9 \\
239: 4 \\
242.2\end{array}$ & $\begin{array}{l}0.6277 E-07 \\
0.2833 E-07 \\
0.1678 E-07 \\
0.6935 E-08 \\
0.2930 E-08 \\
0.8688 E-09\end{array}$ & $\begin{array}{l}0.6007 E-08 \\
0.2755 E-08 \\
0.1679 E-08 \\
0.6425 E-09 \\
0.3322 E-09 \\
0.1754 E-09\end{array}$ & $\begin{array}{l}0.4732 E-08 \\
0.1480 E-08 \\
0.6098 E-09 \\
0.1833 \mathrm{E}-09 \\
0.6283 \mathrm{E}-10 \\
0.1829 \mathrm{E}-10\end{array}$ \\
\hline $\begin{array}{l}0.6413 \\
0.6356 \\
0.6415 \\
0.6447\end{array}$ & $\begin{array}{r}47.25 \\
64.43 \\
88.65 \\
127.97\end{array}$ & $\begin{array}{l}239.6 \\
237.3 \\
240.6 \\
237.6\end{array}$ & $\begin{array}{l}0.7760 E-08 \\
0.3015 E-08 \\
0.2090 E-08 \\
0.5061 E-09\end{array}$ & $\begin{array}{l}0.1165 \mathrm{E}-08 \\
0.4517 \mathrm{E}-09 \\
0.2922 \mathrm{E}-09 \\
0.1186 \mathrm{E}-09\end{array}$ & $\begin{array}{l}0.5596 \mathrm{E}-09 \\
0.1351 \mathrm{E}-09 \\
0.7083 \mathrm{E}-100 \\
0.1379 \mathrm{E}-10\end{array}$ \\
\hline $\begin{array}{l}0.7434 \\
0.7168\end{array}$ & $\begin{array}{r}94.61 \\
128.16\end{array}$ & $\begin{array}{l}248.0 \\
239.1\end{array}$ & $\begin{array}{l}0.3559 \mathrm{E}-09 \\
0.9867 \mathrm{E}-10\end{array}$ & $\begin{array}{l}0.1197 \mathrm{E}-09 \\
0.4934 \mathrm{E}-10\end{array}$ & $\begin{array}{l}0.2262 \mathrm{E}-10 \\
0.3514 \mathrm{E}-11\end{array}$ \\
\hline
\end{tabular}


Table II d

\begin{tabular}{|c|c|c|c|c|c|}
\hline \multicolumn{6}{|c|}{$\begin{array}{l}\text { Values of the Differential cross-section for Deep Inelastic } \\
\text { Beam Energy }=280 \text { GeV Sc Target }=6 \mathrm{~m} \text { Hydrogen } \\
\times \quad 0^{2}\end{array}$} \\
\hline $\begin{array}{l}0.0281 \\
0.0282 \\
0.0316\end{array}$ & $\begin{array}{r}7.08 \\
8: 96 \\
11.27\end{array}$ & $\begin{array}{l}275: 9 \\
2777: 1 \\
278: 4\end{array}$ & $\begin{array}{l}0.3865 E-04 \\
0.2257 E-04 \\
0.1244 E-04\end{array}$ & $\begin{array}{l}0.8069 E-06 \\
0: 3508 E-06 \\
0.1998 E-06\end{array}$ & $\begin{array}{l}0.2067 E-05 \\
0: 1019 E=05 \\
0.5593 E-06\end{array}$ \\
\hline $\begin{array}{l}0.0490 \\
0.0494 \\
0.0491 \\
0.0491 \\
0.0510\end{array}$ & $\begin{array}{r}7: 12 \\
9: 00 \\
11: 43 \\
14: 89 \\
19.31\end{array}$ & $\begin{array}{l}274.8 \\
276: 7 \\
277.4 \\
277: 6 \\
279: 1\end{array}$ & $\begin{array}{l}0.3044 E-04 \\
0.1610 E-04 \\
0.9012 E-05 \\
0.4921 E=05 \\
0.2780 \mathrm{E}-05\end{array}$ & $\begin{array}{l}0.1028 E-05 \\
0.4533 E-06 \\
0.1774 E-06 \\
0.9133 E-07 \\
0.4926 E-07\end{array}$ & $\begin{array}{l}0.2258 E-05 \\
0: 7875 E-06 \\
0: 3859 E-06 \\
0.2015 E-06 \\
0.1219 E-06\end{array}$ \\
\hline $\begin{array}{l}0.0785 \\
0.0781 \\
0.0782 \\
0.0779 \\
0.0786 \\
0.0876\end{array}$ & $\begin{array}{r}88.99 \\
11: 44 \\
14: 86 \\
19680 \\
26: 56 \\
34: 54\end{array}$ & $\begin{array}{l}277: 1 \\
277: 2 \\
277: 4 \\
277: 5 \\
278: 5 \\
280: 5\end{array}$ & $\begin{array}{l}0.1198 E-04 \\
0: 6800 E=05 \\
0: 3774 E-05 \\
0.1863 E-05 \\
0.9482 E=06 \\
0.4895 E-06\end{array}$ & $\begin{array}{l}0.3267 E-06 \\
0.1506 E-06 \\
0.6777 E-07 \\
0: 2911 E=07 \\
0.1243 E-07 \\
0.1021 E-07\end{array}$ & $\begin{array}{l}0.7150 E-06 \\
0.3015 E-06 \\
0: 1339 E-06 \\
0: 5325 E-07 \\
0.2906 E-07 \\
0.1777 E-07\end{array}$ \\
\hline $\begin{array}{l}0.1229 \\
0: 1230 \\
0: 1229 \\
0: 1231 \\
0: 1230 \\
0: 1228 \\
0.1264\end{array}$ & $\begin{array}{l}88.98 \\
11: 47 \\
14: 88 \\
19677 \\
26: 79 \\
35: 64 \\
46.39\end{array}$ & $\begin{array}{l}276.6 \\
277: 3 \\
277: 4 \\
278: 3 \\
277: 7 \\
277: 8 \\
279: 4\end{array}$ & $\begin{array}{l}0.8843 E-05 \\
0.50100-05 \\
0.2761 E-05 \\
0.1385 E-05 \\
0.6630 E-06 \\
0.3240 E-06 \\
0.1805 E-06\end{array}$ & $\begin{array}{l}0.2856 E-06 \\
0.1296 E=06 \\
0.5793 E-07 \\
0: 2810 E-07 \\
0.1269 E=07 \\
0: 5519 E-08 \\
0.3645 E-08\end{array}$ & $\begin{array}{l}0.6093 E-06 \\
0.2485 E=06 \\
0.1033 E-06 \\
0.4368 E-07 \\
0.1793 E=07 \\
0.8414 E-08 \\
0.5283 E-08\end{array}$ \\
\hline $\begin{array}{l}0.1737 \\
0: 1736 \\
0: 1732 \\
0: 1739 \\
0: 1740 \\
0: 1739 \\
0: 1743 \\
0.1759\end{array}$ & $\begin{array}{l}99.01 \\
11: 44 \\
14: 91 \\
19: 84 \\
26: 74 \\
35: 71 \\
47: 40 \\
62.97\end{array}$ & $\begin{array}{l}276: 3 \\
276: 8 \\
277: 4 \\
277: 9 \\
277: 6 \\
277: 5 \\
277: 7 \\
279: 2\end{array}$ & $\begin{array}{l}0.5335 E-05 \\
0.3661 E-05 \\
0.1873 E=05 \\
0.9701 E=06 \\
0.4891 E-06 \\
0.2479 E-06 \\
0.1288 E-06 \\
0.6394 E-07\end{array}$ & $\begin{array}{l}0.2226 E-06 \\
0: 1176 E=06 \\
0.5125 E-07 \\
0: 2488 E-07 \\
0: 1194 E=07 \\
0: 5391 E=08 \\
0: 3071 E=08 \\
0.1766 E-08\end{array}$ & $\begin{array}{l}0.4201 E-06 \\
0: 2196 E-06 \\
00.9466 E-07 \\
0.4234 E-07 \\
0.1940 E-07 \\
0.9615 E-08 \\
0.4765 E-08 \\
0.2465 E-08\end{array}$ \\
\hline $\begin{array}{l}0.2396 \\
0: 2447 \\
0: 2446 \\
0: 2447 \\
0: 2457 \\
0: 2450 \\
0: 2439 \\
0: 2510\end{array}$ & $\begin{array}{l}11153 \\
114: 91 \\
19: 69 \\
26: 57 \\
35: 82 \\
47: 22 \\
64: 05 \\
85: 79\end{array}$ & $\begin{array}{l}277.1 \\
277: 6 \\
277: 5 \\
278: 0 \\
277: 2 \\
277: 5 \\
278: 1 \\
279: 4\end{array}$ & $\begin{array}{l}0.2165 E-05 \\
0.1223 E-05 \\
0.6953 E-06 \\
0.3533 E=06 \\
0.1587 E=06 \\
0.8777 E-07 \\
0.4261 E-07 \\
0.2091 E-07\end{array}$ & $\begin{array}{l}0.8153 E-07 \\
0.3361 E=07 \\
0.1575 E=07 \\
0: 8582 E=08 \\
0.3805 E=08 \\
0: 2027 E-08 \\
0.97415=09 \\
0.6490=09\end{array}$ & $\begin{array}{l}0.1378 E-06 \\
0.6072 E-07 \\
0: 2915 E-07 \\
0: 1356=07 \\
0.4357 E-08 \\
0.1982 E-08 \\
0: 9203 E-09 \\
0.5251 E-09\end{array}$ \\
\hline $\begin{array}{l}0.3383 \\
0: 3450 \\
0: 3440 \\
0: 3445 \\
0: 3465 \\
0: 3444 \\
0: 3449 \\
0.3498\end{array}$ & $\begin{array}{r}15.08 \\
19.77 \\
26.59 \\
35.79 \\
47.69 \\
64.04 \\
87.58 \\
118.17\end{array}$ & $\begin{array}{l}276.6 \\
277: 3 \\
27779 \\
277: 6 \\
277: 9 \\
278: 1 \\
278: 5 \\
280.7\end{array}$ & $\begin{array}{l}0.7096 E-06 \\
0.3866 E-06 \\
0.2060 E-06 \\
0.1023 E=06 \\
0.4869 E-07 \\
0.2569 E-07 \\
0.1072 E=07 \\
0.6163 E-08\end{array}$ & $\begin{array}{l}0.2934 E-07 \\
0.1233 \mathrm{E}=07 \\
0.6793 \mathrm{E}-08 \\
0.3307 \mathrm{E}=08 \\
0.1549 \mathrm{E}-08 \\
0.7734 \mathrm{E}-09 \\
0.4319 \mathrm{E}-09 \\
0.3271 \mathrm{E}-09\end{array}$ & $\begin{array}{l}0.2916 E-07 \\
0: 10125-07 \\
0: 5233 E-08 \\
0: 2206 E-08 \\
0: 1069=08 \\
0: 5080 E-09 \\
0: 21066=09 \\
0.1583 E-09\end{array}$ \\
\hline $\begin{array}{l}0.4403 \\
0.4447 \\
0.4442 \\
0.4444 \\
0.4456 \\
0.4422 \\
0.4465 \\
0.4522\end{array}$ & $\begin{array}{r}19.81 \\
26: 75 \\
35: 59 \\
47.66 \\
63: 84 \\
87.92 \\
120.48 \\
165.07\end{array}$ & $\begin{array}{l}276.8 \\
277: 3 \\
277: 0 \\
277: \frac{1}{1} \\
277: 1 \\
278: 6 \\
278: 9 \\
286: 1\end{array}$ & $\begin{array}{l}0.2141 E-06 \\
0.1171=-06 \\
0.6076 E-07 \\
0: 2801 E-07 \\
0.1335 E-07 \\
0.6434 E=08 \\
0.2929 E-08 \\
0.1627 E-08\end{array}$ & 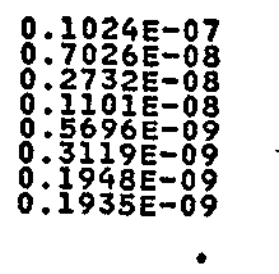 & $\begin{array}{l}0.1370 E-07 \\
0: 5837 E-08 \\
0: 20178 E-08 \\
0: 7431 E-09 \\
0: 2522 E=09 \\
0.1214 E-09 \\
0.5866 E-10 \\
0.5587 E-10\end{array}$ \\
\hline
\end{tabular}


Table II d (cont'd,

\begin{tabular}{|c|c|c|c|c|c|}
\hline$v_{2}$ & $\begin{array}{r}\text { es of the } \\
\text { Beam } \\
Q^{2} \\
\left(G e v^{2}\right)\end{array}$ & $\begin{array}{r}\text { Differen } \\
\text { Muon } \\
\text { Energy }= \\
\text { Energy }\end{array}$ & $\begin{array}{c}\text { Cross-section } \\
\text { ton scattering } \\
\text { GeV, Target } \\
\text { X-sect } \\
\text { (mB/GeV })\end{array}$ & $\begin{array}{l}\text { for Deep Inela } \\
\text { 6m Hydrogen } \\
\text { Stat. Errors }\end{array}$ & astic \\
\hline $\begin{array}{l}0.5429 \\
0.5451 \\
0.5408 \\
0.5433 \\
0.5412 \\
0.5448 \\
0.5476\end{array}$ & $\begin{array}{r}26.80 \\
35.89 \\
47.41 \\
63.92 \\
87.83 \\
121.84 \\
167.87\end{array}$ & $\begin{array}{l}277 \cdot 2 \\
276: 1 \\
277: 8 \\
276: 7 \\
278: 0 \\
280: 2 \\
281: 5\end{array}$ & $\begin{array}{l}0.5857 E-07 \\
0.2258 E-07 \\
0.1239 E-07 \\
0.765 I E-08 \\
0.3248 E-08 \\
0.1420 E-08 \\
0.5543 E-09\end{array}$ & $\begin{array}{l}0.3795 E-08 \\
0.2285 E-08 \\
0.8020 E-09 \\
0.4386 E-09 \\
0.2227 E-09 \\
0.1327 E=09 \\
0.8869 E-10\end{array}$ & $\begin{array}{l}0.5538 \mathrm{E}-08 \\
0.1501 \mathrm{E}-08 \\
0.5199 \mathrm{E}-09 \\
0.2234 \mathrm{E}-09 \\
0.7205 \mathrm{E}-10 \\
0.2814 \mathrm{E}-10 \\
0.1316 \mathrm{E}-10\end{array}$ \\
\hline $\begin{array}{l}0.6414 \\
0.6437 \\
0.6378 \\
0.6473 \\
0.6373 \\
0.6304\end{array}$ & $\begin{array}{r}35.28 \\
48.27 \\
64: 15 \\
88.02 \\
121.80 \\
164.17\end{array}$ & $\begin{array}{l}278 \cdot 4 \\
278: 9 \\
278: 1 \\
279: 0 \\
277: 7 \\
275.8\end{array}$ & $\begin{array}{l}0.1486 E-07 \\
0.6328 E-08 \\
0.2662 E=08 \\
0.1576 E=08 \\
0.7797 E=09 \\
0.2513 E-09\end{array}$ & $\begin{array}{l}0.1433 E-08 \\
0.7066 E-09 \\
0.2582 E-09 \\
0.1518 E-09 \\
0.1012 E-09 \\
0.6118 E-10\end{array}$ & $\begin{array}{l}0.2049 \mathrm{E}-08 \\
0.5623 \mathrm{E}-09 \\
0.1484 \mathrm{E}-09 \\
0.6223 \mathrm{E}-10 \\
0.2106 \mathrm{E}-10 \\
0.6466 \mathrm{E}-11\end{array}$ \\
\hline $\begin{array}{l}0.7346 \\
0.7395 \\
0.7390 \\
0.7424 \\
0.7230\end{array}$ & $\begin{array}{r}46.40 \\
62.62 \\
88.10 \\
121.58 \\
153.44\end{array}$ & $\begin{array}{l}277 \cdot 2 \\
277: 5 \\
287: 5 \\
279.4 \\
277.6\end{array}$ & $\begin{array}{l}0.2414 E-08 \\
0.1475 E-08 \\
0: 6866 E-09 \\
0.3309 E-09 \\
0.1395 E-09\end{array}$ & $\begin{array}{l}0.3996 E-09 \\
0.2095 E-09 \\
0.1118 E-09 \\
0.6729 E-10 \\
0.4956 E-10\end{array}$ & $\begin{array}{l}0.3527 E-09 \\
0.1516 E-09 \\
0.4876 E-10 \\
0.1677 E-10 \\
0.4317 E-11\end{array}$ \\
\hline
\end{tabular}


Table 12

\begin{tabular}{|c|c|c|c|c|c|c|}
\hline \multirow[b]{2}{*}{$\left(\mathrm{GeV}^{2}\right)$} & \multicolumn{5}{|c|}{$\begin{array}{l}\text { Valucs of the Ratio } R=\sigma / \sigma \\
\text { for Deep Inelastic muon-proton scattering }\end{array}$} & \multirow[b]{2}{*}{ syst. } \\
\hline & $\left(G a^{2} v^{2}\right)$ & $x$ & $\mathbf{R}$ & Total & $\begin{array}{l}\text { Errors } \\
\text { stat. }\end{array}$ & \\
\hline $\begin{array}{l}70.0 \\
70: 0 \\
70.0 \\
70.0 \\
70.0\end{array}$ & $\begin{array}{l}15: 00 \\
250: 00 \\
27: 00 \\
36: 00 \\
48: 00\end{array}$ & $\begin{array}{l}0.114 \\
0: 152 \\
0: 208 \\
0: 274 \\
0.365\end{array}$ & $\begin{array}{r}0.257 \\
-0.154 \\
-0.025 \\
0.306 \\
1.542\end{array}$ & $\begin{array}{l}0.395 \\
0.206 \\
.2065 \\
0.506 \\
2.094\end{array}$ & $\begin{array}{l}0.223 \\
0.125 \\
0.150 \\
0.435 \\
1.970\end{array}$ & $\begin{array}{l}0.326 \\
0.164 \\
0.185 \\
0.260 \\
0.708\end{array}$ \\
\hline $\begin{array}{l}90.0 \\
90: 0 \\
90: 0 \\
90: 0 \\
90.0\end{array}$ & $\begin{array}{l}11: 50 \\
15: 00 \\
200: 00 \\
27: 00 \\
36: 00\end{array}$ & $\begin{array}{l}0.068 \\
0: 089 \\
0: 118 \\
0: 160 \\
0.213\end{array}$ & $\begin{array}{r}-0.088 \\
-0.013 \\
-0.174 \\
0.000 \\
-0.110\end{array}$ & $\begin{array}{l}0.149 \\
0: 162 \\
0: 219 \\
0: 196 \\
0: 202\end{array}$ & $\begin{array}{l}0.094 \\
0.0908 \\
0: 098 \\
0: 159 \\
0.177\end{array}$ & $\begin{array}{l}0.116 \\
0: 121 \\
0: 156 \\
0.115 \\
0.097\end{array}$ \\
\hline $\begin{array}{l}110: 0 \\
110: 0 \\
110: 0 \\
110: 0\end{array}$ & $\begin{array}{l}27.00 \\
36: 00 \\
48: 00 \\
65: 00\end{array}$ & $\begin{array}{l}0.131 \\
0: 174 \\
0: 233 \\
0: 315\end{array}$ & $\begin{array}{r}0.100 \\
0: 338 \\
-0.071 \\
-0.476\end{array}$ & $\begin{array}{l}0.447 \\
0.559 \\
0: 340 \\
0: 179\end{array}$ & $\begin{array}{l}0.429 \\
0.523 \\
0: 334 \\
0.177\end{array}$ & $\begin{array}{r}0.127 \\
0.0183 \\
0.0067 \\
0.027\end{array}$ \\
\hline $\begin{array}{l}1300 \\
130: 0 \\
130: 0 \\
130: 0 \\
130: 0 \\
130: 0 \\
130: 0\end{array}$ & $\begin{array}{l}15.00 \\
20: 00 \\
27000 \\
36: 00 \\
48: 00 \\
65: 00 \\
90: 00\end{array}$ & $\begin{array}{l}0.062 \\
0: 082 \\
0: 111 \\
0: 148 \\
0: 197 \\
0: 266 \\
0: 369\end{array}$ & $\begin{array}{l}-0.288 \\
-0: 235 \\
-0.025 \\
-0.232 \\
-0.232 \\
-0.252 \\
-0.368\end{array}$ & $\begin{array}{l}0.156 \\
0: 330 \\
0: 209 \\
0: 170 \\
0: 197 \\
0: 294 \\
0.467\end{array}$ & $\begin{array}{l}0.145 \\
0: 318 \\
0: 201 \\
0: 195 \\
0: 193 \\
0: 293 \\
0: 226\end{array}$ & $\begin{array}{l}0.058 \\
0: 0839 \\
0: 058 \\
0.038 \\
0.039 \\
0: 032 \\
0.369\end{array}$ \\
\hline $\begin{array}{l}150: 0 \\
150: 0 \\
150: 0 \\
150: 0 \\
150: 0 \\
150: 0 \\
150: 0\end{array}$ & $\begin{array}{l}11750 \\
175: 00 \\
20: 00 \\
27: 00 \\
36: 00 \\
48: 00 \\
65: 00\end{array}$ & $\begin{array}{l}0.041 \\
0: 053 \\
0: 071 \\
0: 096 \\
0: 128 \\
0: 170 \\
0: 231\end{array}$ & $\begin{array}{r}-0.060 \\
0: 064 \\
-00: 081 \\
0: 092 \\
0: 037 \\
0: 560 \\
0.469\end{array}$ & $\begin{array}{l}0.190 \\
0: 268 \\
0: 184 \\
0: 194 \\
0: 225 \\
0: 457 \\
0: 721\end{array}$ & $\begin{array}{l}0.169 \\
0: 252 \\
0: 173 \\
0: 179 \\
0: 210 \\
0: 440 \\
0: 543\end{array}$ & $\begin{array}{l}0.086 \\
0: 093 \\
0: 082 \\
0: 075 \\
0: 082 \\
0: 126 \\
0.474\end{array}$ \\
\hline
\end{tabular}


Table 13

Values of $R$ as a function of $Q^{2}, v$ and $x$

a)

\begin{tabular}{|lccccc|}
\hline $\begin{array}{c}\mathrm{Q}^{2} \\
\left(\mathrm{GeV}^{2}\right)\end{array}$ & $\begin{array}{l}\text { v bins } \\
(\mathrm{GeV})\end{array}$ & $\mathrm{R}$ & Tota1 & $\begin{array}{r}\text { Errors } \\
\text { Stat. }\end{array}$ & Syst. \\
\hline 11.5 & 90,150 & -0.081 & 0.131 & 0.082 & 0.102 \\
15 & $70,90,130,150$ & -0.047 & 0.158 & 0.081 & 0.135 \\
20 & $70,90,130,150$ & -0.110 & 0.121 & 0.071 & 0.098 \\
27 & $70-150$ & 0.022 & 0.131 & 0.089 & 0.095 \\
36 & $70-150$ & -0.007 & 0.135 & 0.105 & 0.084 \\
48 & $70,110-150$ & 0.220 & 0.224 & 0.203 & 0.094 \\
65 & $110-150$ & -0.059 & 0.228 & 0.222 & 0.051 \\
90 & 110,130 & 0.076 & 0.489 & 0.484 & 0.066 \\
\hline
\end{tabular}

b)

\begin{tabular}{|rrrrrr|}
\hline $\begin{array}{c}\nu \\
(\mathrm{GeV})\end{array}$ & $\begin{array}{c}\mathrm{Q}^{2} \text { range } \\
\left(\mathrm{GeV}^{2}\right)\end{array}$ & $\mathrm{R}$ & Total & $\begin{array}{r}\text { Errors } \\
\text { stat. }\end{array}$ & syst. \\
\hline 70 & $15-48$ & 0.092 & 0.254 & 0.103 & 0.233 \\
90 & $11.5-36$ & -0.077 & 0.121 & 0.052 & 0.109 \\
110 & $27-90$ & 0.059 & 0.227 & 0.202 & 0.104 \\
130 & $15-125$ & -0.125 & 0.098 & 0.083 & 0.052 \\
150 & $11.5-65$ & 0.104 & 0.116 & 0.085 & 0.079 \\
\hline
\end{tabular}

c)

\begin{tabular}{|c|c|c|c|c|c|}
\hline \multirow[t]{2}{*}{$x$} & \multirow[t]{2}{*}{$\begin{array}{l}\left\langle Q^{2}\right\rangle \\
\left(\mathrm{GeV}^{2}\right)\end{array}$} & \multirow[t]{2}{*}{$\mathbf{R}$} & \multicolumn{3}{|c|}{ Errors } \\
\hline & & & Tota1 & stat. & syst. \\
\hline 0.05 & 12.5 & 0.081 & 0.208 & 0.144 & 0.151 \\
\hline 0.07 & 15 & -0.119 & 0.130 & 0.073 & 0.107 \\
\hline 0.09 & 18 & 0.045 & 0.159 & 0.090 & 0.132 \\
\hline 0.12 & 22.5 & -0.009 & 0.149 & 0.078 & 0.127 \\
\hline 0.16 & 30 & -0.011 & 0.170 & 0.090 & 0.145 \\
\hline 0.22 & 40 & -0.048 & 0.169 & 0.106 & 0.132 \\
\hline 0.32 & 55 & 0.069 & 0.254 & 0.189 & 0.170 \\
\hline
\end{tabular}




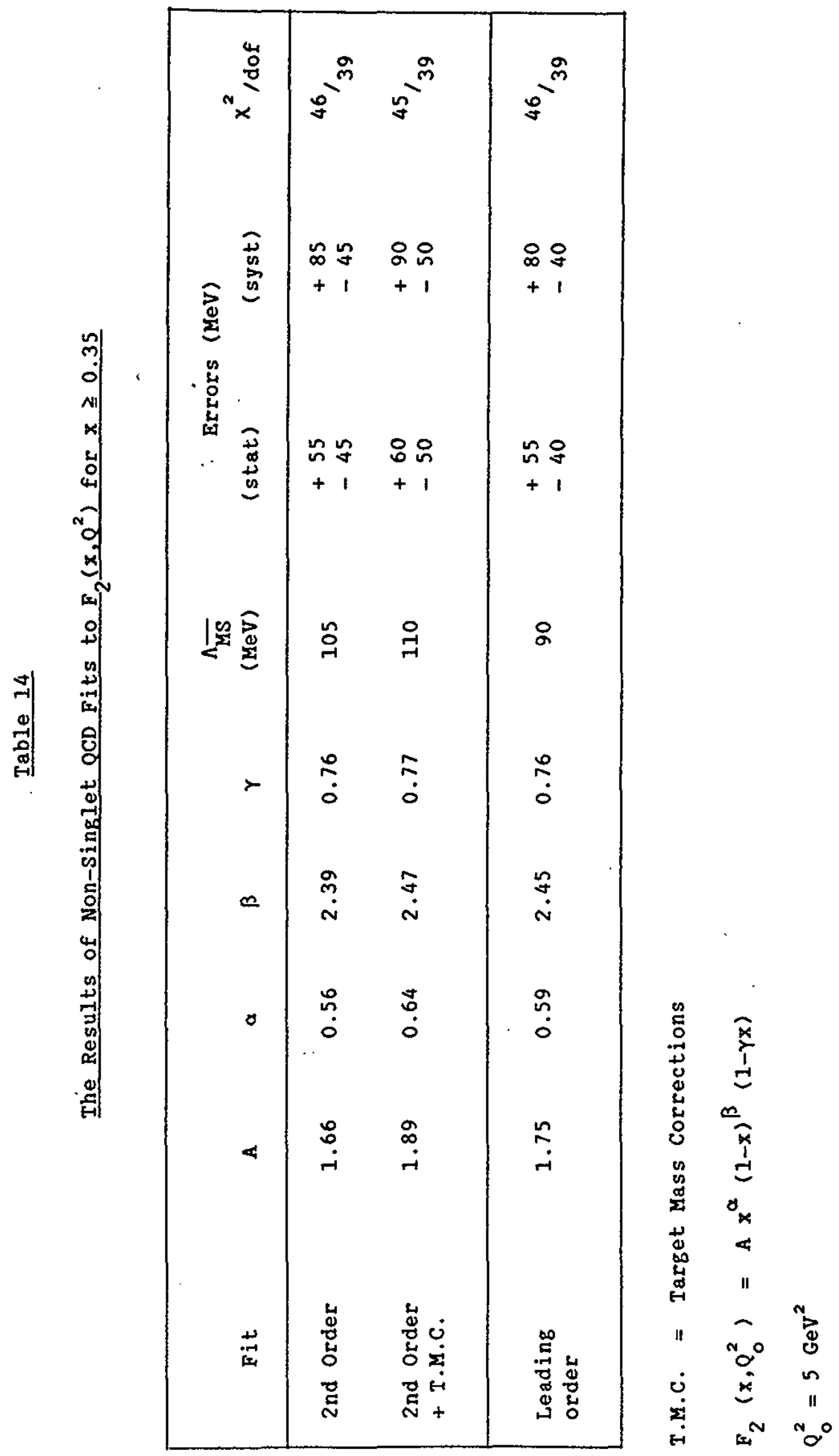




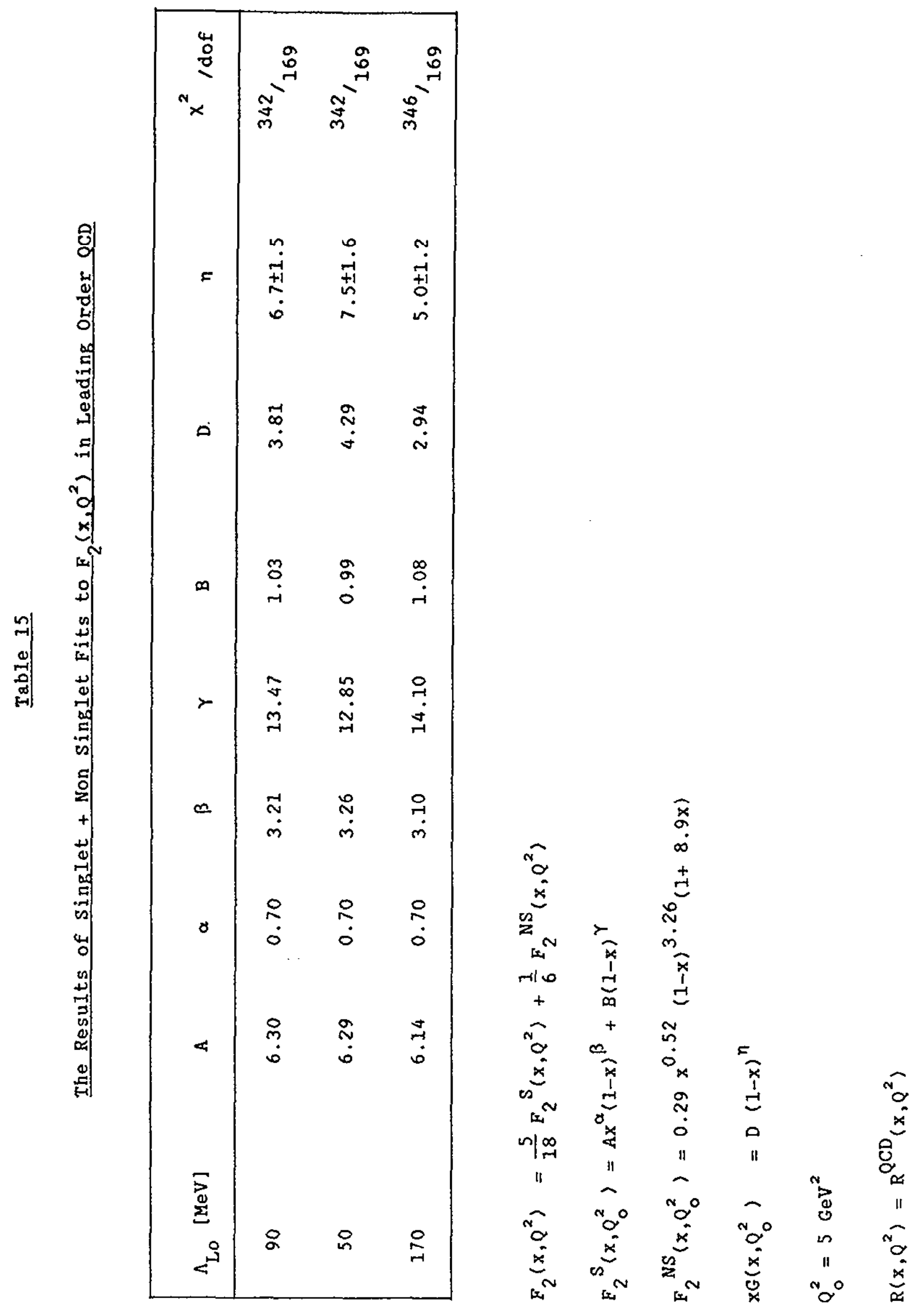


Table 16

The Results for Higher Twist Fits to the EMC and SLAC-MIT

Data for $x \geq 0.35$ and $Q^{2}>2 \mathrm{GeV}^{2}$

a) $\mathrm{F}_{2}=\mathrm{F}_{2}^{\mathrm{LT}}\left(1+\mathrm{H}_{4}(\mathrm{x}) / \mathrm{Q}^{2}\right)$

\begin{tabular}{|c|c|c|}
\hline$\overline{\mathrm{MS}}(\mathrm{MeV})$ & $\begin{array}{r}105+75 \\
-55\end{array}$ & $\begin{array}{r}100^{+} 85 \\
-60\end{array}$ \\
\hline Target Mass Corrections & No & YES \\
\hline Higher Twist Values & \multicolumn{2}{|c|}{$\mathrm{H}_{4}(\mathrm{x})\left(\mathrm{GeV}^{2}\right)$} \\
\hline$x=0.35$ & $-0.15 \pm 0.08$ & $-0.03 \pm 0.08$ \\
\hline$x=0.45$ & $0.13 \pm 0.16$ & $0.29 \pm 0.15$ \\
\hline$x=0.55$ & $0.91 \pm 0.33$ & $0.92 \pm 0.28$ \\
\hline$x=0.65$ & $2.52 \pm 0.55$ & $1.80 \pm 0.44$ \\
\hline$x=0.75$ & $5.32 \pm 0.85$ & $2.28 \pm 0.69$ \\
\hline$x=0.80$ & $8.35 \pm 1.17$ & $2.49 \pm 1.03$ \\
\hline$x^{2} /$ dof & $71 / 71$ & $71 / 71$ \\
\hline
\end{tabular}

b) $\mathrm{F}_{2}=\mathrm{F}_{2}^{\mathrm{LT}}+\mathrm{H}_{4}{ }^{\prime}(\mathrm{x}) / \mathrm{Q}^{2}$

\begin{tabular}{|c|c|c|}
\hline$\Lambda_{\mathrm{MS}}(\mathrm{MeV})$ & $\begin{array}{r}85+85 \\
-55\end{array}$ & $\begin{array}{r}80+75 \\
-50\end{array}$ \\
\hline Target Mass Corrections & No & YES \\
\hline Higher Iwist Values & $\mathrm{H}_{4}$ & \\
\hline$x=0.35$ & $-0.032 \pm 0.027$ & $0.002 \pm 0.022$ \\
\hline$x=0.45$ & $0.032 \pm 0.033$ & $0.059 \pm 0.026$ \\
\hline$x=0.55$ & $0.106 \pm 0.033$ & $0.106 \pm 0.027$ \\
\hline$x=0.65$ & $0.139 \pm 0.023$ & $0.109 \pm 0.020$ \\
\hline$x=0.75$ & $0.101 \pm 0.012$ & $0.062 \pm 0.012$ \\
\hline$x=0.80$ & $0.074 \pm 0.008$ & $0.039 \pm 0.010$ \\
\hline$x^{2} /$ dof & $72 / 71$ & $72 / 71$ \\
\hline
\end{tabular}




\section{Table 17}

The Results of QCD and QCD + Higher Twist Fits to the EMC and SLAC-MIT Data, $x \geq 0.33, \mathrm{Q}^{2}>2 \mathrm{GeV}^{2}$

\begin{tabular}{|c|c|c|c|c|}
\hline Type of Fit & $\begin{array}{c}\Lambda \overline{M S} \text {, Error (stat) } \\
(\mathrm{MeV})\end{array}$ & $\alpha$ & $\begin{array}{l}\mu_{4}^{2} \\
\left(\mathrm{GeV}^{2}\right)\end{array}$ & $x^{2} /$ dof \\
\hline QCD & $255 \pm 15$ & - & - & $204 / 83$ \\
\hline$Q C D+$ T.M.C. & $280 \pm 20$ & - & - & $131 / 83$ \\
\hline$F_{2}=F_{2}^{L T}\left(1+\frac{\mu_{4}{ }^{2} x^{\alpha}}{(1-x) Q^{2}}\right)$ & $115 \pm \begin{array}{l}70 \\
55\end{array}$ & $3.1 \pm 0.5$ & $1.7 \pm 0.5$ & $97 / 80$ \\
\hline+ T.M.C & & & & \\
\hline
\end{tabular}

T.M.C. = Target Mass Corrections 


\section{Figure Captions}

1) The Feynman diagram for the first order deep inelastic muon-proton scattering process.

2) $F_{2}$ as a function of $y$ for different values of $R$, assuming the same cross-section.

3) The $Q^{2}-x$ measurement region of EMC compared to those of SLAC $[11,12]$ and CHIO [15].

4) The EMC Forward spectrometer.

5) The basic single muon trigger.

6) A typical fitted spatial efficiency variation from the drift chamber plane W1 Y1.

7) Lowest order contributions to the radiative corrections.

8) Some second order contributions to the radiative corrections.

9) The magnitude of the radiative correction factor, $n$, for the $280 \mathrm{GeV}$ data in various $x$ bins as a function of $y$.

10) The effect of a $0.4 \%$ change in the beam energy on the measurement of $F_{2}$.

11) Ratio of empty to full target events as a function of position along the target in $x$. The arrows indicate the limits on the vertex position accepted in the analysis.

12) A comparison of the $F_{2}\left(x, Q^{2}\right)$ results from the $120,200,240$ and $280 \mathrm{GeV}$ datasets.

13) The final values of $F_{2}\left(x, Q^{2}\right)$ in bins of $x$ as a function of $Q^{2}$.

14) A comparison of the EMC and SLAC-MIT results for $F_{2}\left(x, Q^{2}\right)$ in the region $Q^{2}>2 \mathrm{Gev}^{2}$. 
15) $b(x)=\mathrm{dF}_{2} / \mathrm{dln} Q^{2}$ vs $x$. The inner error bars are statistical and the outer bars are the total errors. (a) $R=0.0$, (b) $R=R$, $\Lambda_{L O}=90 \mathrm{MeV}$. The solid curve is the leading order QCD fit to the data.

16) The $Q^{2}-v$ region for which measurements of $R$ have been made. The region covered by the data at each energy is indicated.

17) $\sigma_{L}+\varepsilon \sigma_{T}$ verses $\varepsilon$ for three typical $Q^{2}, \nu$ bins. The straight Iines are the fits from which $R$ was derived.

18) The $Q^{2}, v$ and $x$-dependences of $R=\sigma_{L} / \sigma_{T}$. The inner error bars are statistical and the outer bars are the total errors. The solid curves are leading order QCD predictions for $\Lambda_{L O}=90 \mathrm{MeV}$.

19) Comparison of the data for $x \geq 0.35$ with the next to leading order QCD fit, with $\overline{\mathrm{MS}}=105 \mathrm{MeV}$.

20) The Energy Momentum Sum Rule. Cornwall Norton and Nachtmann integrals of $F_{2}\left(x, Q^{2}\right)$ derived by combining the EMC and SLAC-MIT proton data. The solid curves are leading order QCD calculations for $\Lambda_{\text {LO }}=90 \mathrm{MeV}$.

21) The twist 4 functions $H_{4}(x)$ and $H_{4}^{\prime}(x)$ from fits to the EMC and SLAC-MIT data.

$\mathrm{H}_{4}(\mathrm{x})$ (a) no target mass corrections

(b) with target mass corrections included..

$\mathrm{H}_{4}^{\prime}(\mathrm{x})$ (c) no target mass corrections

(d) with target mass corrections included

22) EMC and SLAC-MIT data for $x \geq 0.45$ showing the effects of higher twist contributions. The solid curve is the combined next to leading order, leading twist and twist 4 fit to the data. The dashed curve is the result of the next to leading order fit to the EMC data. Target mass corrections are included in both fits. 
Scattered muon

$P_{3}=\left(E^{\prime}, P^{\prime}\right)$

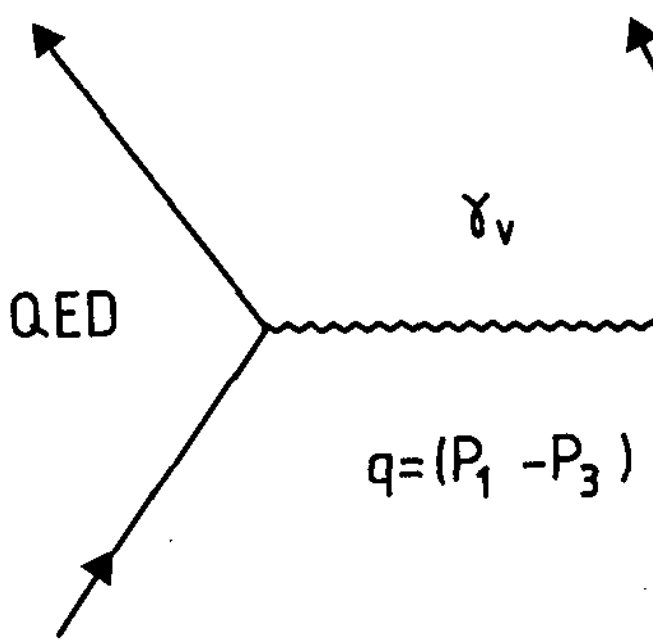

$$
P_{1}=(E, P)
$$

Incident muon
Final state hadrons $W^{2}$

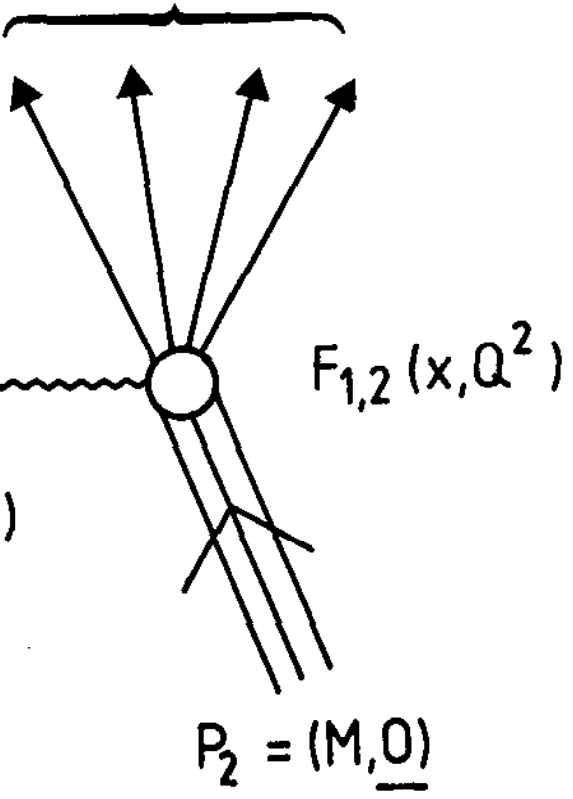

Target proton

Fig. 1 


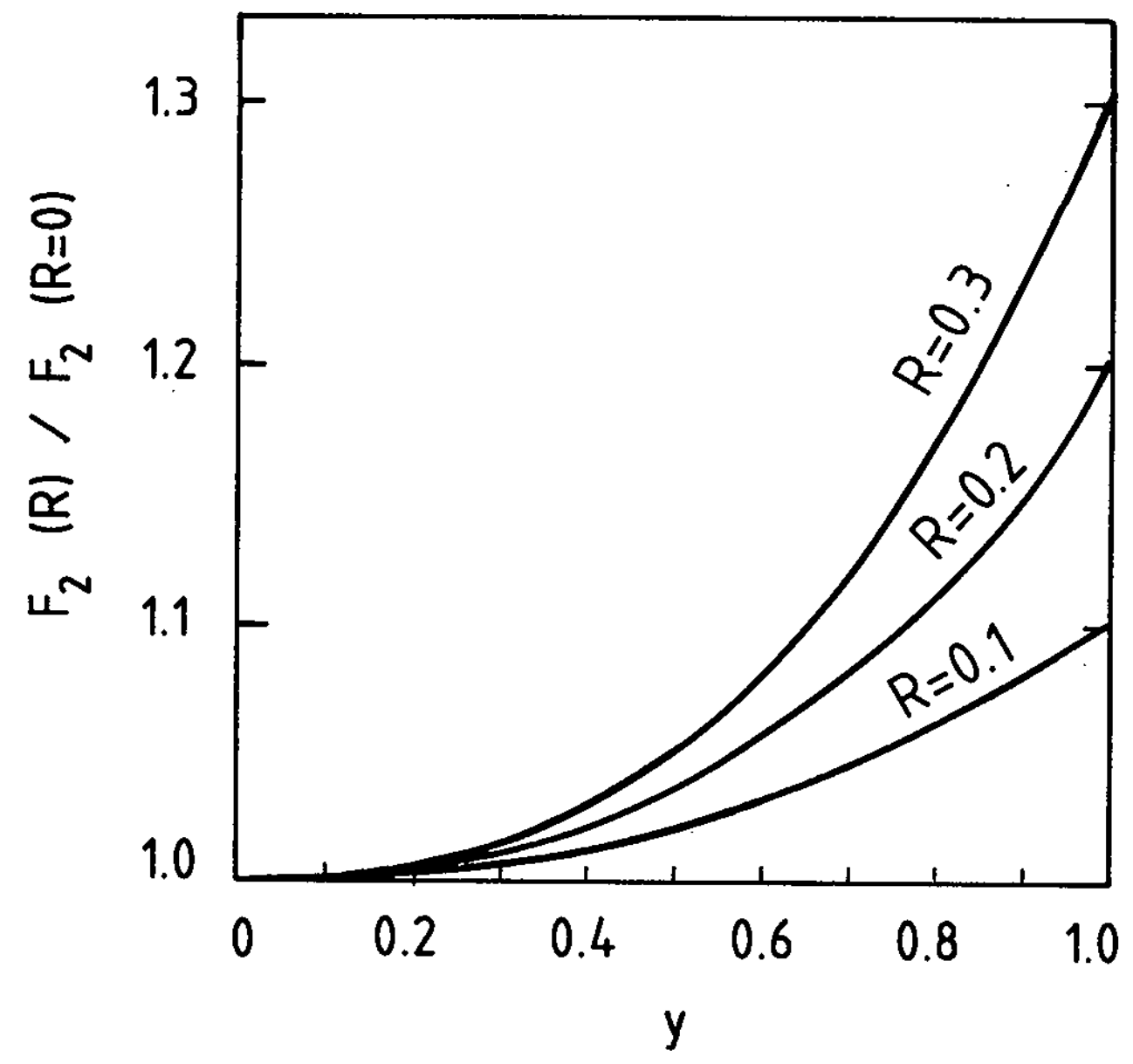

Fig. 2 


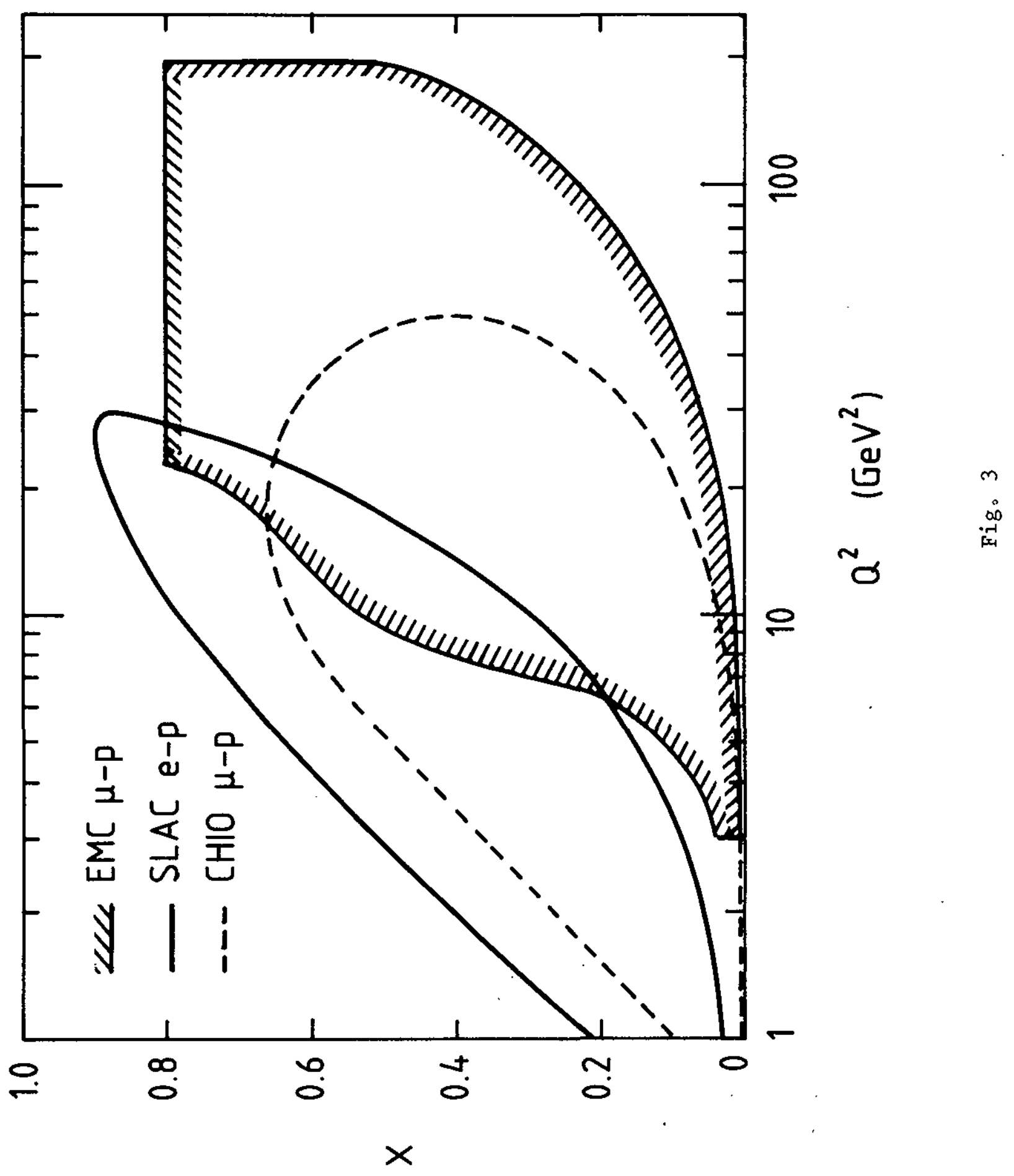




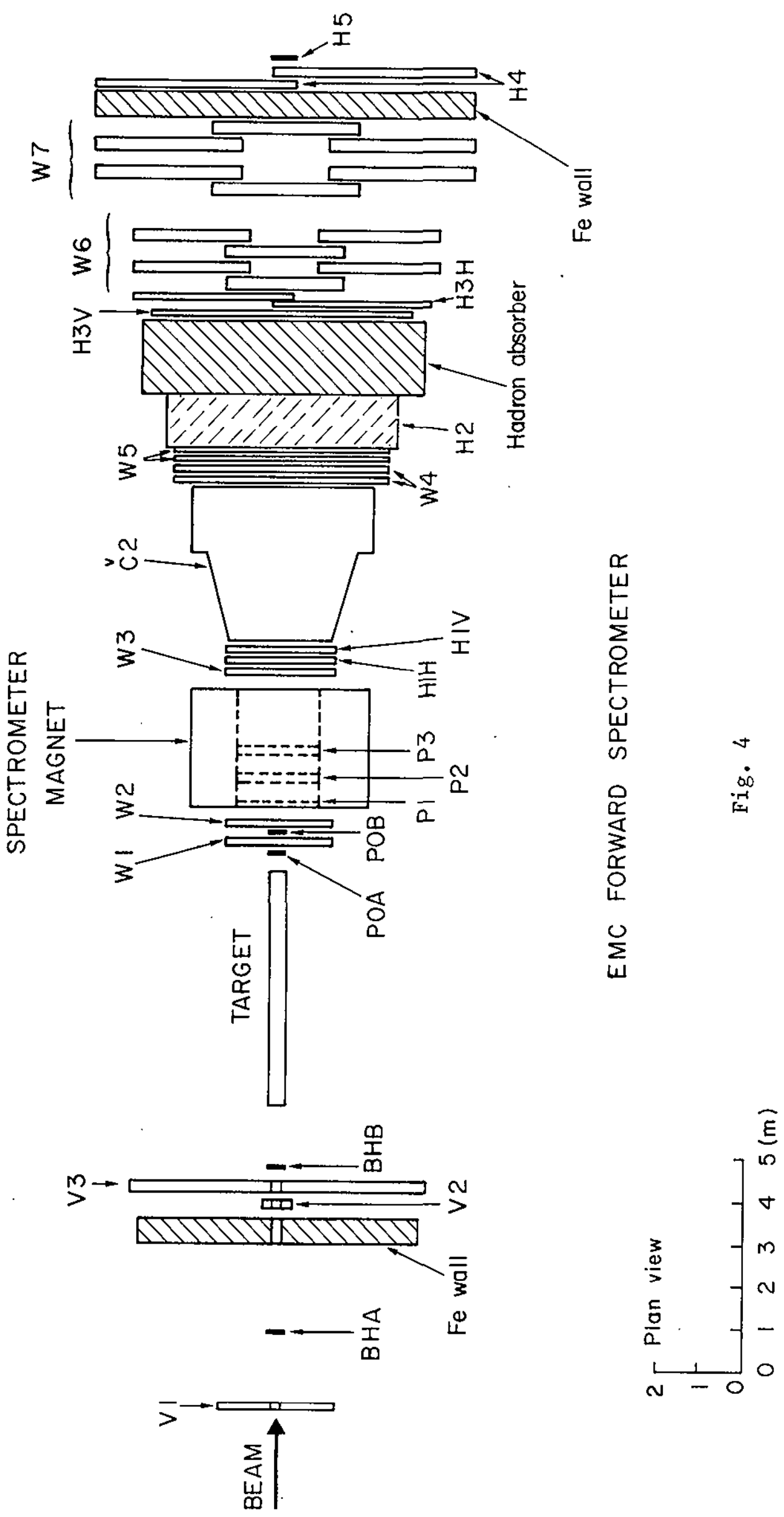




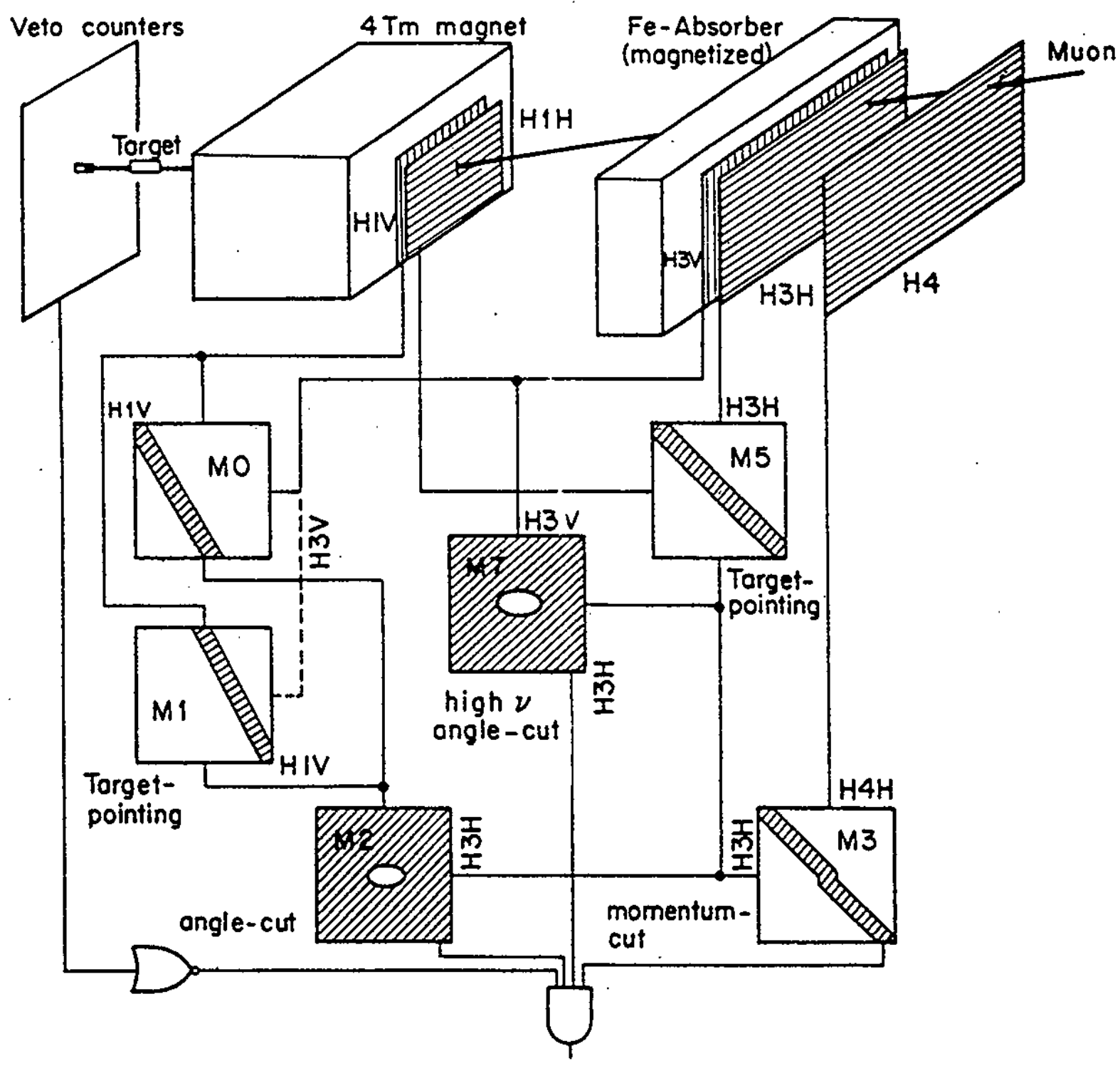

Fig. 5 


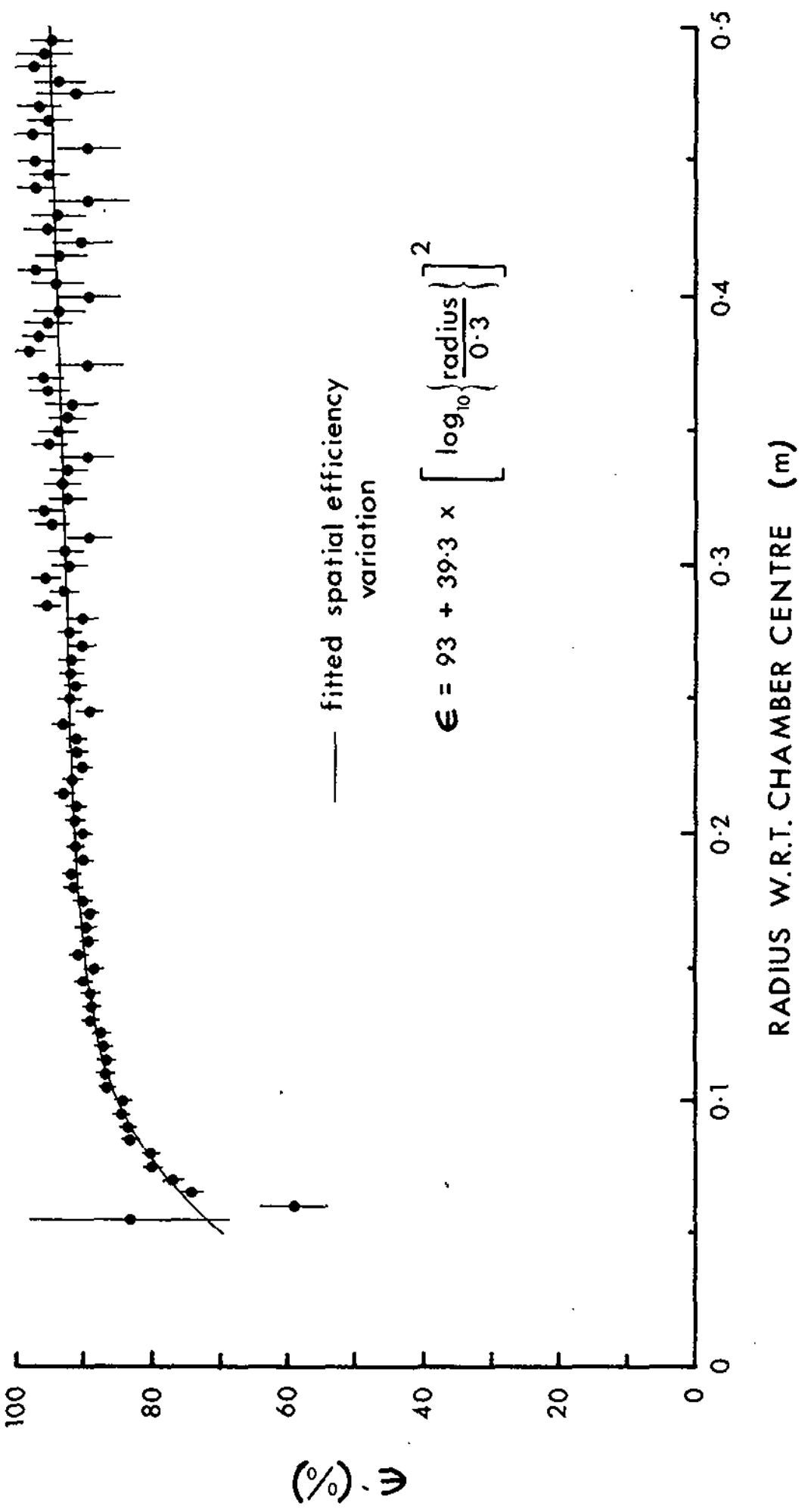

0
of
ir 

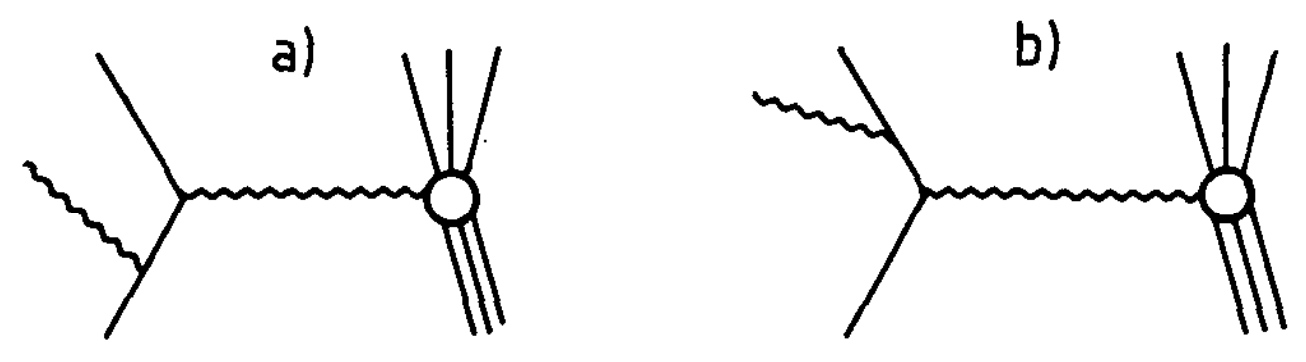

Internal Bremsstrahlung

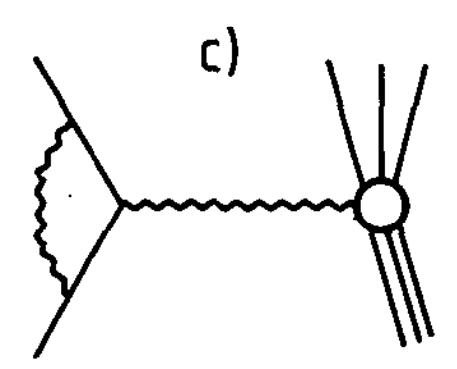

Vertex correction

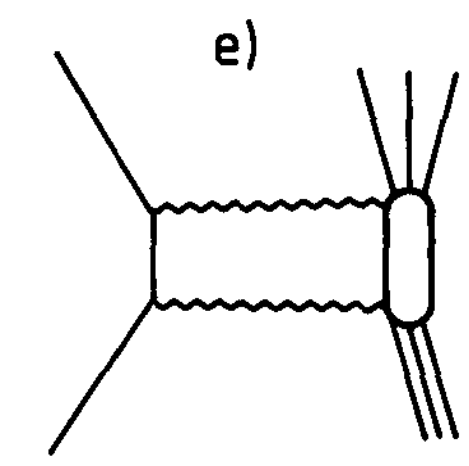

Two photon exchange

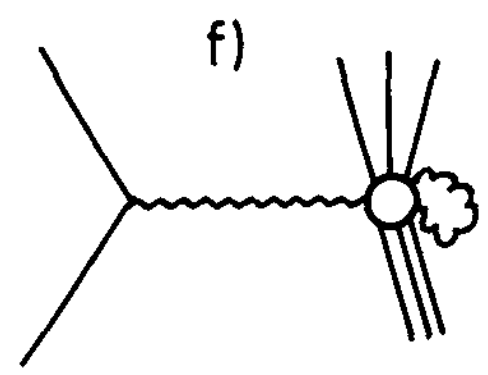

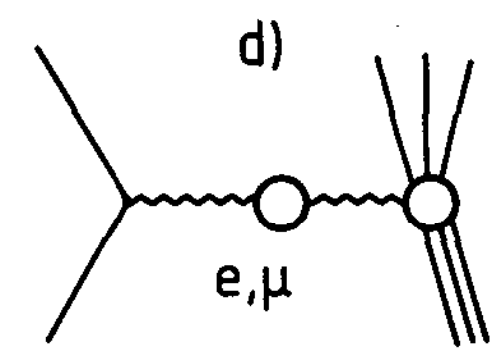

Vacuum polarisation correction

Hadron current corrections 


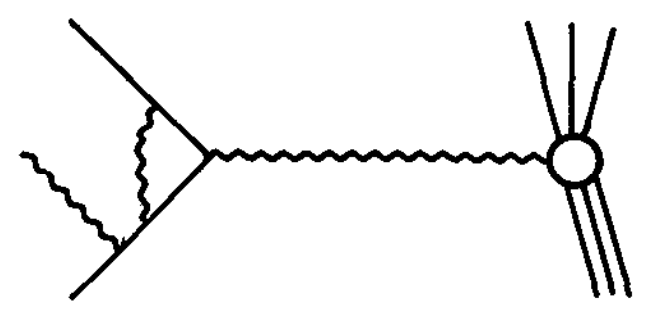

\section{Vertex correction $+$}

Internal Bremsstrahlung
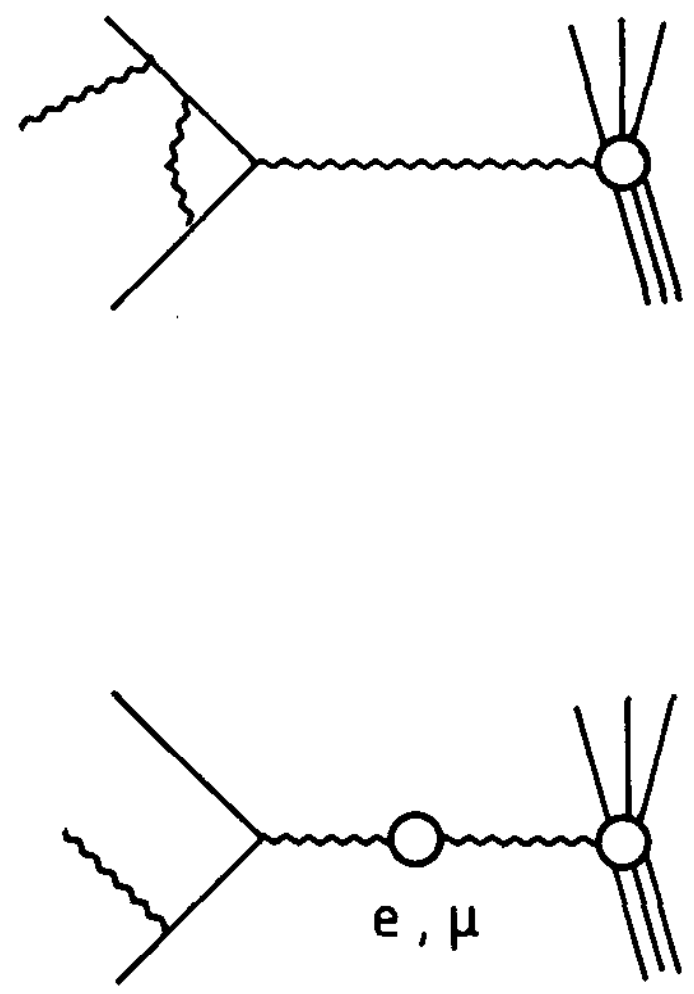

Vacuum polarisation
+

Internal Bremsstrahlung

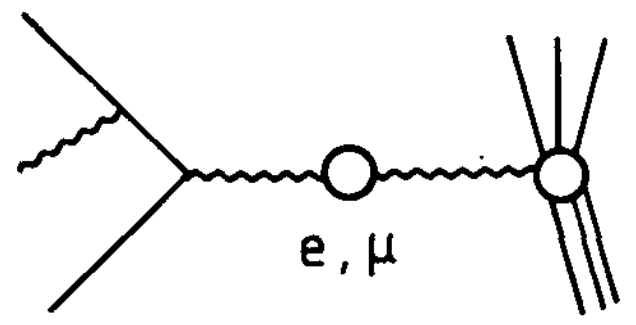

Fig. 8 

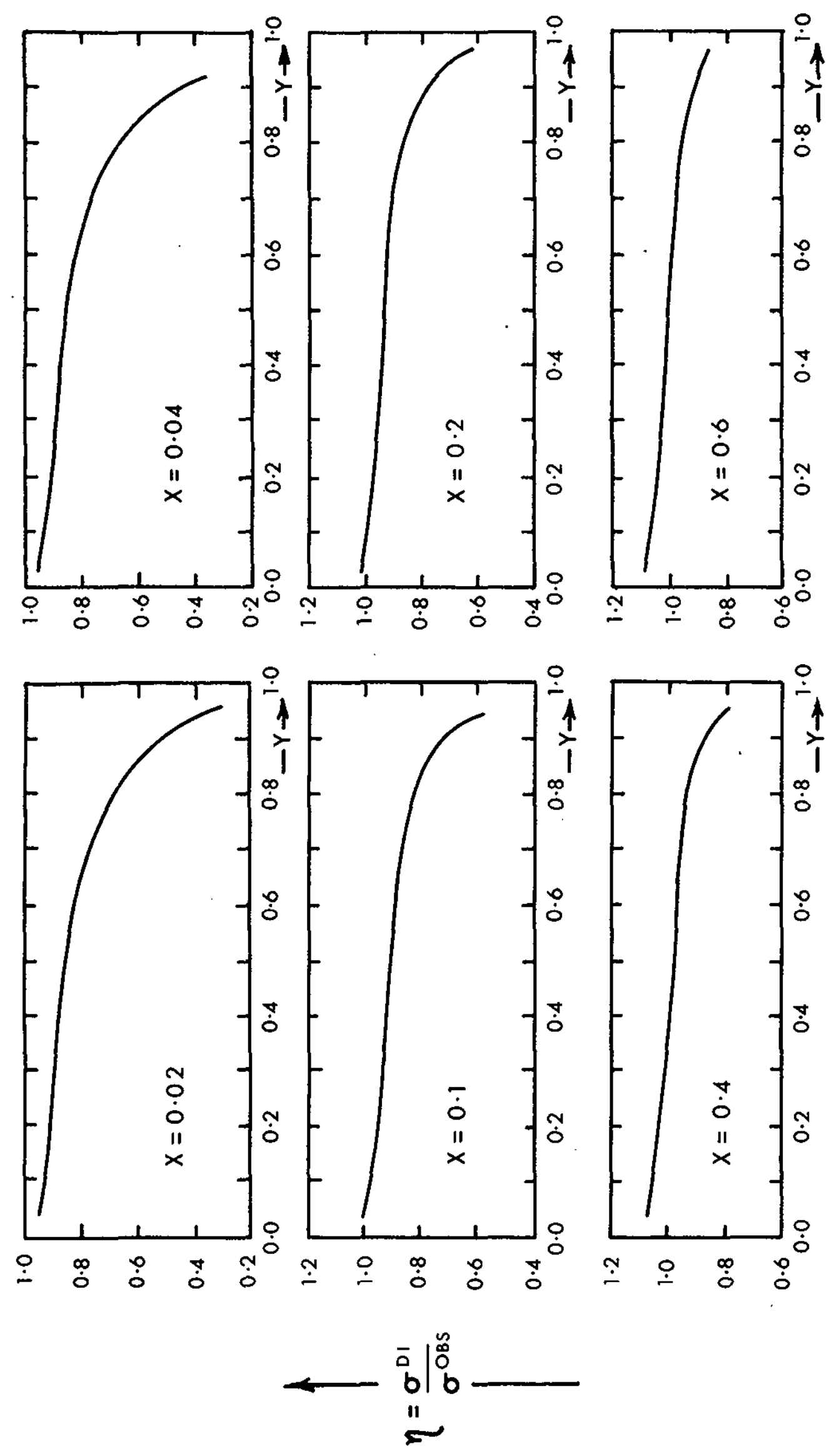

$a$ 


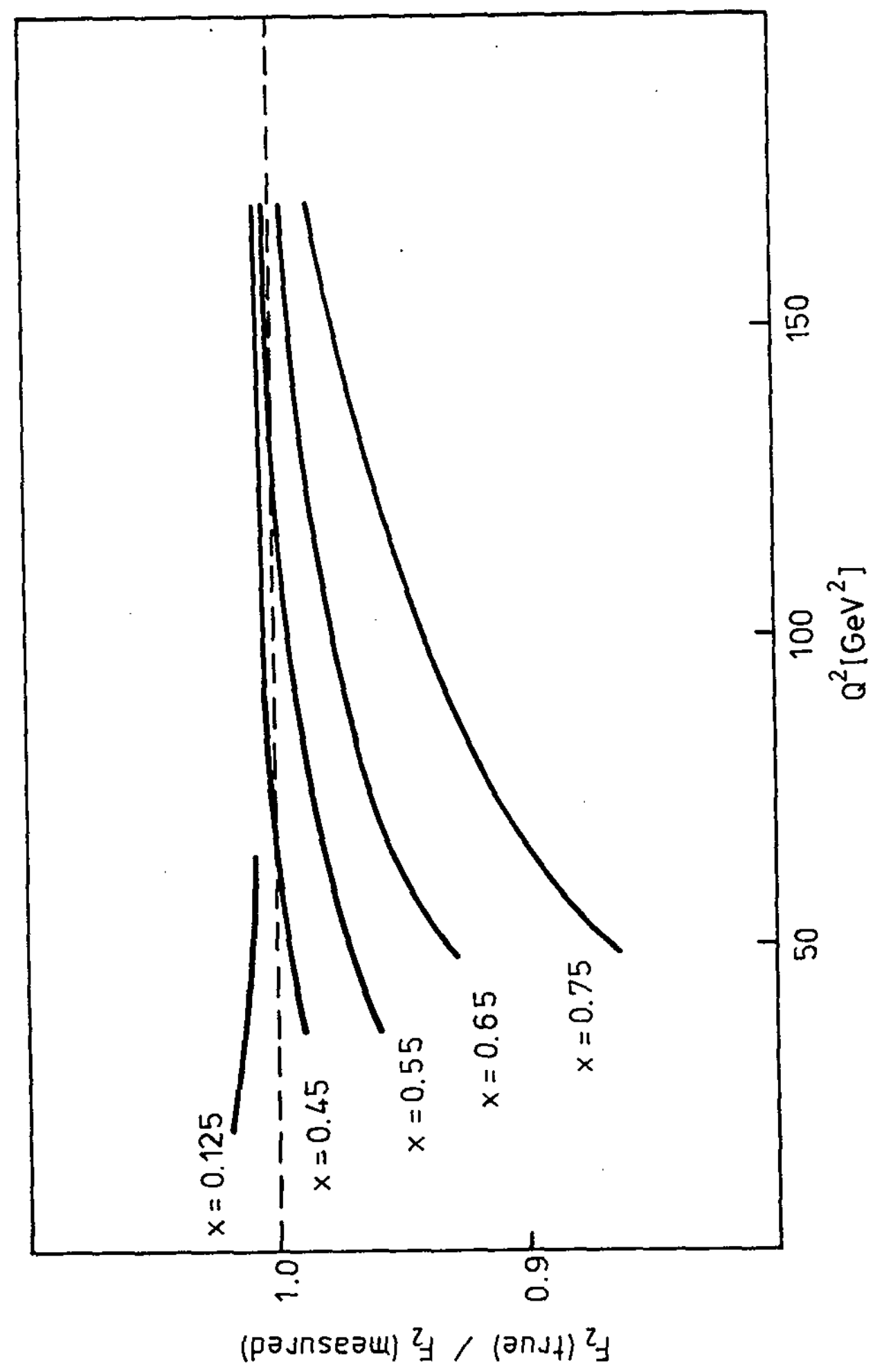




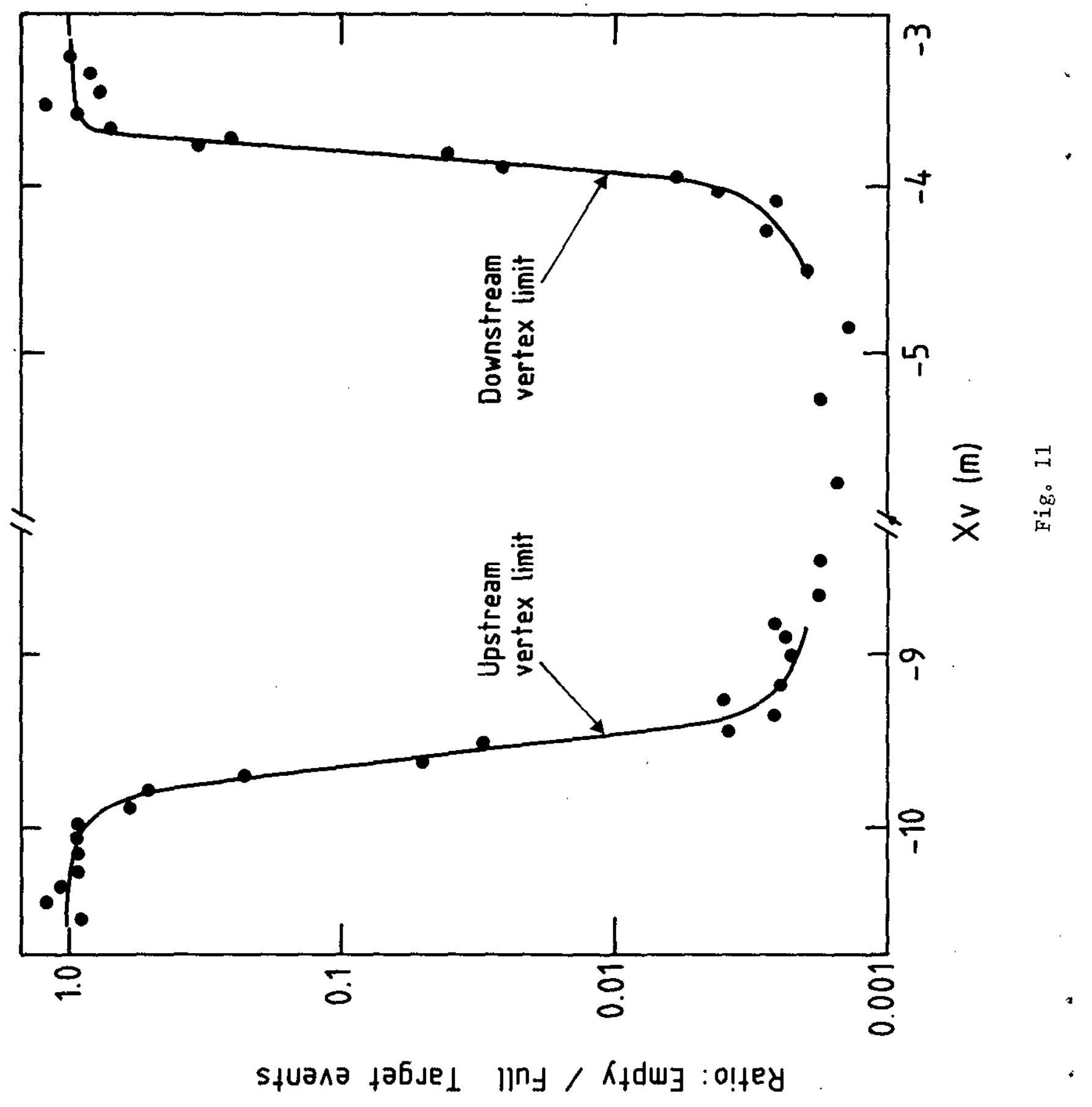



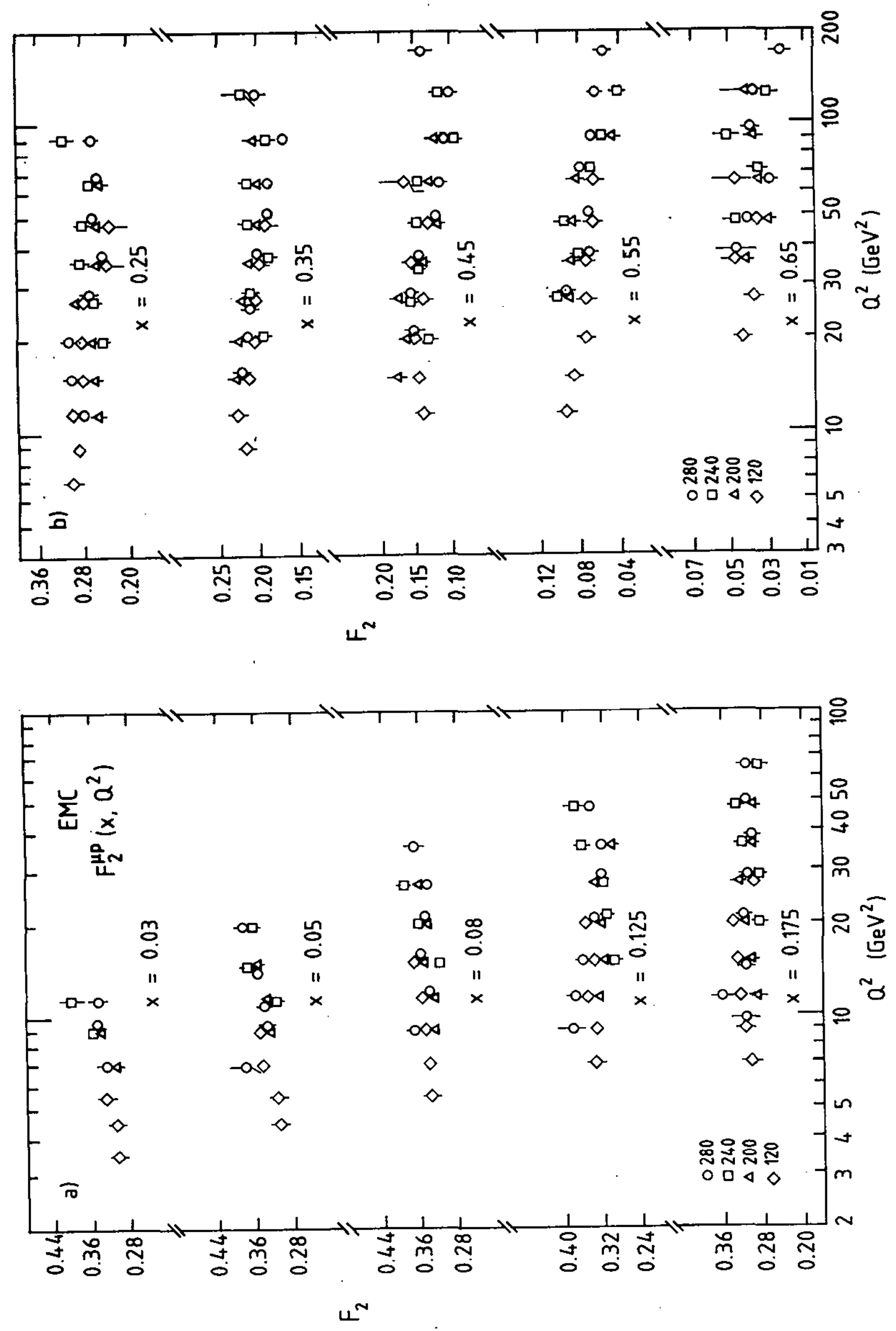


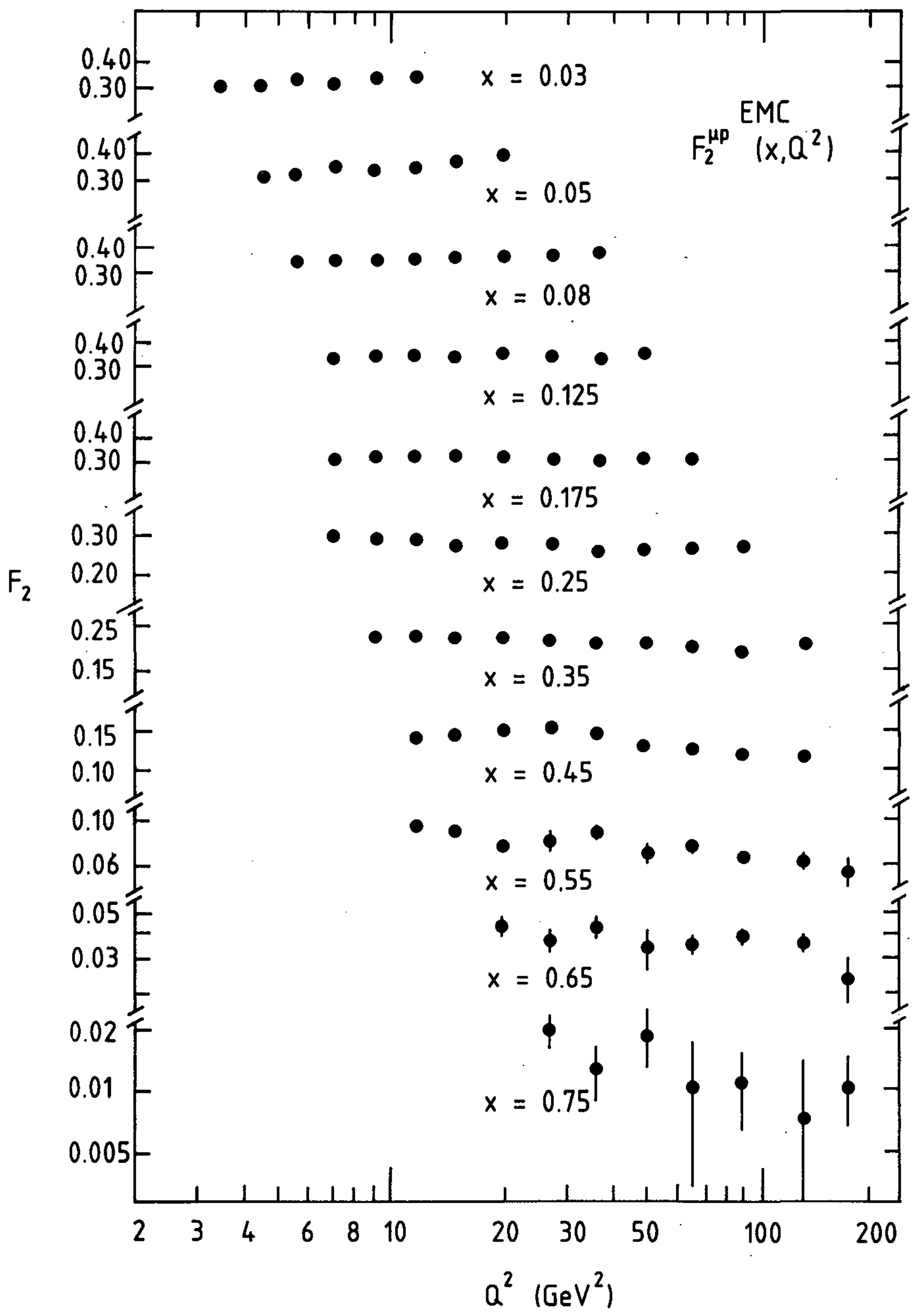

Fig. 13 


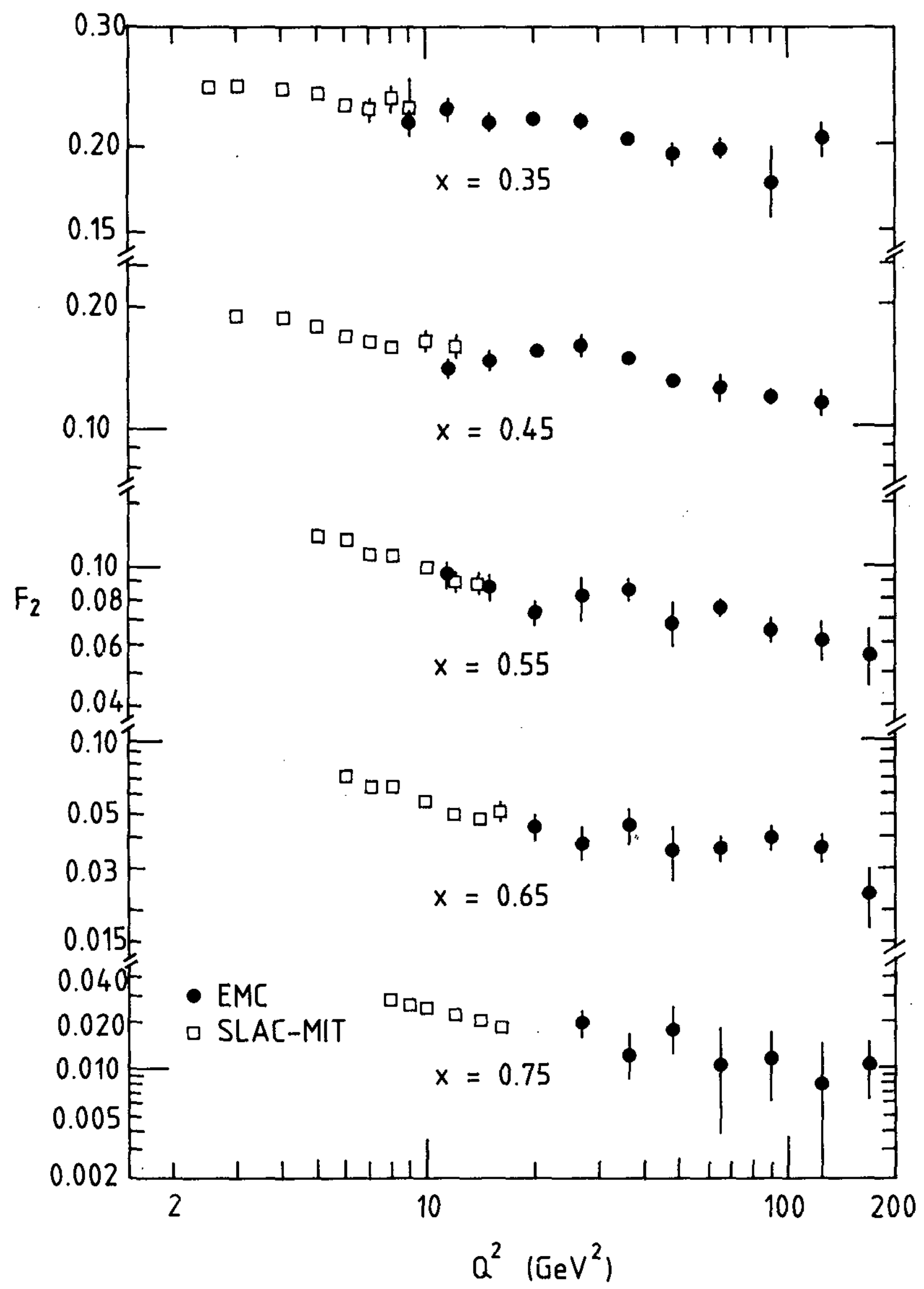

Fig。 14 


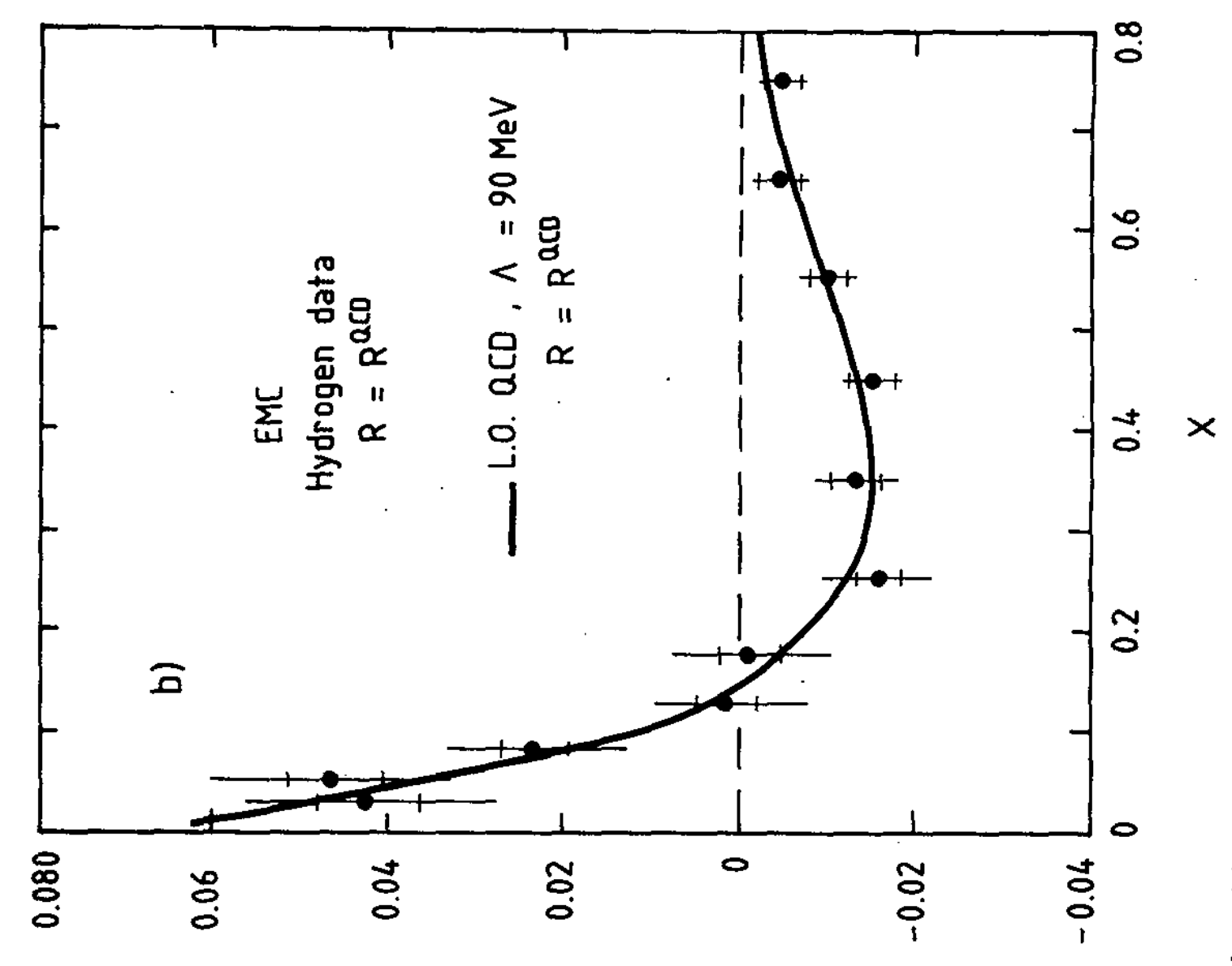

$\underset{n}{\infty}$

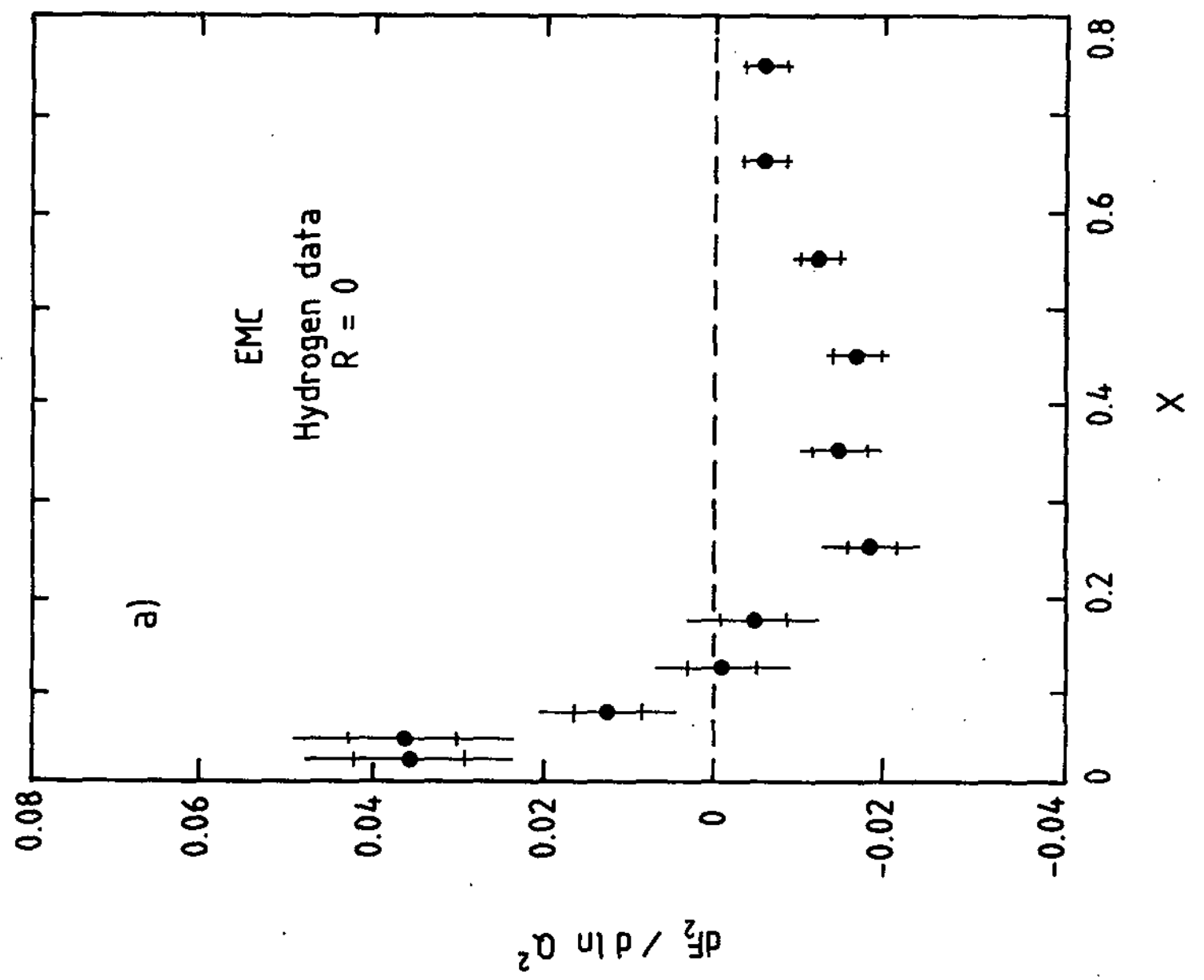




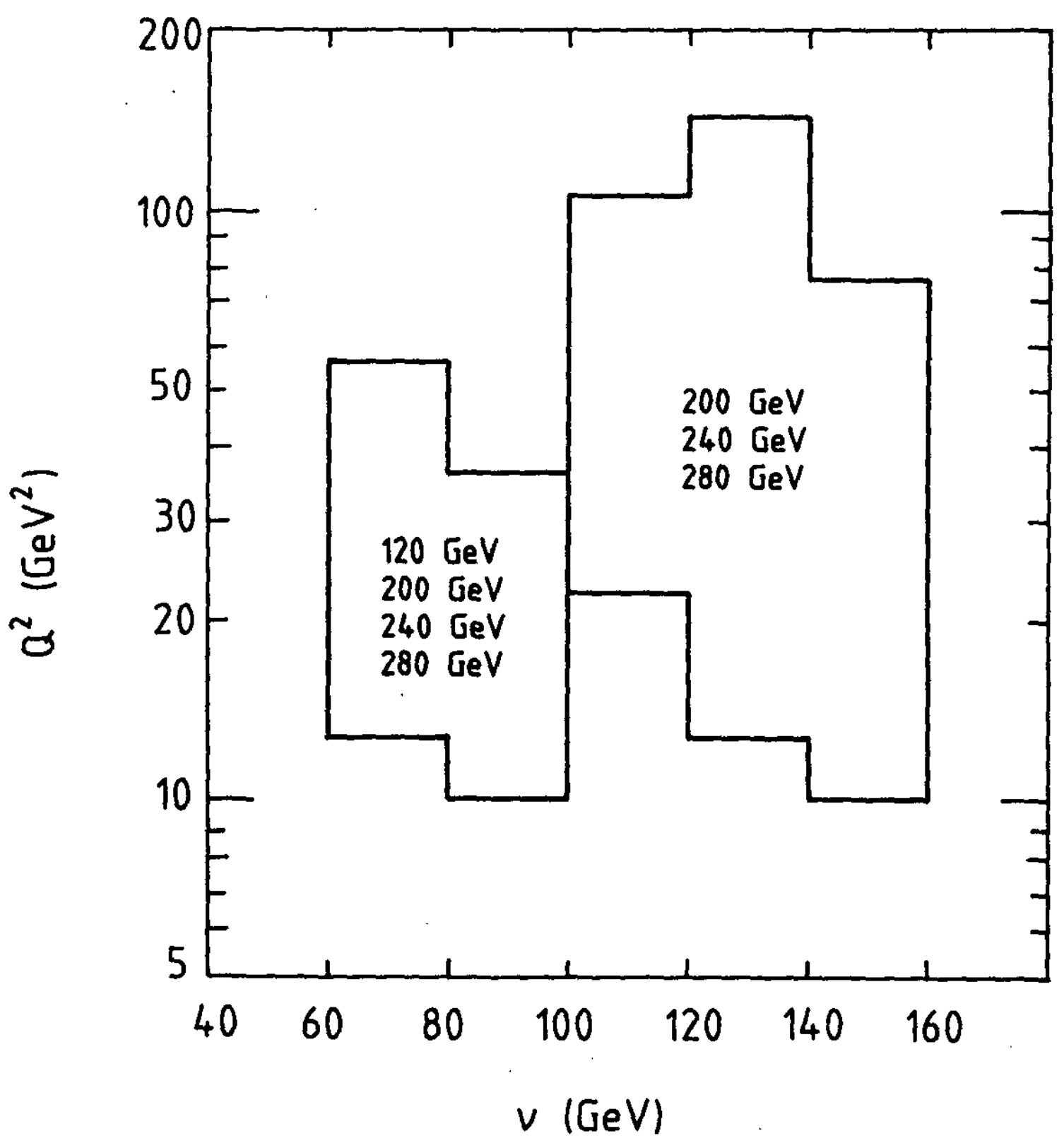

Fig. 16 

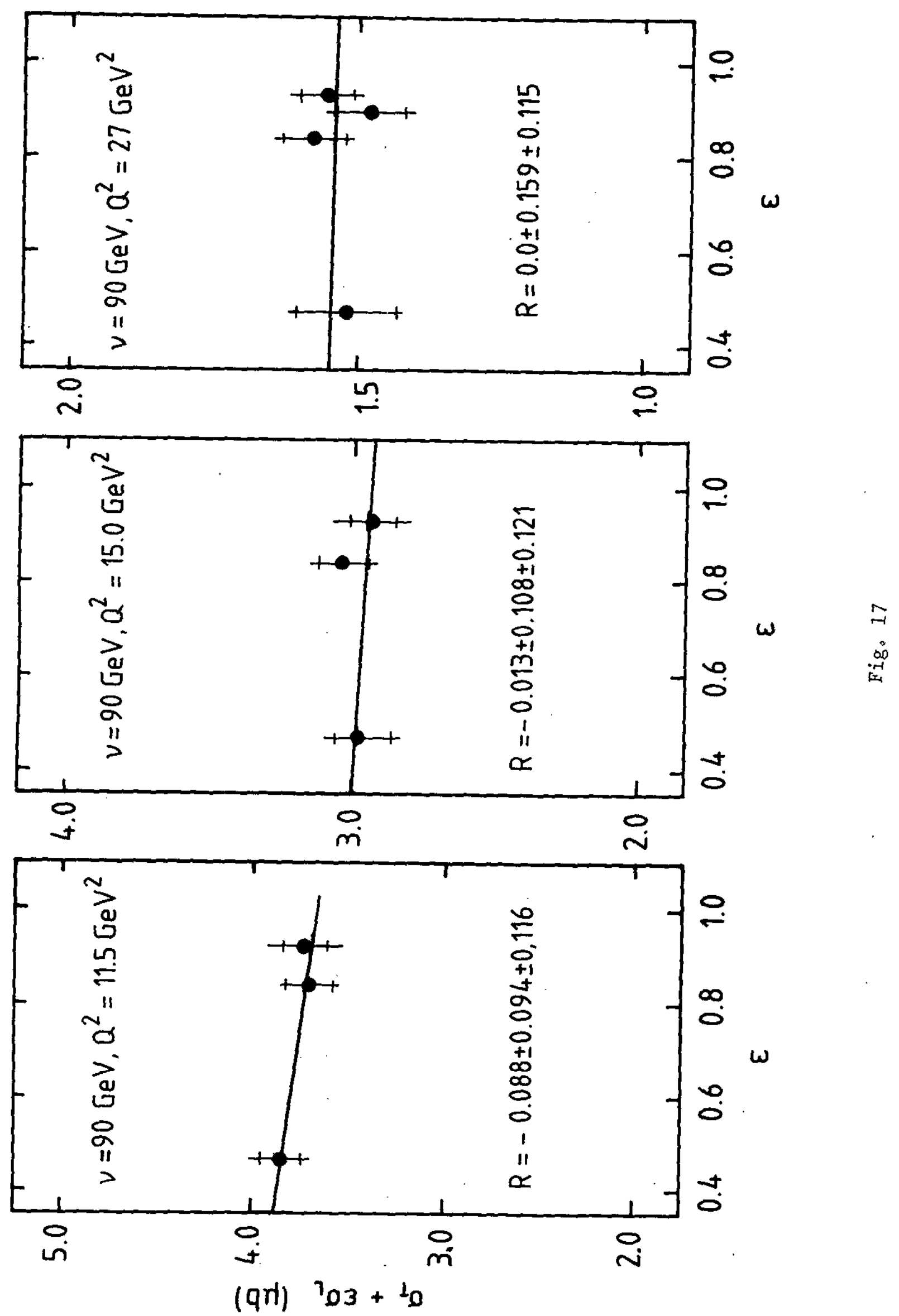

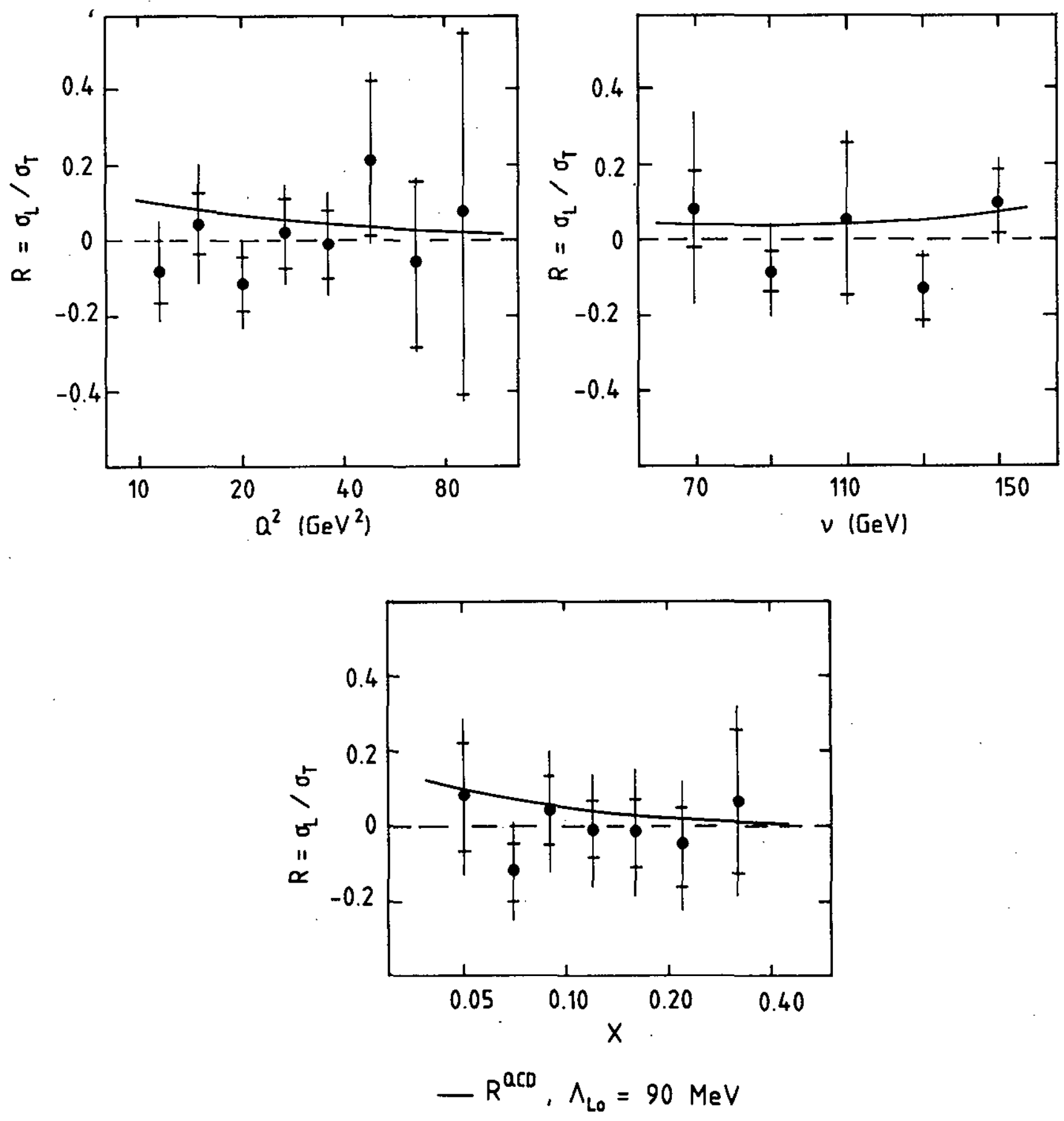

Fig. 18 


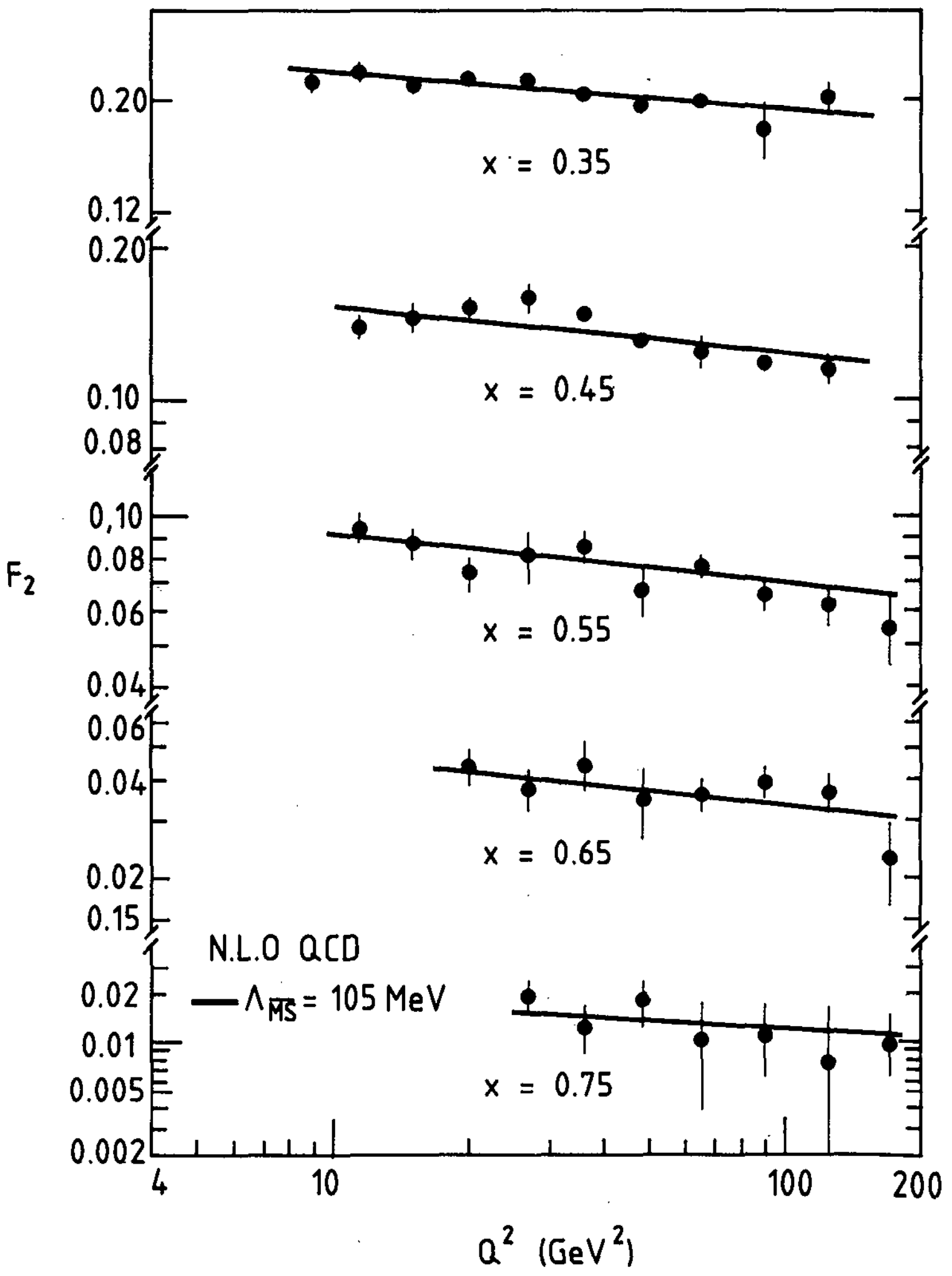

Fig. 19 


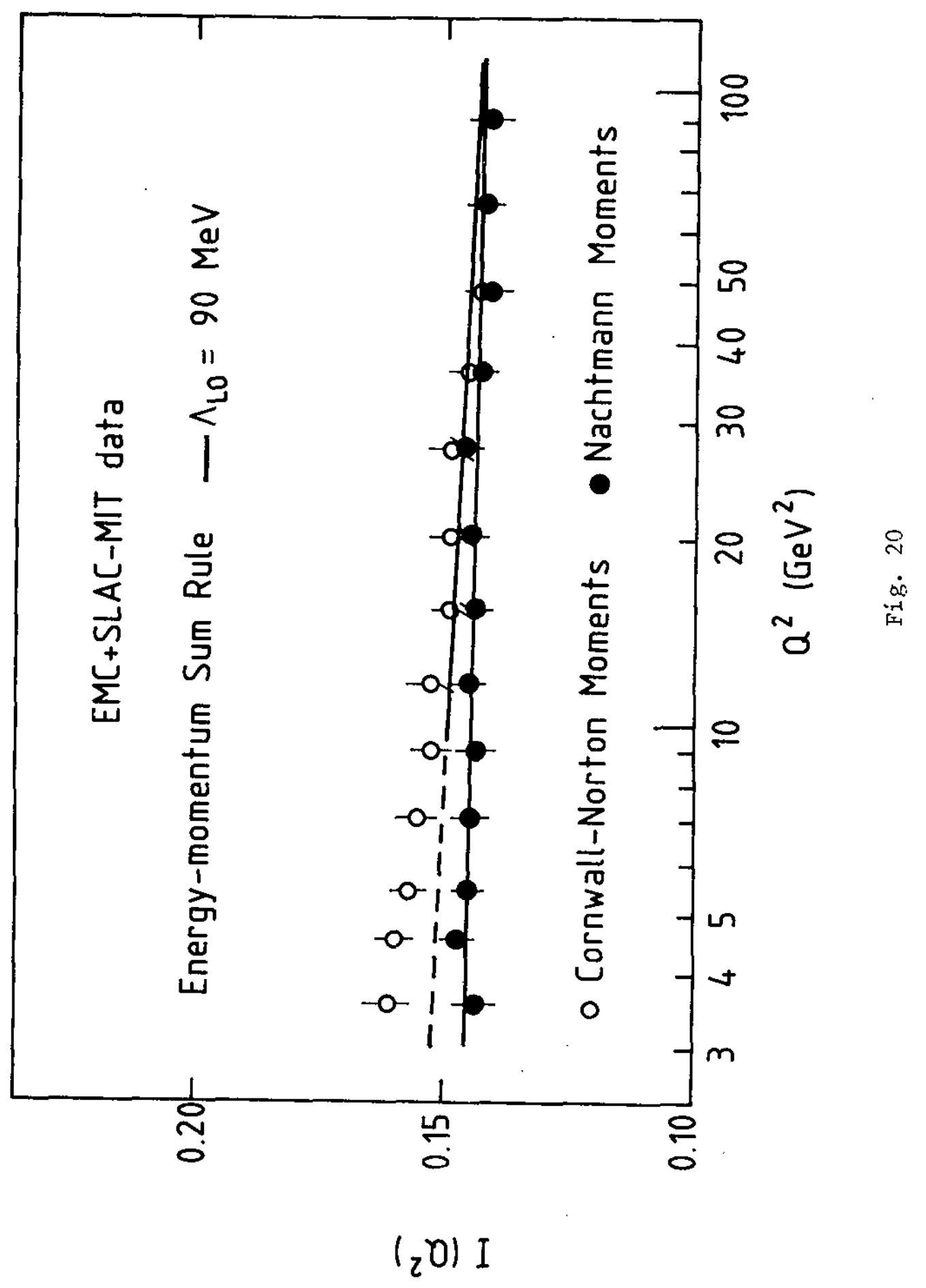



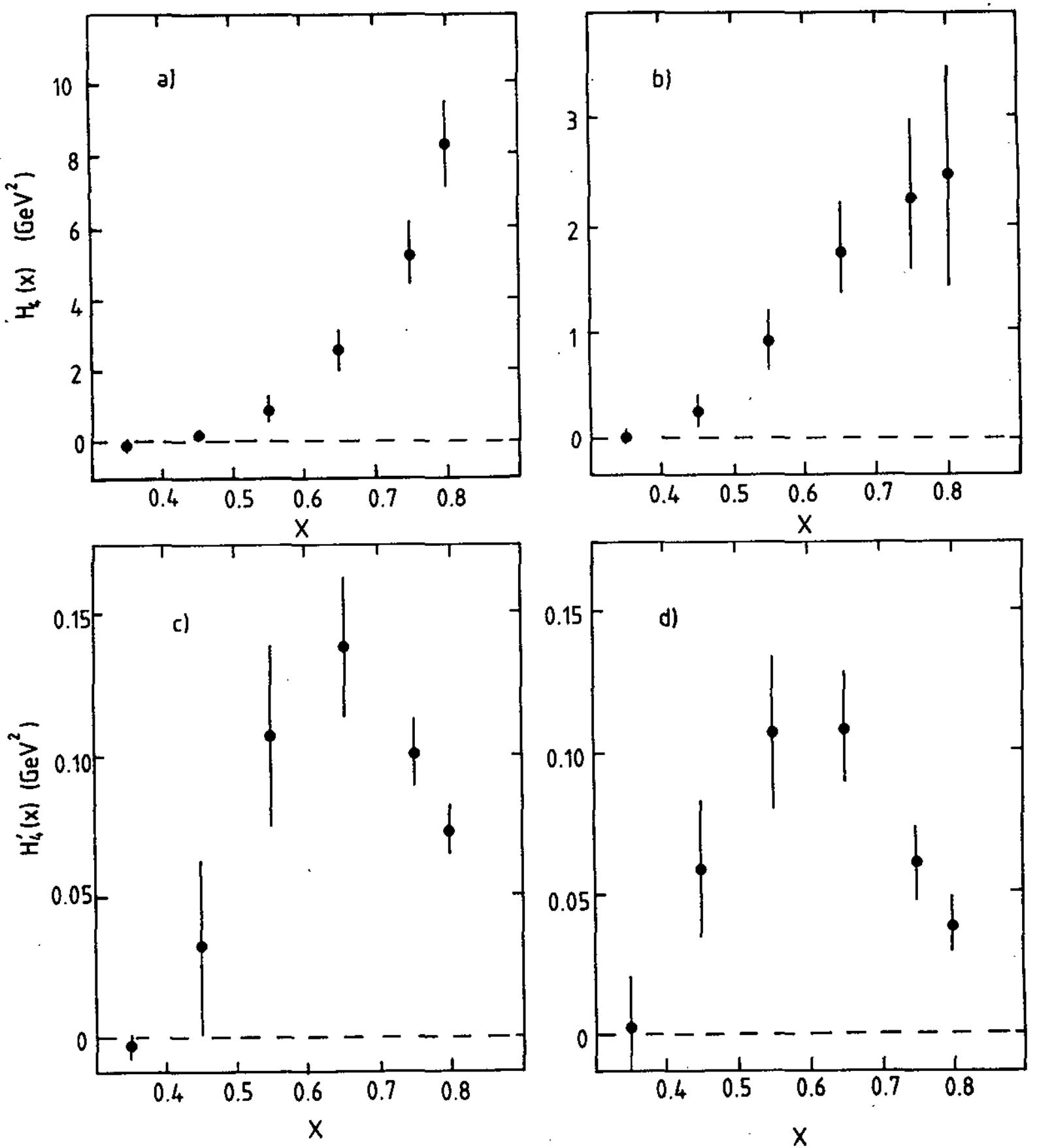

Fig. 21 


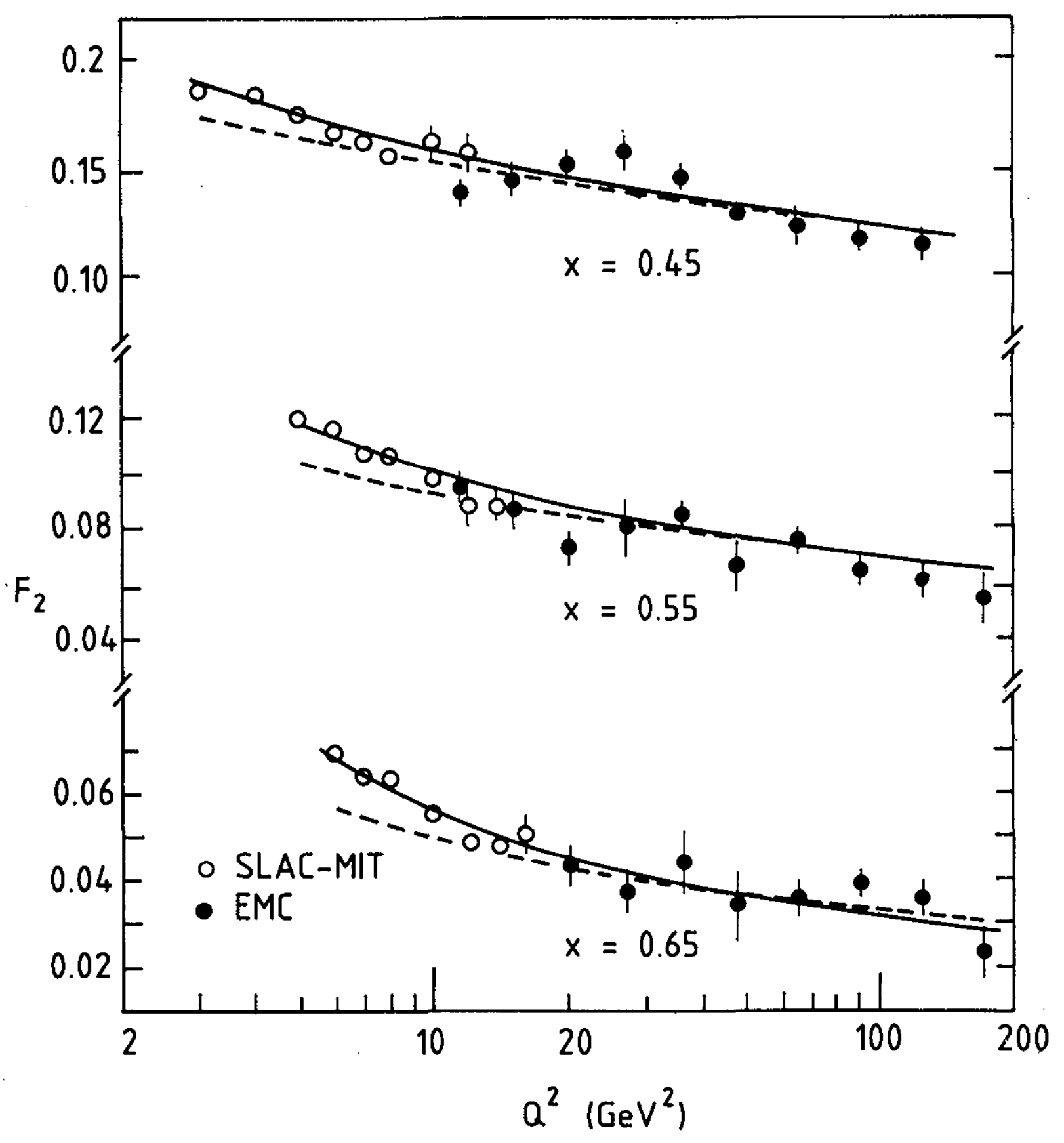

Fig. 22 